\title{
Chiral Separation of Cytotoxic Flavan Derivatives from Daphne giraldii
}

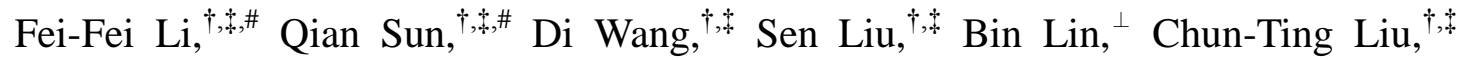

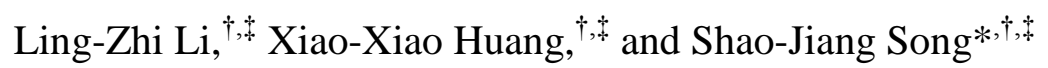

${ }^{\dagger}$ Department of Natural Products Chemistry, ${ }^{\star}$ Key Laboratory of Structure-Based Drug Design and Discovery, Ministry of Education, and ${ }^{\perp}$ School of Pharmaceutical Engineering, Shenyang Pharmaceutical University, Shenyang 110016, People's Republic of China 
Figure S1. $\quad{ }^{1} \mathrm{H} N M R$ spectrum of daphnegiralin $\mathrm{A}_{1} / \mathrm{A}_{2}(\mathbf{1 a})$ in $\mathrm{CD}_{3} \mathrm{OD} . \cdots \cdots \cdots \cdots \cdots \cdot \ldots$

Figure S2. $\quad{ }^{13} \mathrm{C}$ NMR spectrum of daphnegiralin $\mathrm{A}_{1} / \mathrm{A}_{2}(\mathbf{1 a})$ in $\mathrm{CD}_{3} \mathrm{OD} . \quad \cdots \cdots \cdots . . . . . .4$

Figure S3. HSQC spectrum of daphnegiralin $\mathrm{A}_{1} / \mathrm{A}_{2}$ (1a) in $\mathrm{CD}_{3} \mathrm{OD} . \cdots \cdots \ldots . . \cdots \cdots \cdot \ldots$

Figure S4. HMBC spectrum of daphnegiralin $\mathrm{A}_{1} / \mathrm{A}_{2}(\mathbf{1 a})$ in $\mathrm{CD}_{3} \mathrm{OD} . \quad \cdots \cdots \ldots . . . \cdots \cdots$

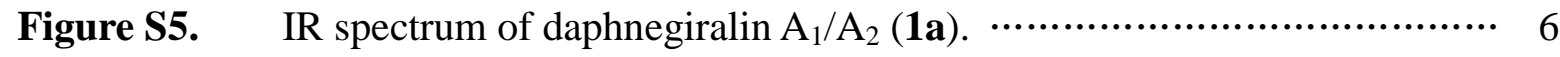

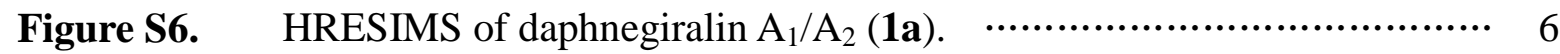

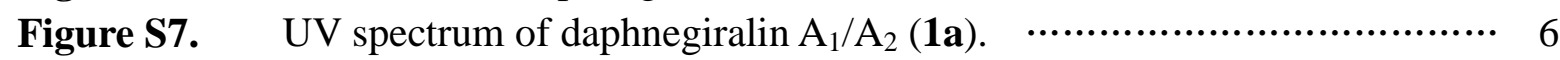

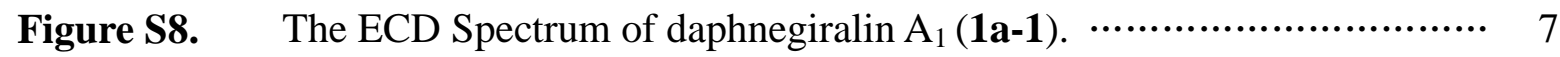

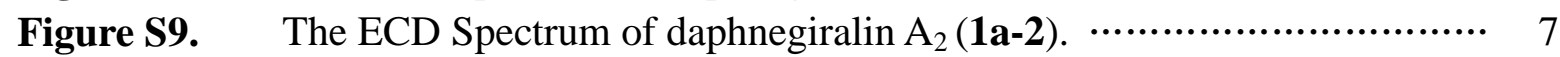

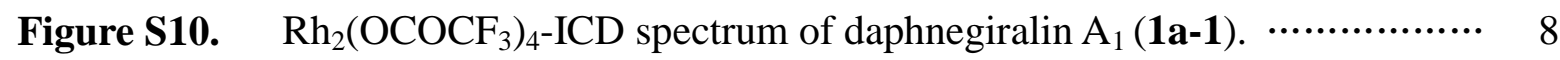

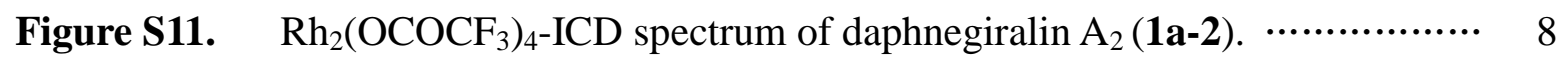

Figure S12. $\quad{ }^{1} \mathrm{H} N M R$ spectrum of daphnegiralin $\mathrm{A}_{3} / \mathrm{A}_{4}(\mathbf{1 b})$ in $\mathrm{CD}_{3} \mathrm{OD} . \quad \cdots \ldots \ldots \ldots . . .6$

Figure S13. $\quad{ }^{13} \mathrm{C}$ NMR spectrum of daphnegiralin $\mathrm{A}_{3} / \mathrm{A}_{4}(\mathbf{1 b})$ in $\mathrm{CD}_{3} \mathrm{OD} . \quad \cdots \cdots \cdots . . . . . .9$

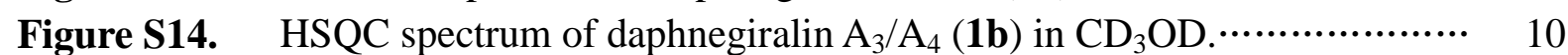

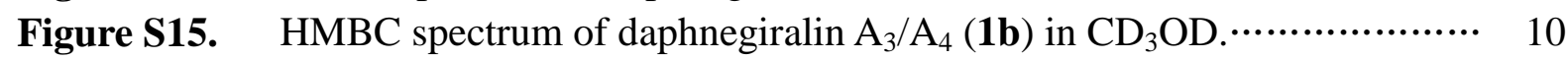

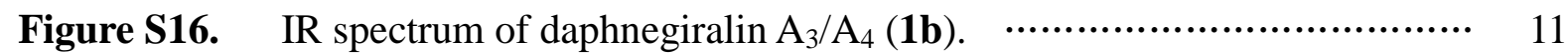

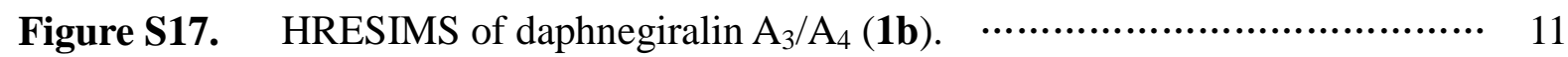

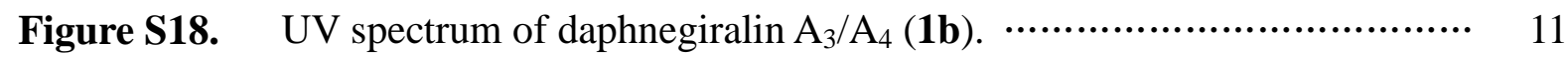

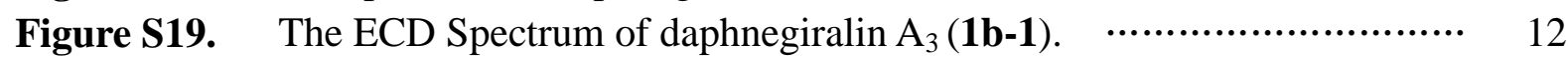

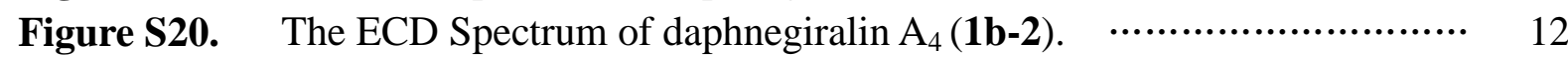

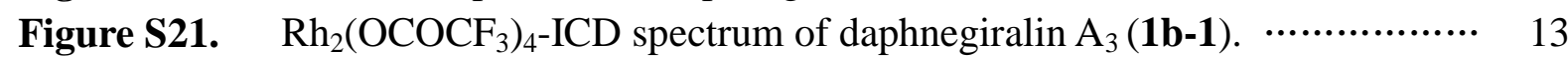

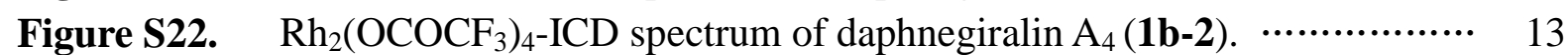

Figure S23. $\quad{ }^{1} \mathrm{H}$ NMR spectrum of daphnegiralin $\mathrm{B}_{1} / \mathrm{B}_{2}(\mathbf{2 a})$ in $\mathrm{CD}_{3} \mathrm{OD} . \cdots \cdots \ldots . . . \cdots \cdots$

Figure S24. $\quad{ }^{13} \mathrm{C}$ NMR spectrum of daphnegiralin $\mathrm{B}_{1} / \mathrm{B}_{2}(\mathbf{2 a})$ in $\mathrm{CD}_{3} \mathrm{OD} . \cdots \cdots \ldots \ldots \ldots . . . .14$

Figure S25. HSQC spectrum of daphnegiralin $\mathrm{B}_{1} / \mathrm{B}_{2}(\mathbf{2 a})$ in $\mathrm{CD}_{3} \mathrm{OD} . \quad \cdots \ldots \ldots \ldots \ldots \ldots . . . . . .15$

Figure S26. HMBC spectrum of daphnegiralin $\mathrm{B}_{1} / \mathrm{B}_{2}(\mathbf{2 a})$ in $\mathrm{CD}_{3} \mathrm{OD} . \quad \cdots \cdots \ldots \ldots \ldots . . . \cdots \cdots$

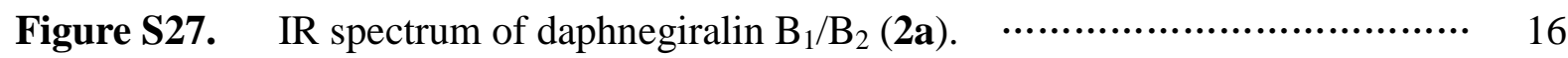

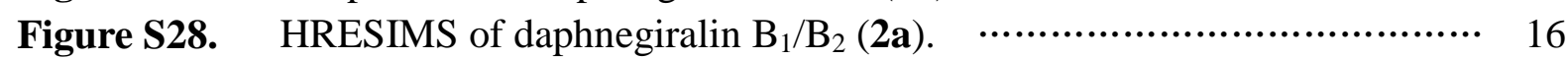

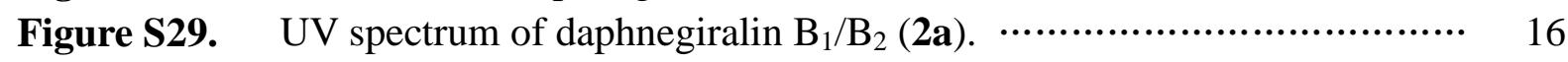

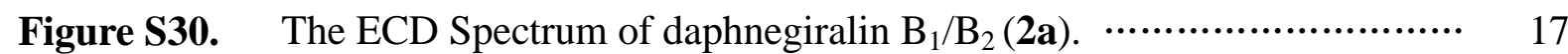

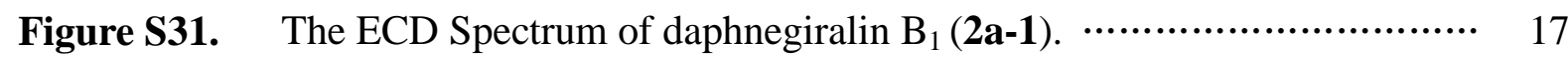

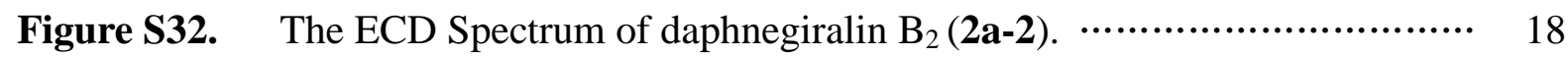

Figure S33. $\quad \mathrm{Rh}_{2}\left(\mathrm{OCOCF}_{3}\right)_{4}$-ICD spectrum of daphnegiralin $\mathrm{B}_{1}(\mathbf{2 a}-\mathbf{1}) . \cdots \cdots \ldots \ldots \ldots \ldots . . . . . .18$

Figure S34. $\quad \mathrm{Rh}_{2}\left(\mathrm{OCOCF}_{3}\right)_{4}$-ICD spectrum of daphnegiralin $\mathrm{B}_{2}(\mathbf{2 a}-\mathbf{2}) . \cdots \cdots \ldots \ldots \ldots . . . . . . .19$

Figure S35. $\quad{ }^{1} \mathrm{H}$ NMR spectrum of daphnegiralin $\mathrm{B}_{3} / \mathrm{B}_{4}(\mathbf{2 b})$ in $\mathrm{CD}_{3} \mathrm{OD} . \cdots \cdots \ldots \ldots \ldots \ldots . . . . . .19$

Figure S36. $\quad{ }^{13} \mathrm{C}$ NMR spectrum of daphnegiralin $\mathrm{B}_{3} / \mathrm{B}_{4}(\mathbf{2 b})$ in $\mathrm{CD}_{3} \mathrm{OD}$................ 20

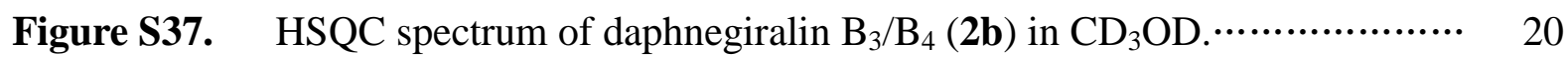

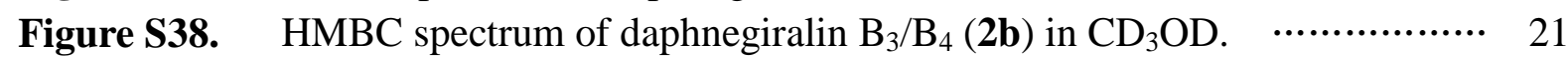

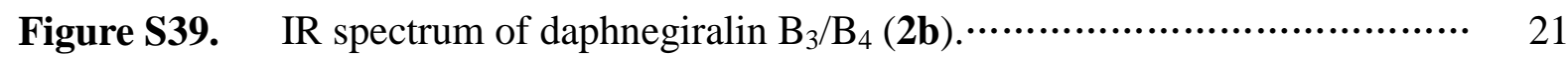

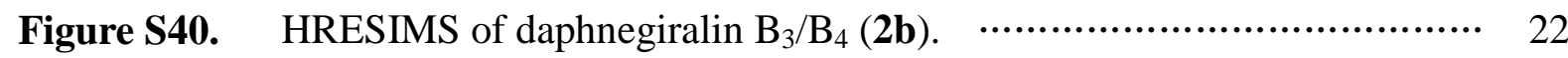

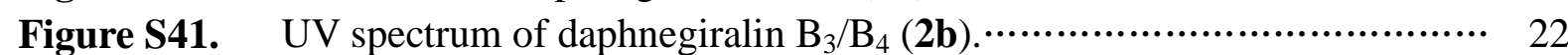

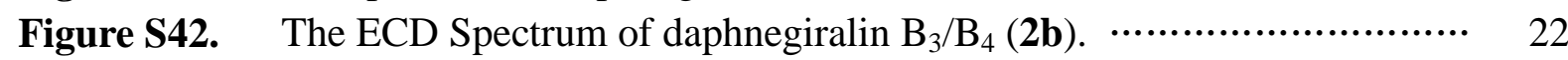

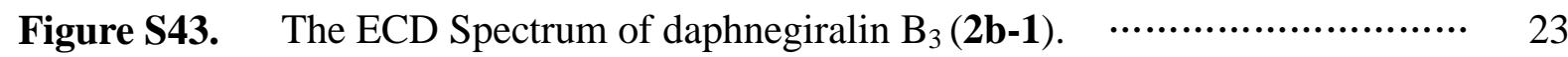

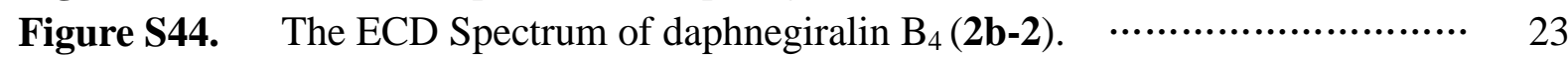




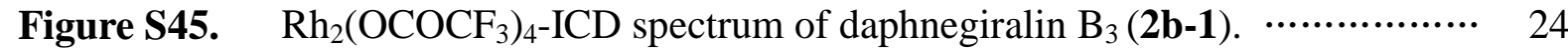

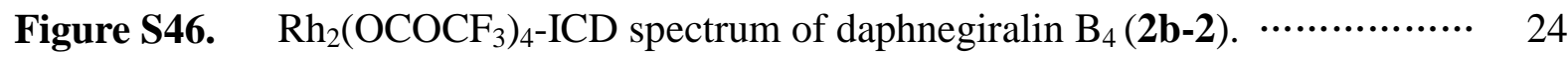

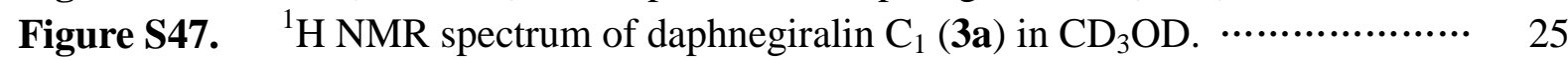

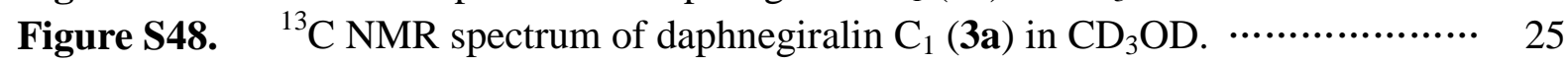

Figure S49. HSQC spectrum of daphnegiralin $\mathrm{C}_{1}(\mathbf{3 a})$ in $\mathrm{CD}_{3} \mathrm{OD} . \quad \cdots \cdots \cdots \cdots \cdots \cdots \cdots \cdots$

Figure S50. HMBC spectrum of daphnegiralin $\mathrm{C}_{1}(\mathbf{3 a})$ in $\mathrm{CD}_{3} \mathrm{OD} . \cdots \cdots \cdots \cdots \cdots \cdots \cdots \cdots \cdots$

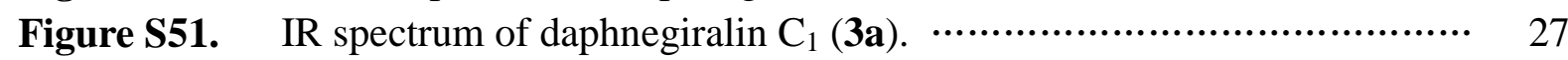

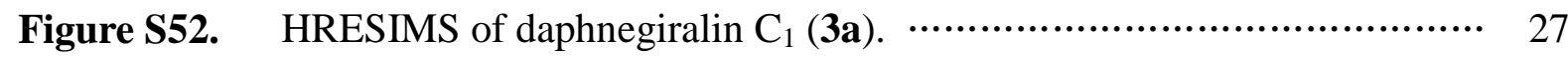

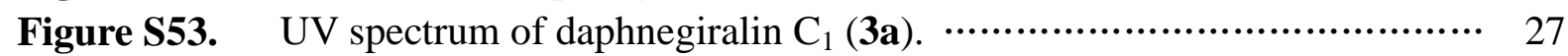

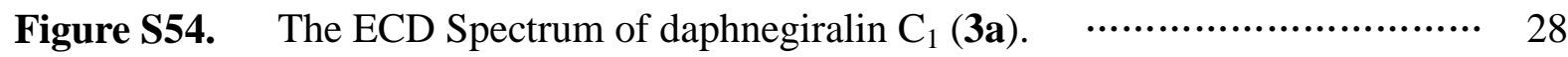

Figure S55. $\quad{ }^{1} \mathrm{H}$ NMR spectrum of daphnegiralin $\mathrm{C}_{2}(\mathbf{3 b})$ in $\mathrm{CD}_{3} \mathrm{OD} . \cdots \cdots \cdots \ldots \ldots \ldots \ldots . . . \cdots \cdots$

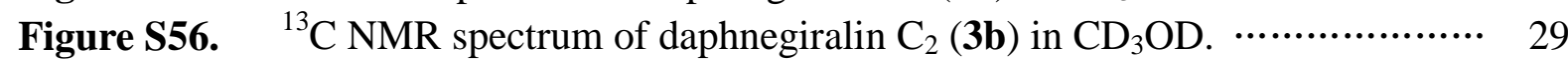

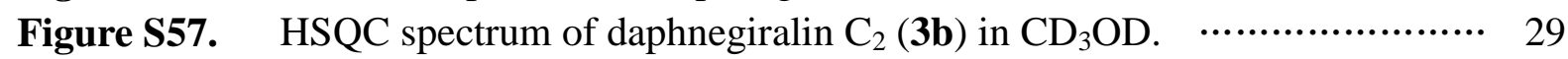

Figure S58. HMBC spectrum of daphnegiralin $\mathrm{C}_{2}(\mathbf{3 b})$ in $\mathrm{CD}_{3} \mathrm{OD} . \cdots \cdots \cdots \cdots \cdots \cdots \cdots \cdots \cdots \cdots \cdots$

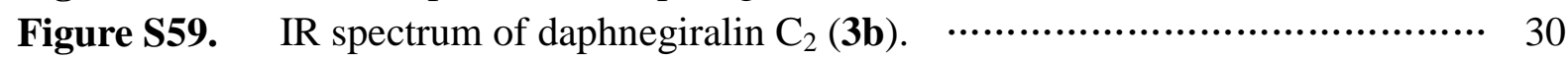

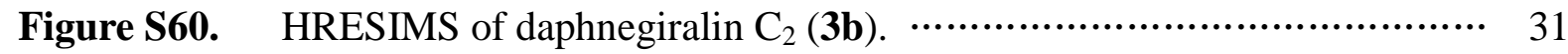

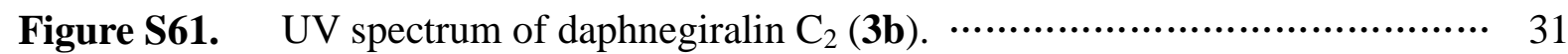

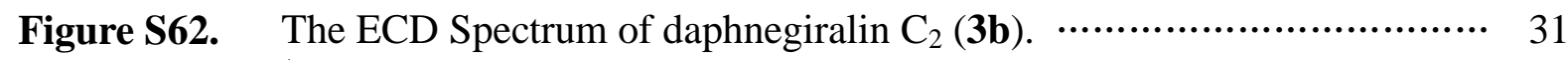

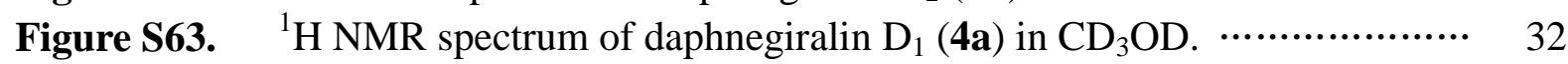

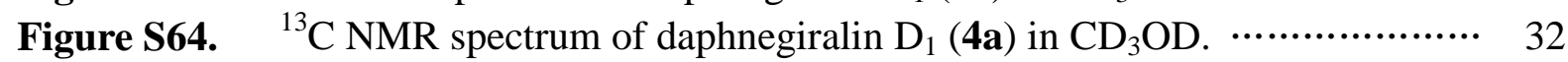

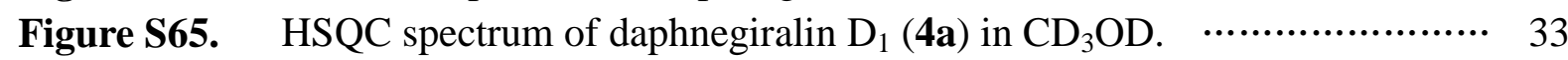

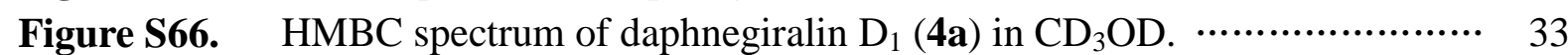

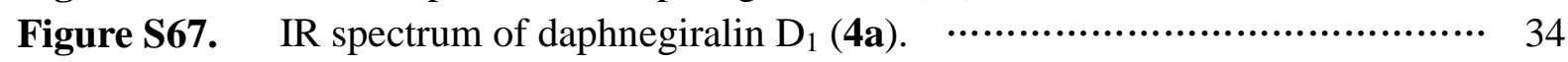

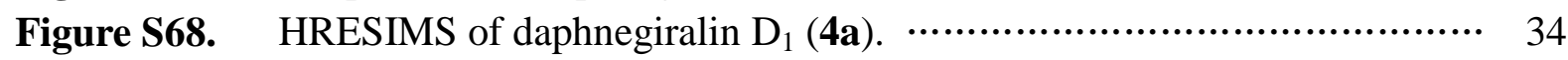

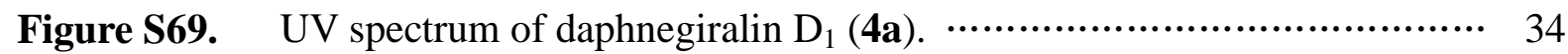

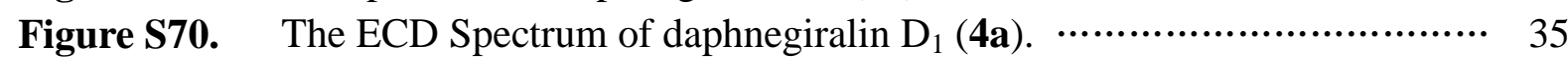

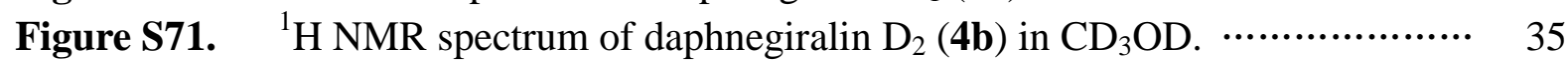

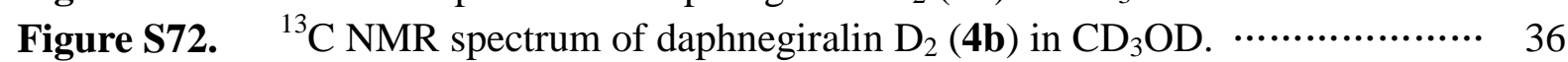

Figure S73. HSQC spectrum of daphnegiralin $\mathrm{D}_{2}(\mathbf{4 b})$ in $\mathrm{CD}_{3} \mathrm{OD} . \cdots \cdots \ldots \ldots \ldots \ldots . . . \cdots \cdots$

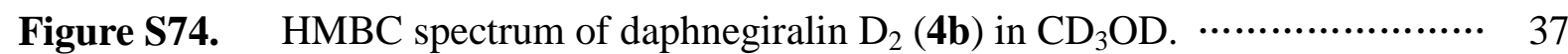

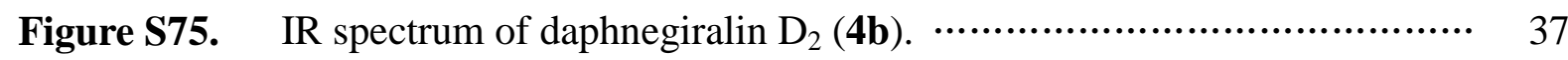

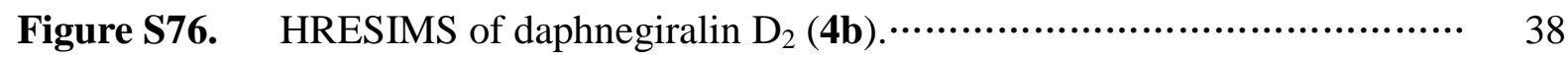

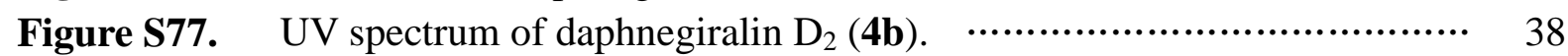

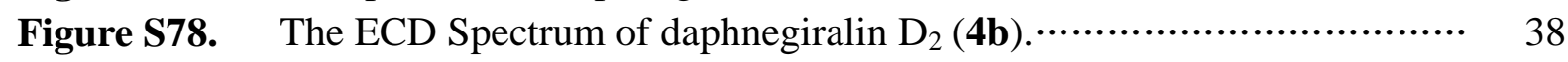

Figure S79. Computational methods for ECD spectra and Optical Rotation.......... 39

Table S1. The conformations of daphnegiralin $\mathrm{C}_{1}$ (3a) were obtained after the optimization .............................................................. 39

Table S2. The computational results for ECD of daphnegiralin $\mathrm{C}_{1}(\mathbf{3 a})\left(2 S, 2^{\prime \prime} R\right) \quad 41$

Table S3. The conformations of daphnegiralin $C_{2}(\mathbf{3 b})$ were obtained after the optimization …........................................................ 42

Table S4. The computational results for ECD of daphnegiralin $\mathrm{C}_{2}(\mathbf{3 b})\left(2 S, 2^{\prime \prime} S\right)$

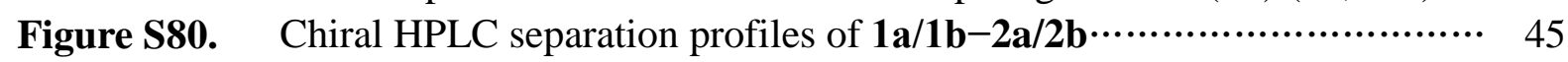


Figure S1. ${ }^{1} \mathrm{H}$ NMR spectrum of daphnegiralin $\mathrm{A}_{1} / \mathrm{A}_{2}$ (1a) in $\mathrm{CD}_{3} \mathrm{OD}$.

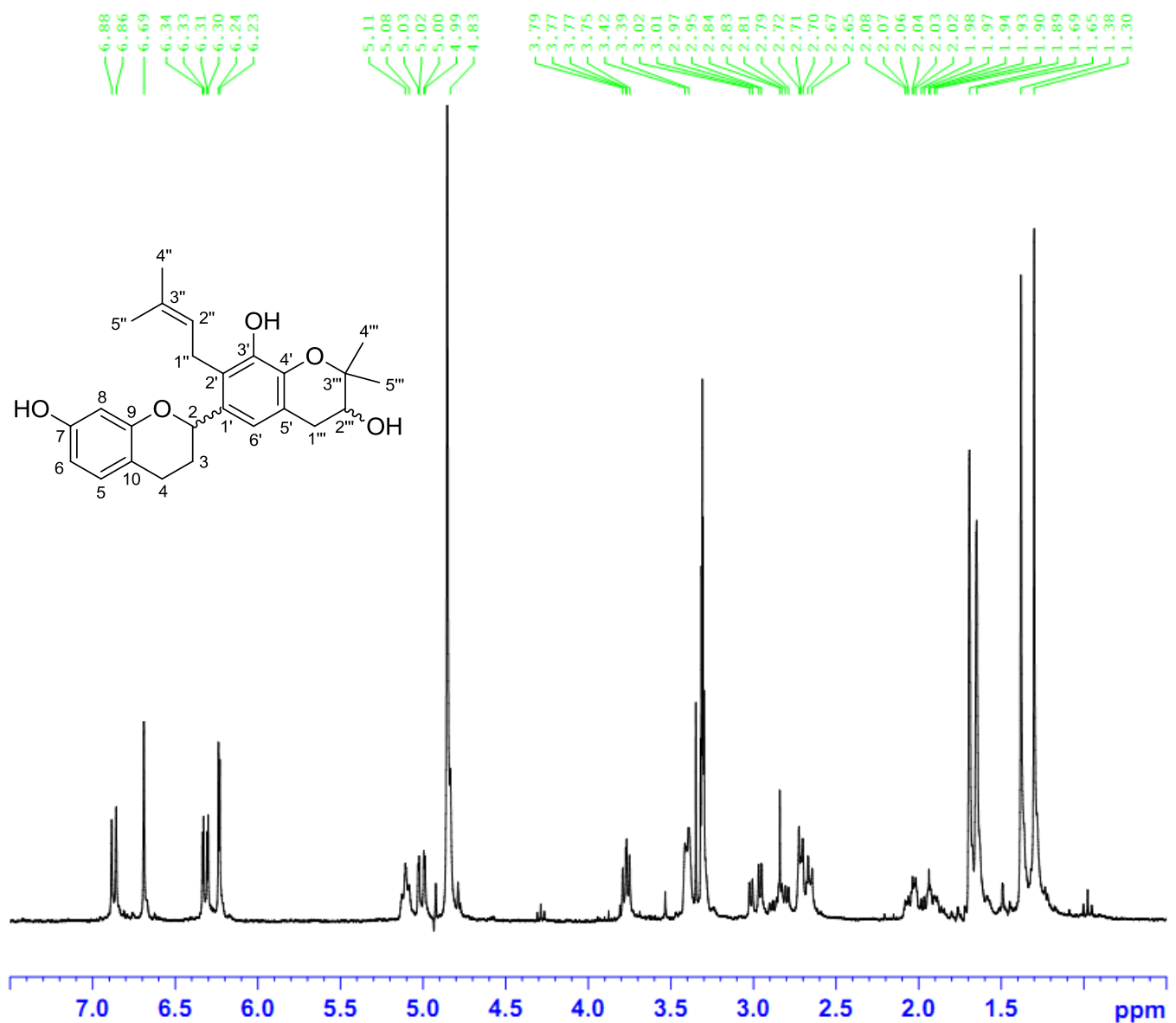

Figure S2. ${ }^{13} \mathrm{C}$ NMR spectrum of daphnegiralin $\mathrm{A}_{1} / \mathrm{A}_{2}(\mathbf{1 a})$ in $\mathrm{CD}_{3} \mathrm{OD}$.
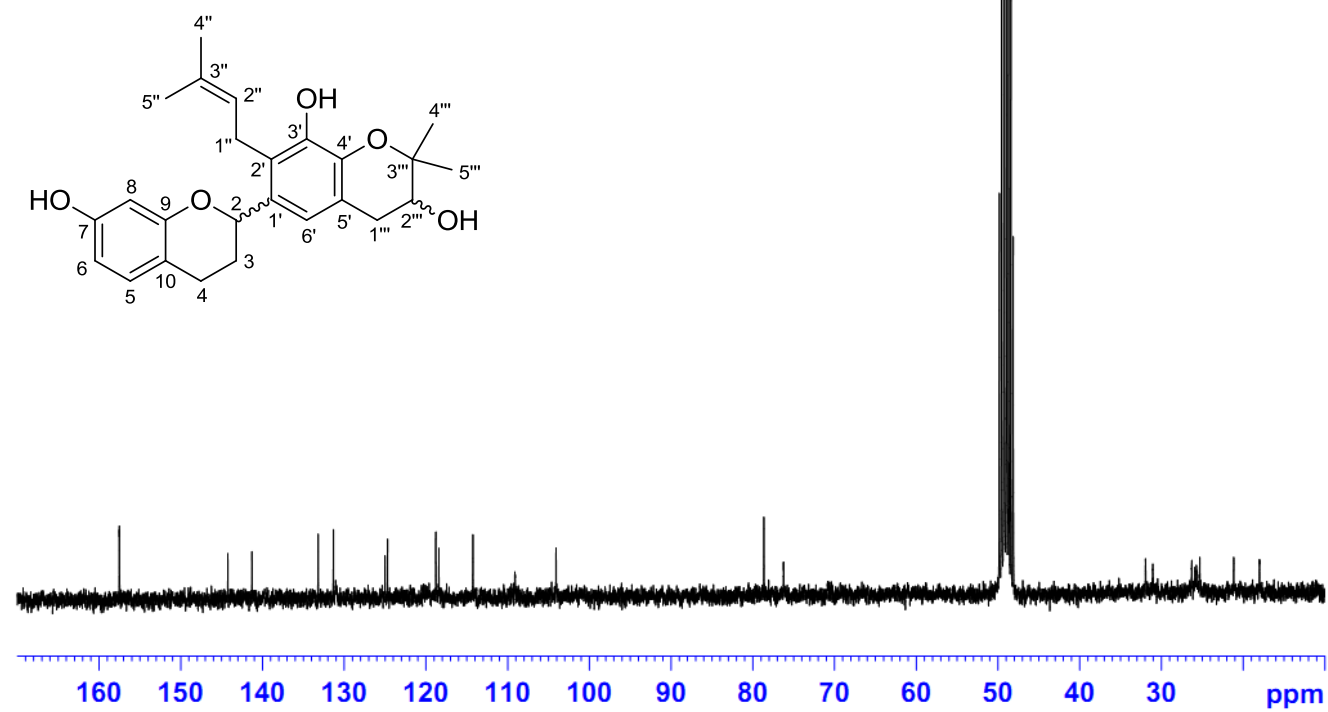
Figure S3. HSQC spectrum of daphnegiralin $\mathrm{A}_{1} / \mathrm{A}_{2}(\mathbf{1 a})$ in $\mathrm{CD}_{3} \mathrm{OD}$.

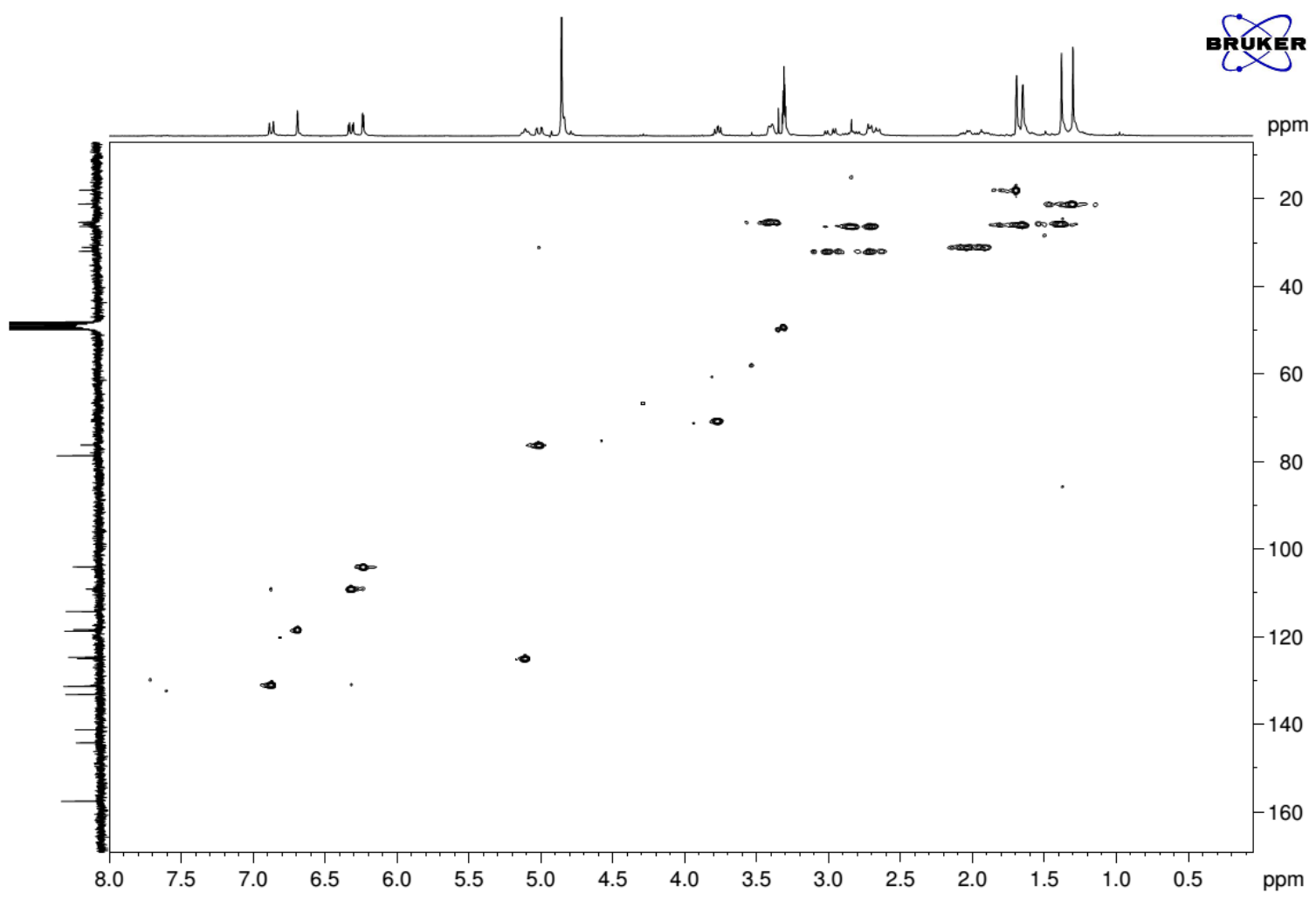

Figure S4. HMBC spectrum of daphnegiralin $A_{1} / A_{2}(\mathbf{1 a})$ in $C_{3} O D$.

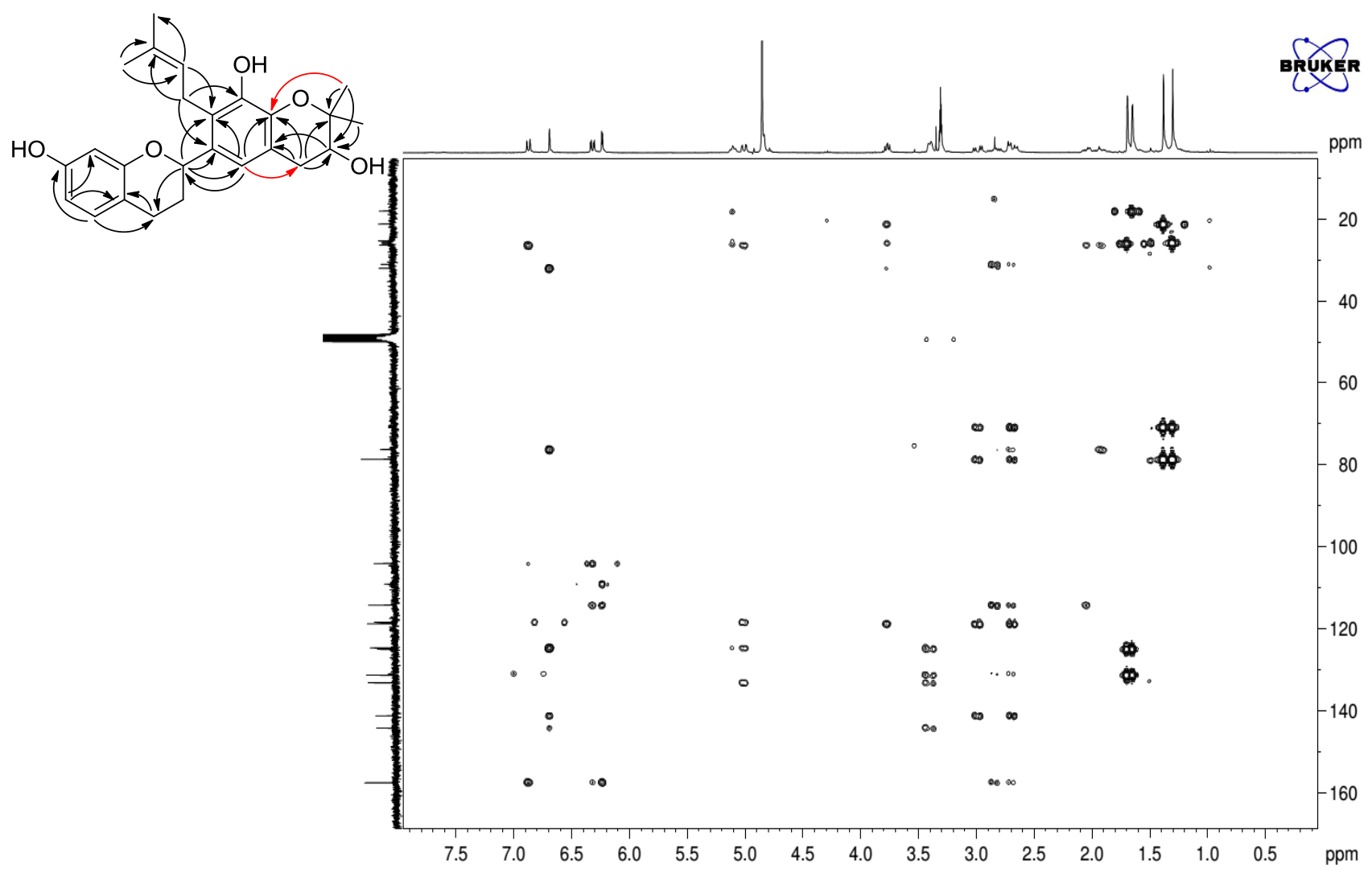

5 
Figure S5. IR spectrum of daphnegiralin $A_{1} / A_{2}(\mathbf{1 a})$.

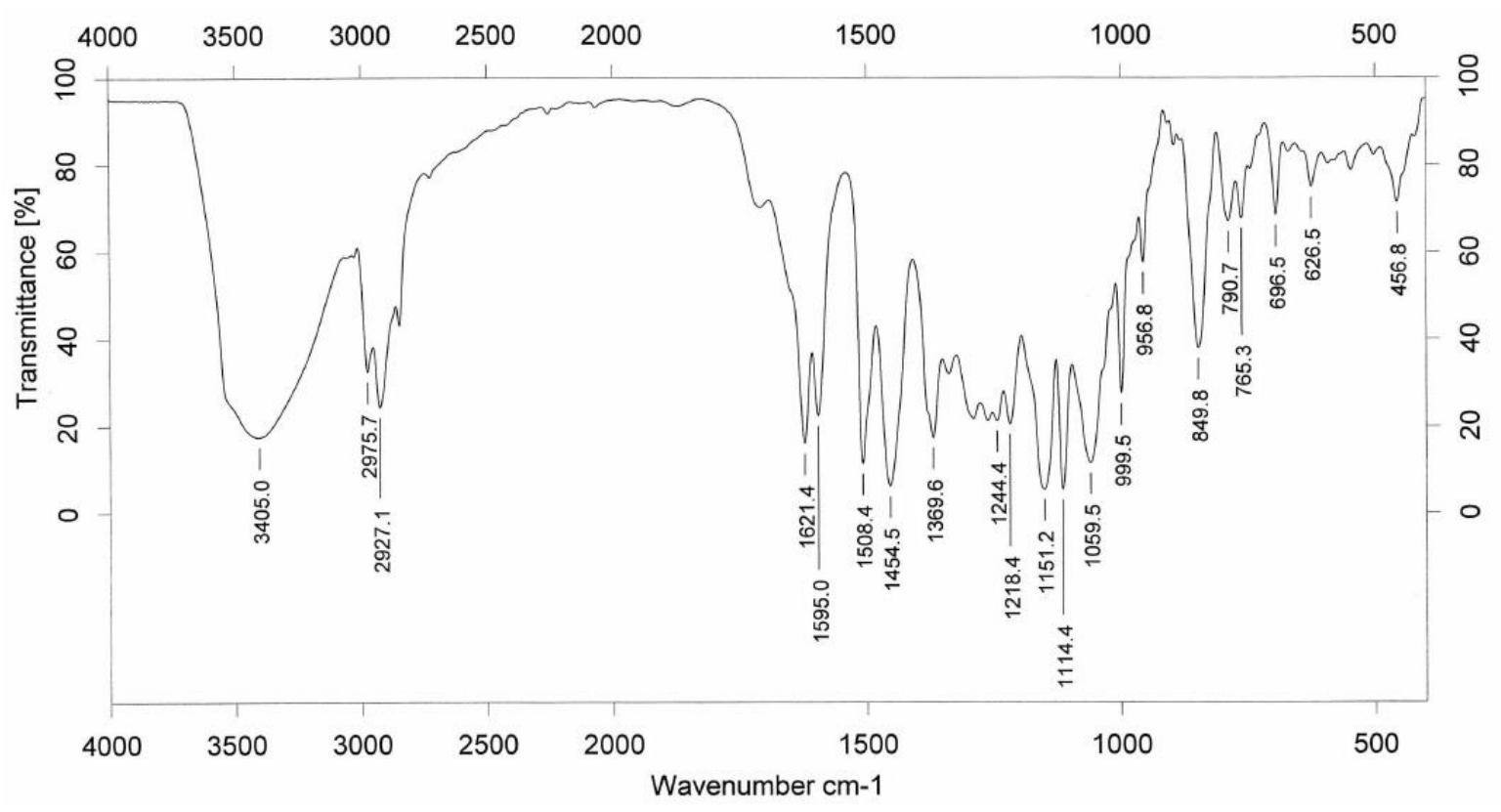

Figure S6. HRESIMS of daphnegiralin $\mathrm{A}_{1} / \mathrm{A}_{2}$ (1a).

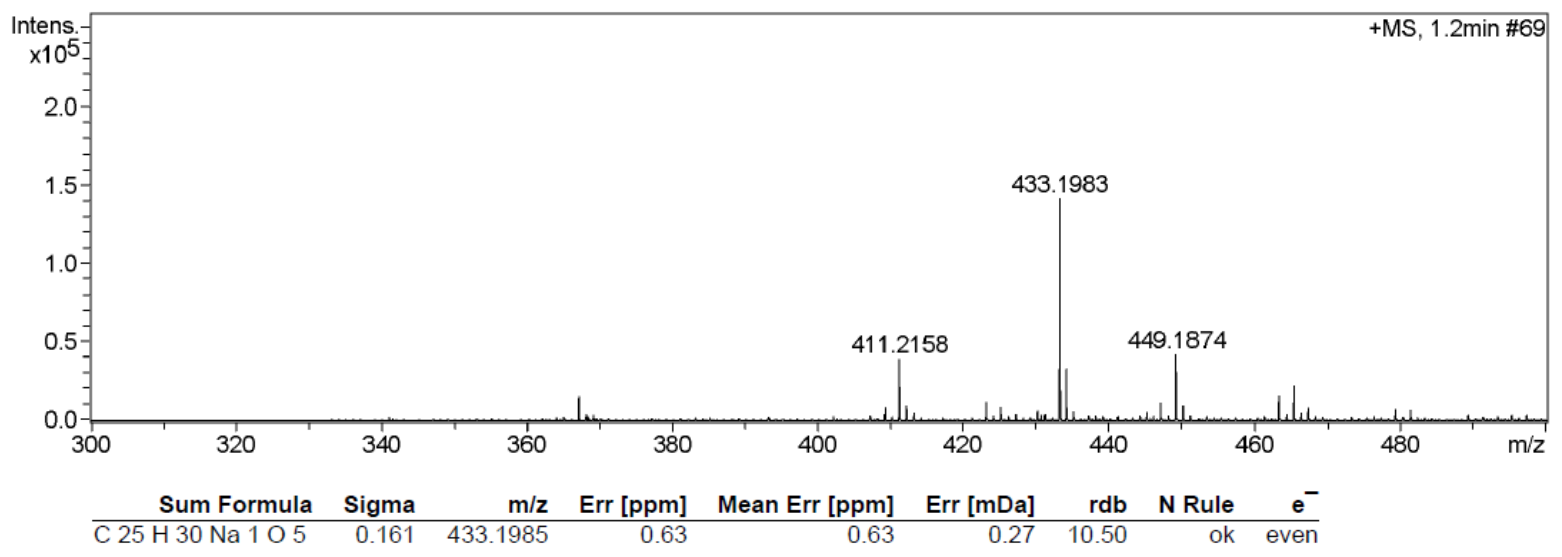

Figure S7. UV spectrum of daphnegiralin $\mathrm{A}_{1} / \mathrm{A}_{2}$ (1a).

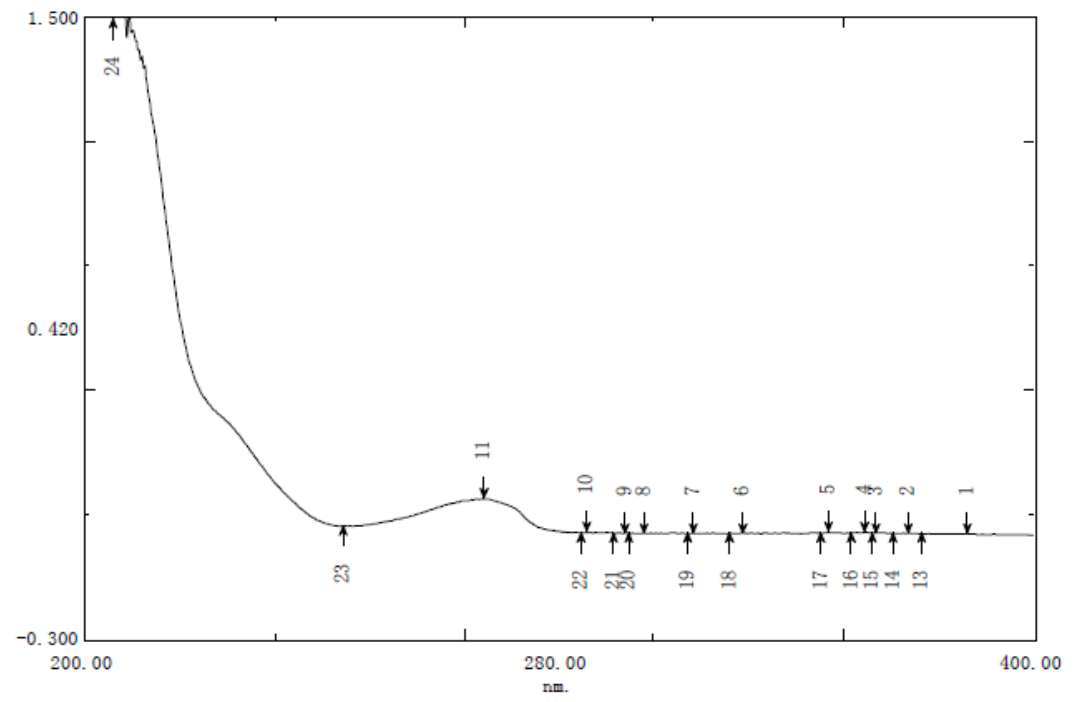


Figure S8. The ECD Spectrum of daphnegiralin $\mathrm{A}_{1}$ (1a-1).

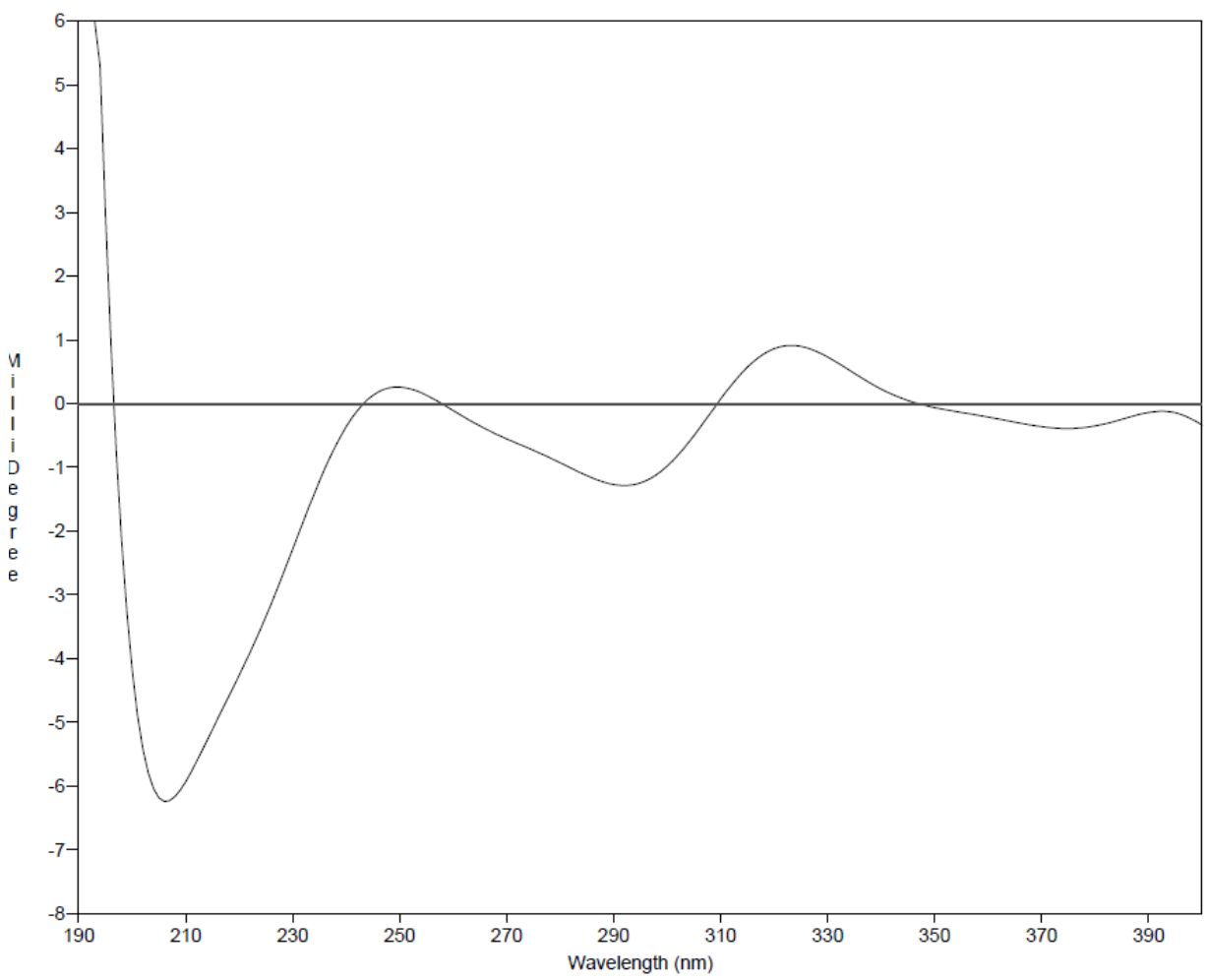

Figure S9. The ECD Spectrum of daphnegiralin $\mathrm{A}_{2}(\mathbf{1 a - 2})$.

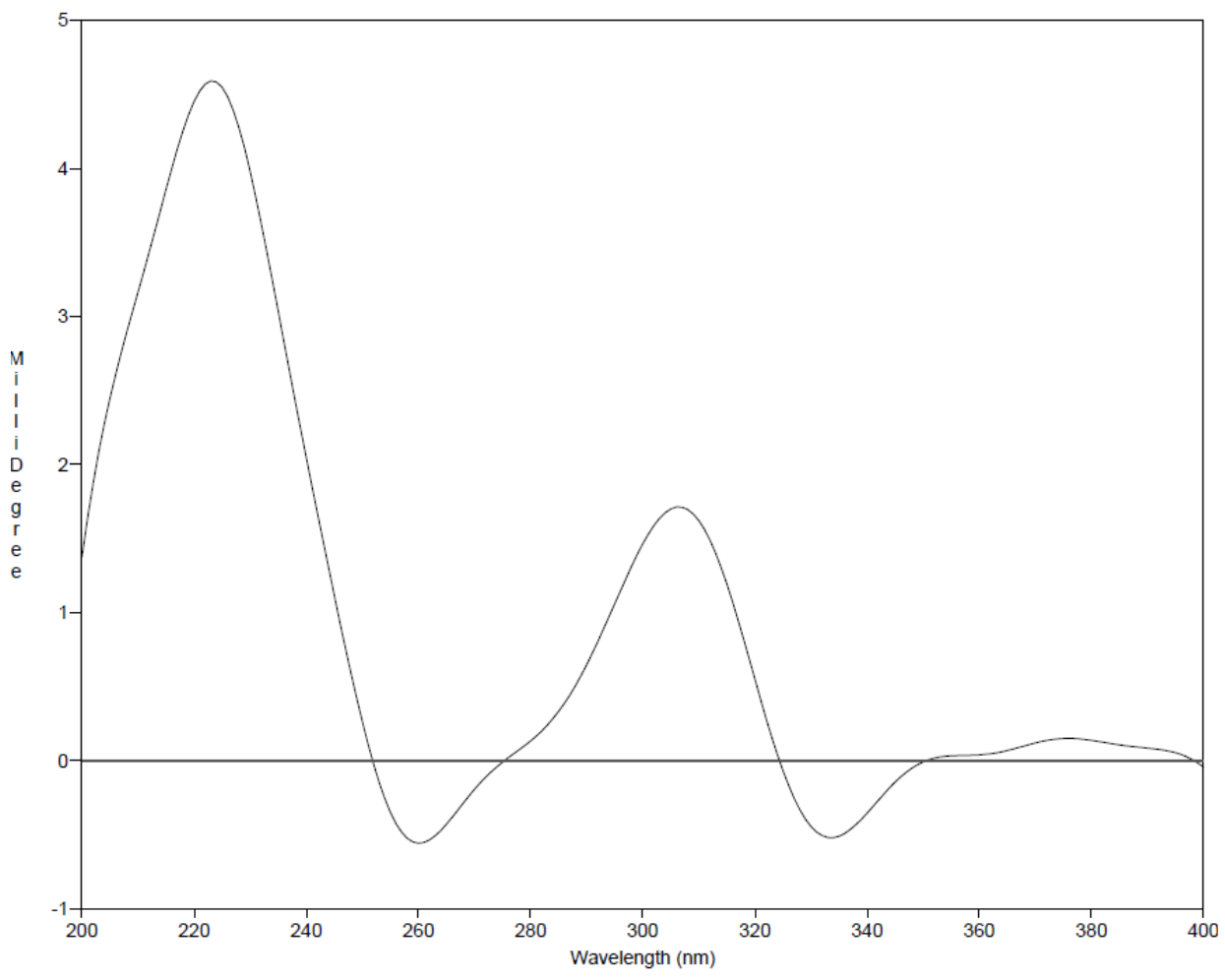


Figure S10. $\mathrm{Rh}_{2}\left(\mathrm{OCOCF}_{3}\right)_{4}$-ICD spectrum of daphnegiralin $\mathrm{A}_{1}(\mathbf{1 a}-\mathbf{1})$.

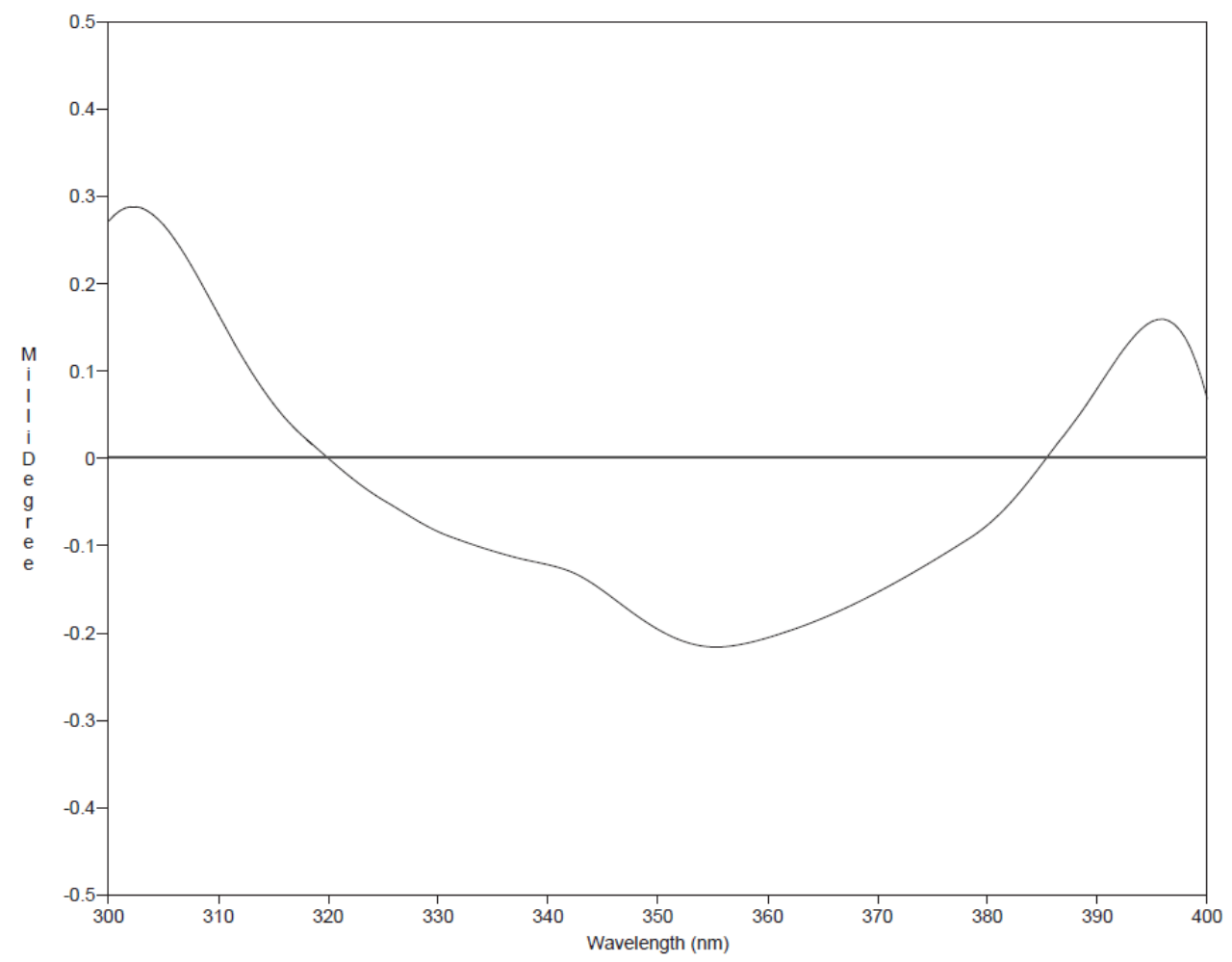

Figure S11. $\mathrm{Rh}_{2}\left(\mathrm{OCOCF}_{3}\right)_{4}$-ICD spectrum of daphnegiralin $\mathrm{A}_{2}(\mathbf{1 a - 2})$.

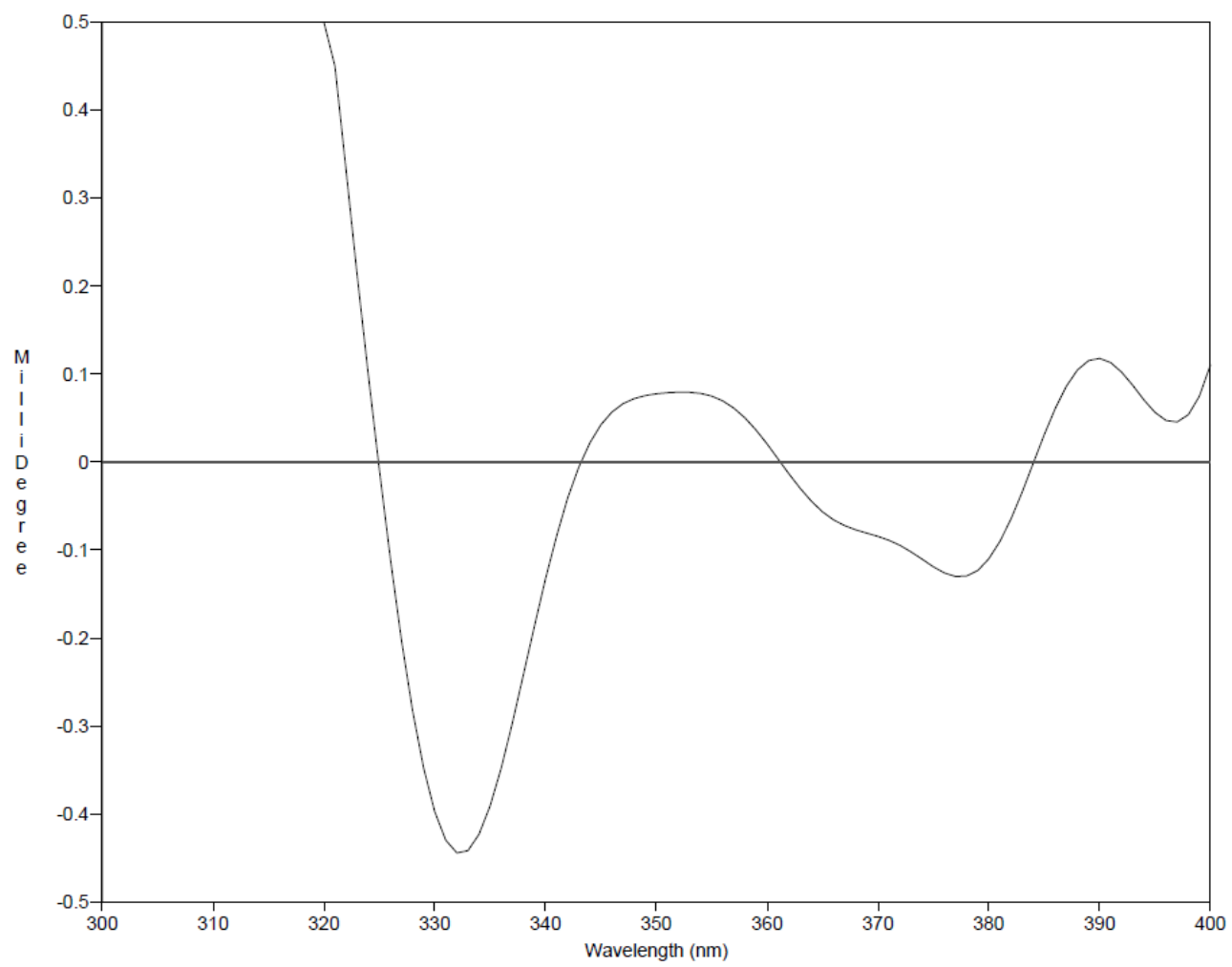


Figure S12. ${ }^{1} \mathrm{H}$ NMR spectrum of daphnegiralin $\mathrm{A}_{3} / \mathrm{A}_{4}(\mathbf{1 b})$ in $\mathrm{CD}_{3} \mathrm{OD}$.
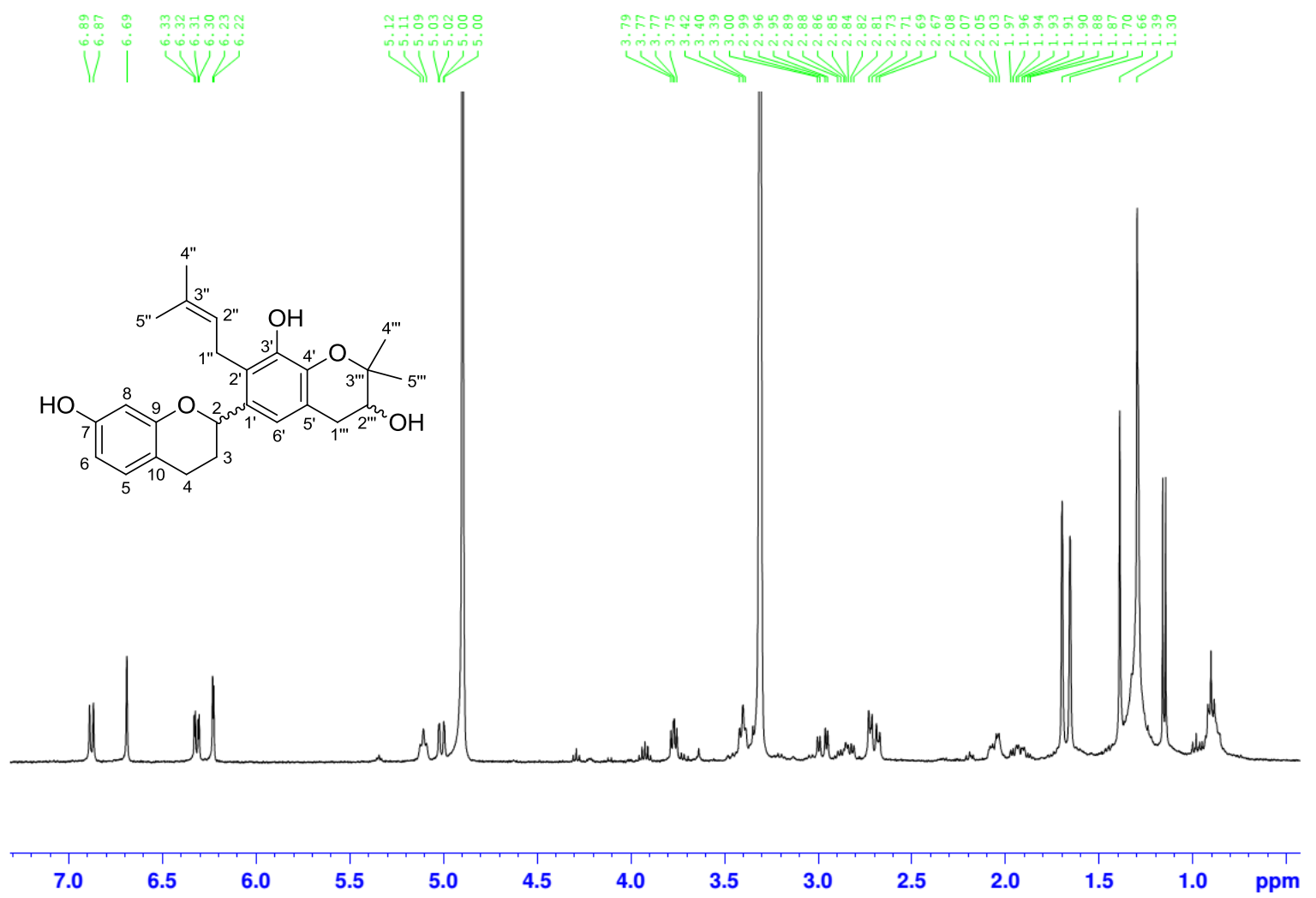

Figure S13. ${ }^{13} \mathrm{C}$ NMR spectrum of daphnegiralin $\mathrm{A}_{3} / \mathrm{A}_{4}(\mathbf{1 b})$ in $\mathrm{CD}_{3} \mathrm{OD}$.

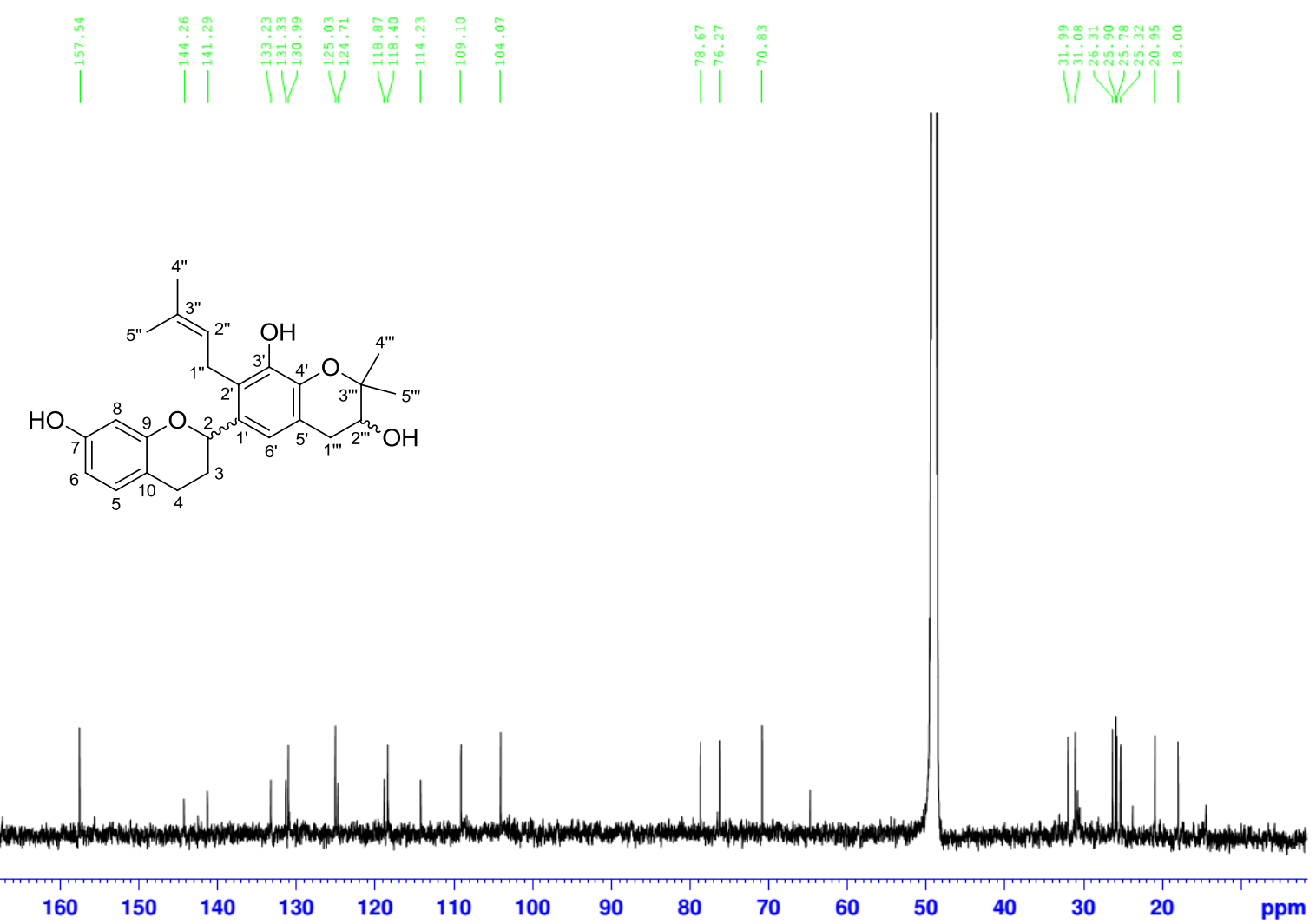


Figure S14. HSQC spectrum of daphnegiralin $\mathrm{A}_{3} / \mathrm{A}_{4}(\mathbf{1 b})$ in $\mathrm{CD}_{3} \mathrm{OD}$.

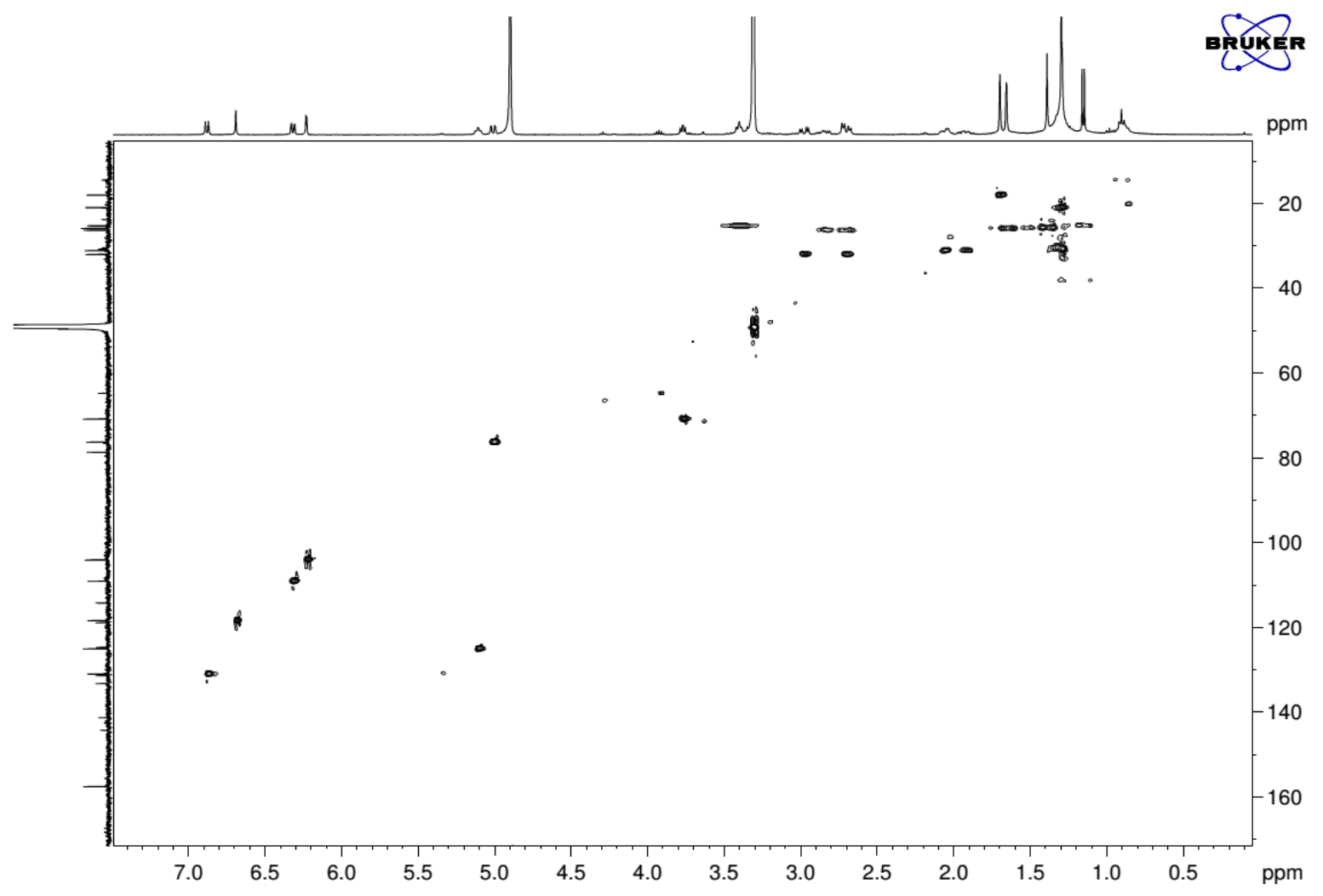

Figure S15. HMBC spectrum of daphnegiralin $A_{3} / A_{4}(\mathbf{1 b})$ in $C_{3} O D$.

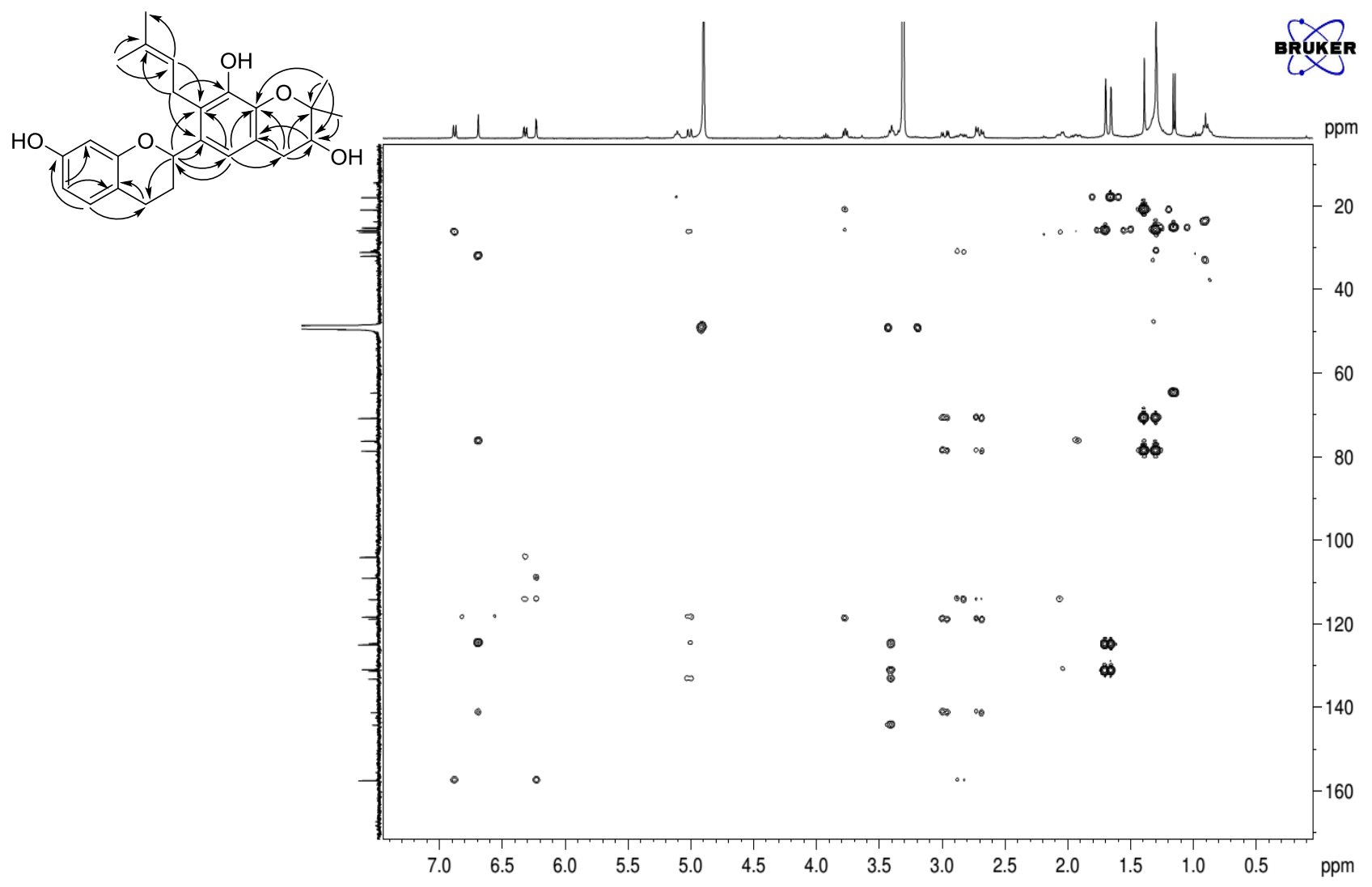


Figure S16. IR spectrum of daphnegiralin $\mathrm{A}_{3} / \mathrm{A}_{4}(\mathbf{1 b})$.

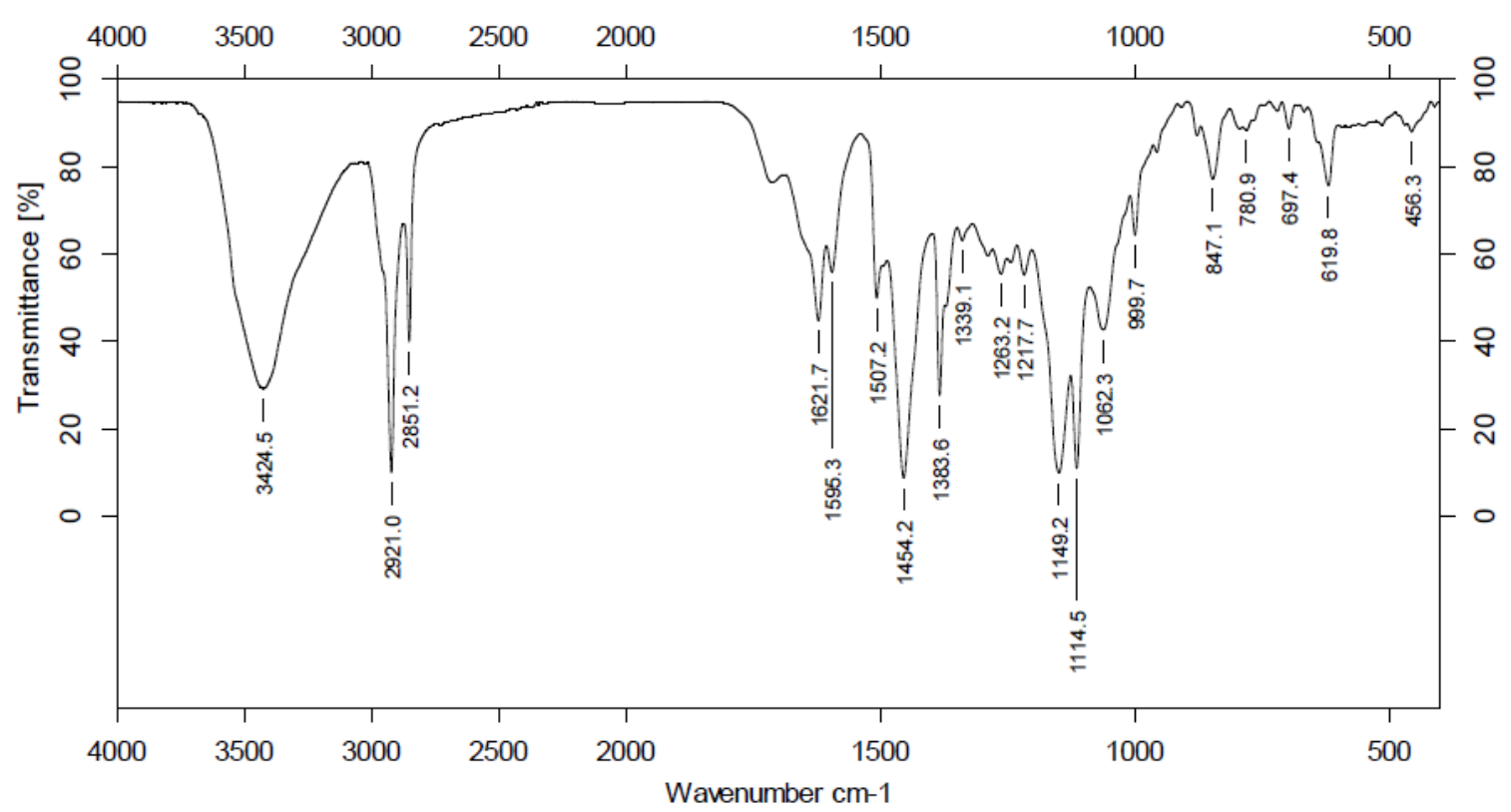

Figure S17. HRESIMS of daphnegiralin $\mathrm{A}_{3} / \mathrm{A}_{4}(\mathbf{1 b})$.

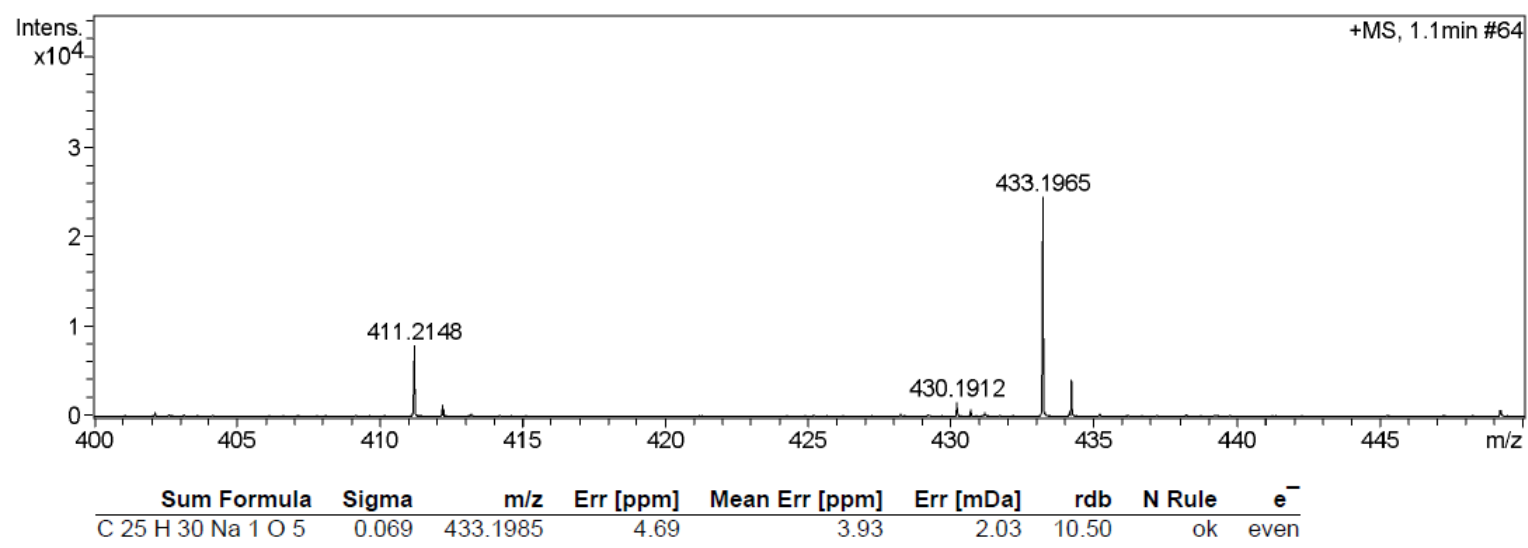

Figure S18. UV spectrum of daphnegiralin $\mathrm{A}_{3} / \mathrm{A}_{4}(\mathbf{1 b})$.

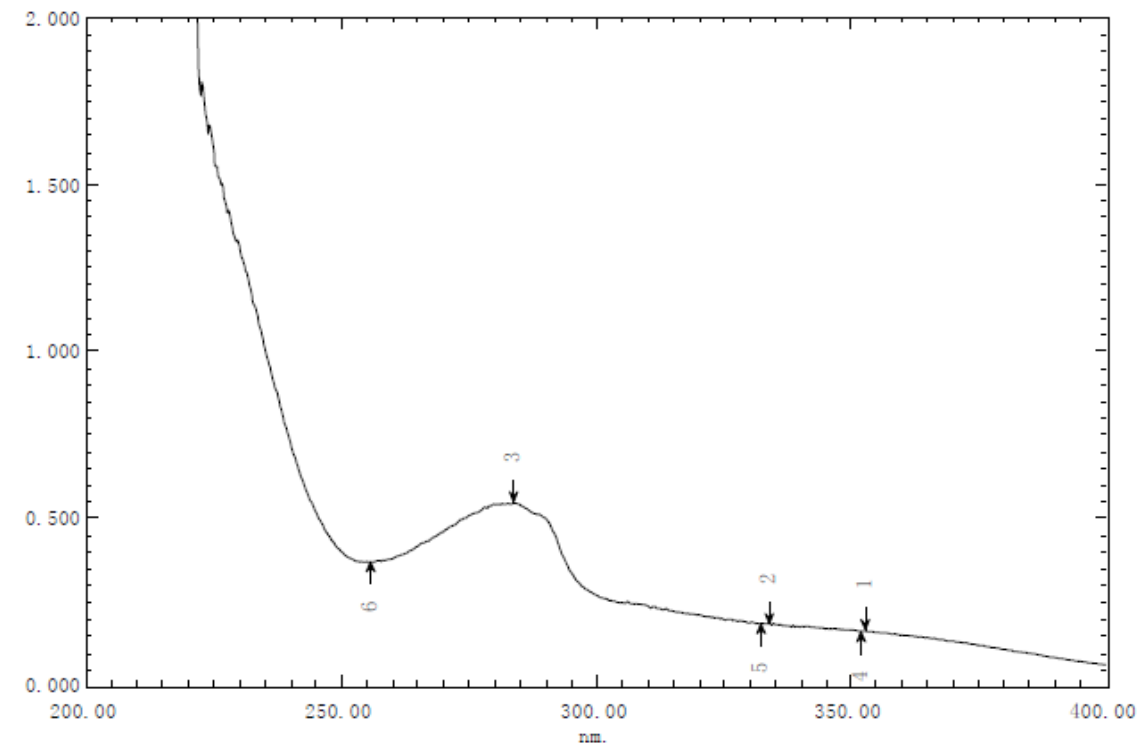


Figure S19. The ECD Spectrum of daphnegiralin $A_{3}$ (1b-1).

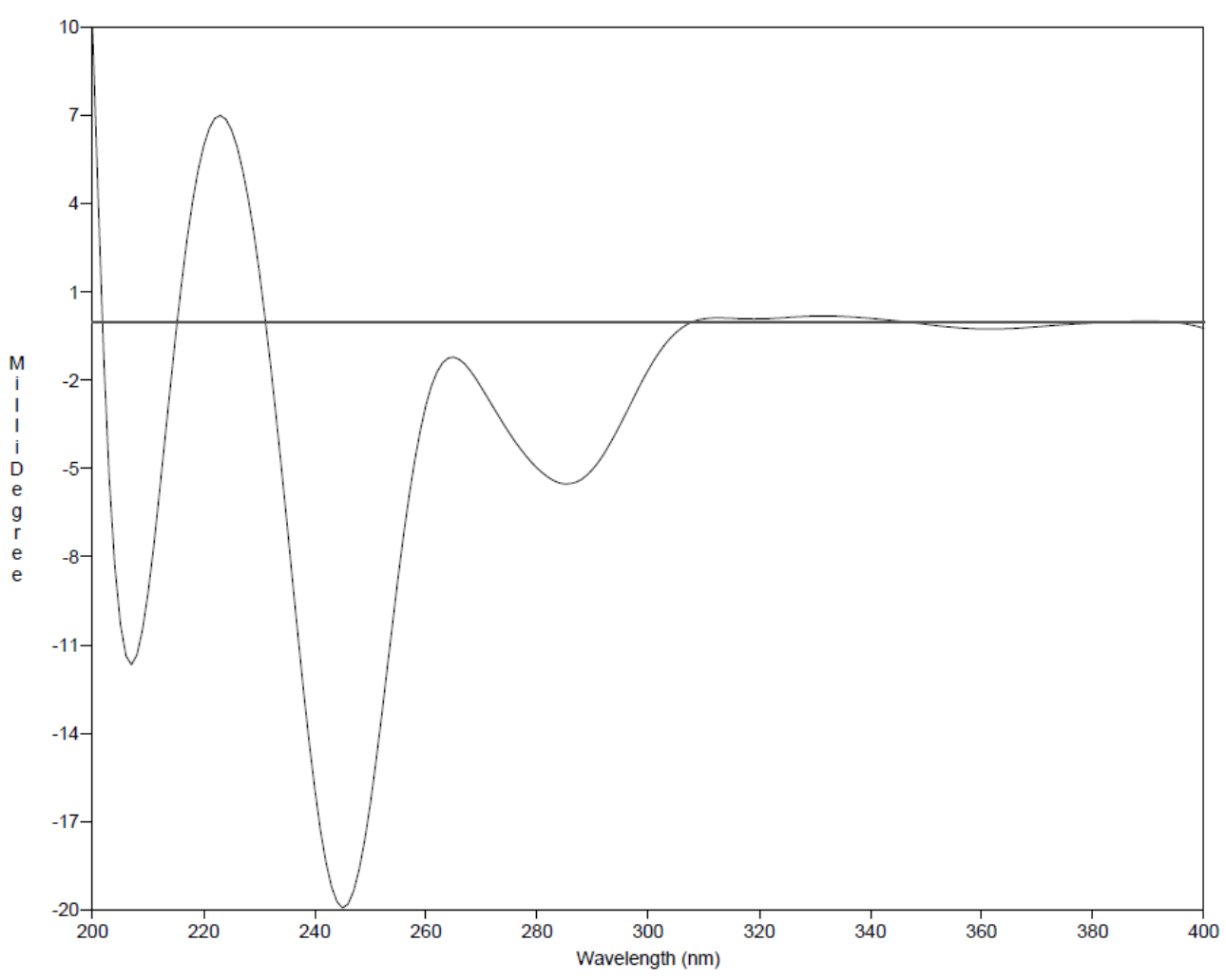

Figure S20. The ECD Spectrum of daphnegiralin $\mathrm{A}_{4}$ (1b-2).

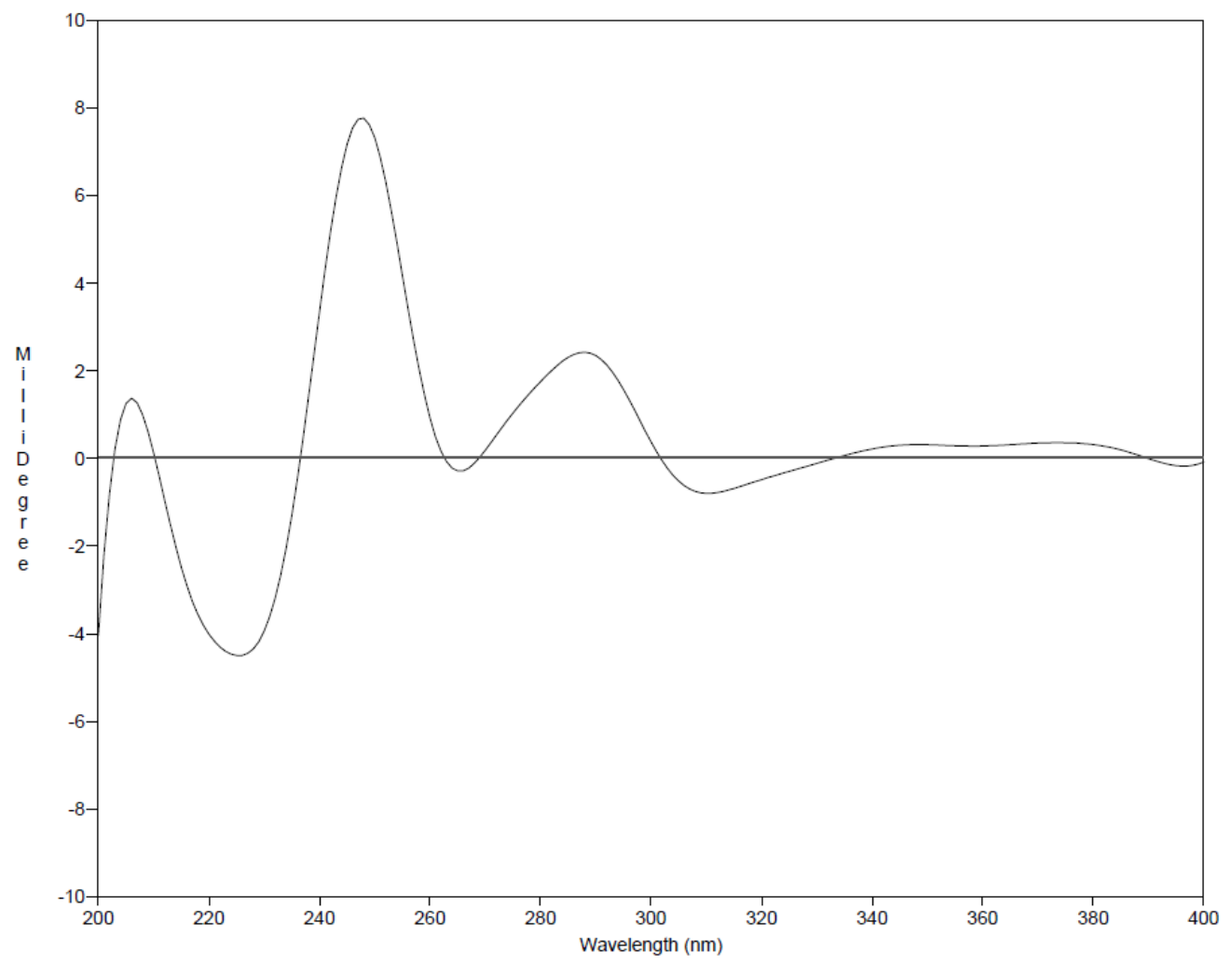


Figure $\mathbf{S 2 1} . \mathrm{Rh}_{2}\left(\mathrm{OCOCF}_{3}\right)_{4}$-ICD spectrum of daphnegiralin $\mathrm{A}_{3}(\mathbf{1 b}-\mathbf{1})$.

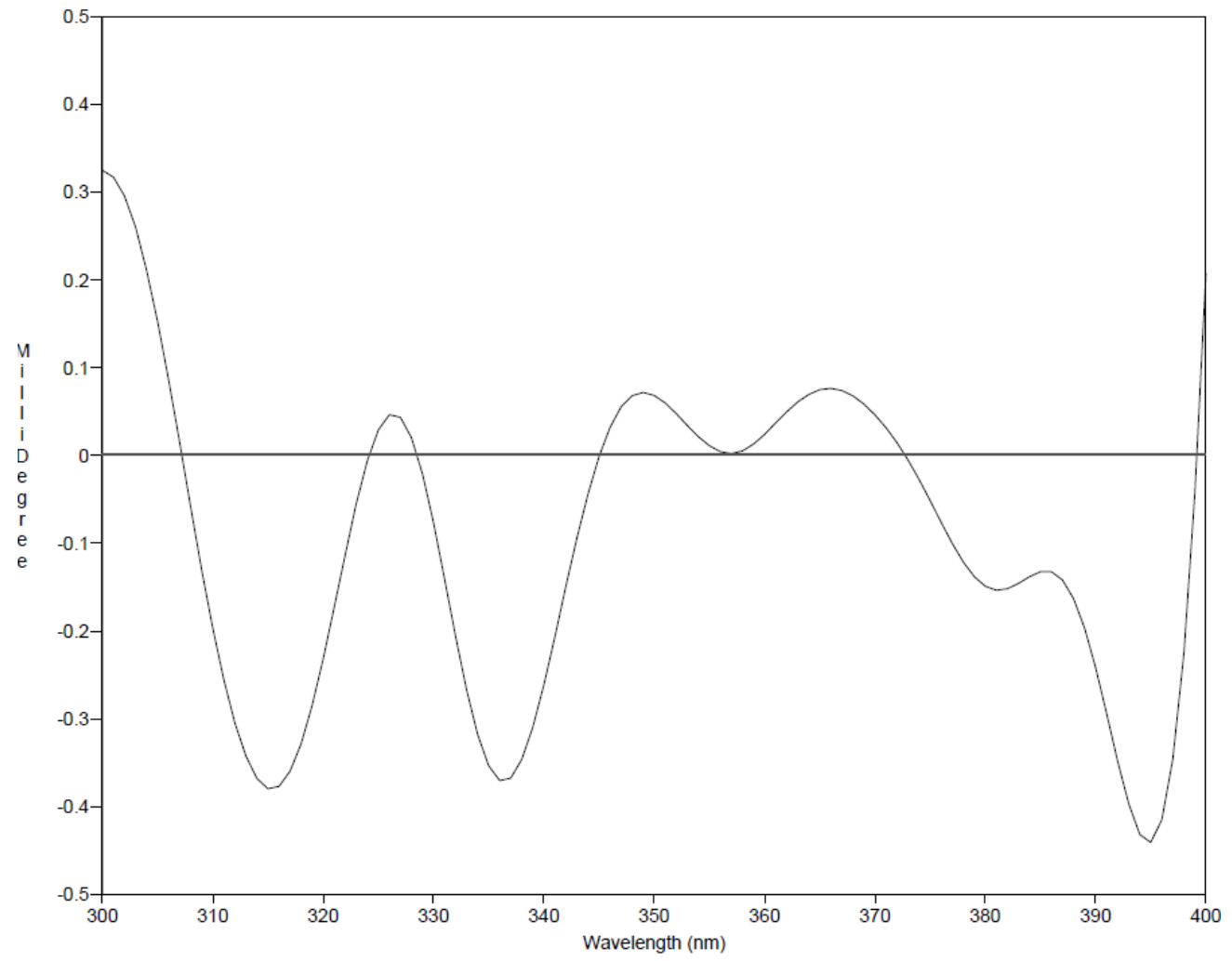

Figure S22. $\mathrm{Rh}_{2}\left(\mathrm{OCOCF}_{3}\right)_{4}$-ICD spectrum of daphnegiralin $\mathrm{A}_{4}(\mathbf{1 b}-\mathbf{2})$.

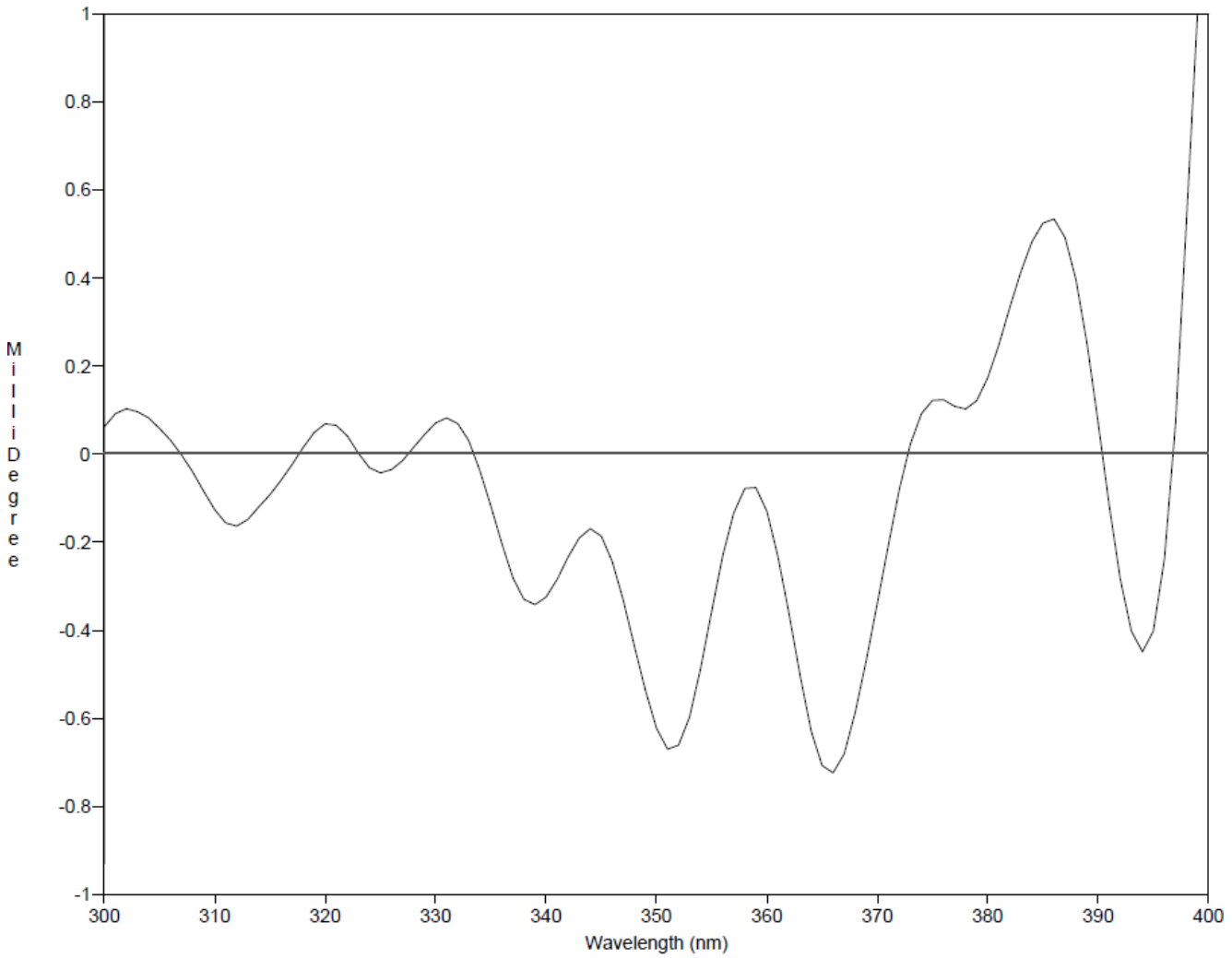


Figure S23. ${ }^{1} \mathrm{H}$ NMR spectrum of daphnegiralin $\mathrm{B}_{1} / \mathrm{B}_{2}(\mathbf{2 a})$ in $\mathrm{CD}_{3} \mathrm{OD}$.
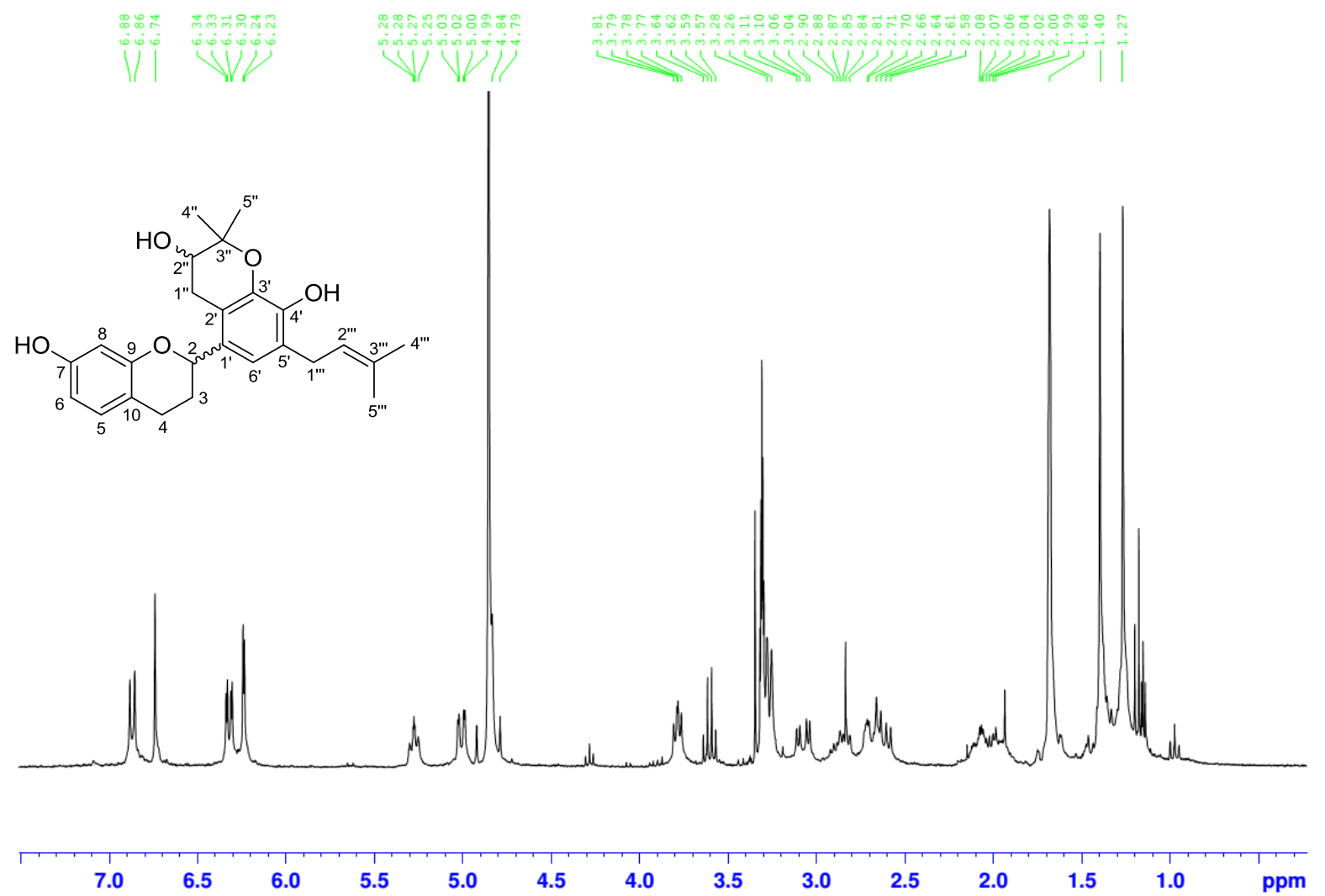

Figure S24. ${ }^{13} \mathrm{C}$ NMR spectrum of daphnegiralin $\mathrm{B}_{1} / \mathrm{B}_{2}(\mathbf{2 a})$ in $\mathrm{CD}_{3} \mathrm{OD}$.

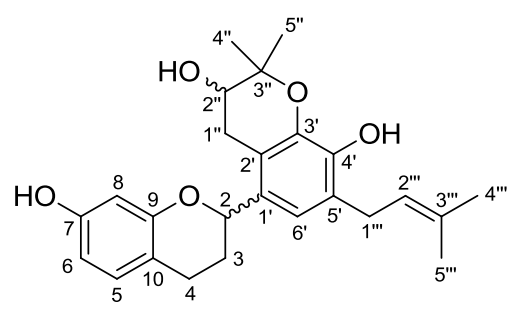

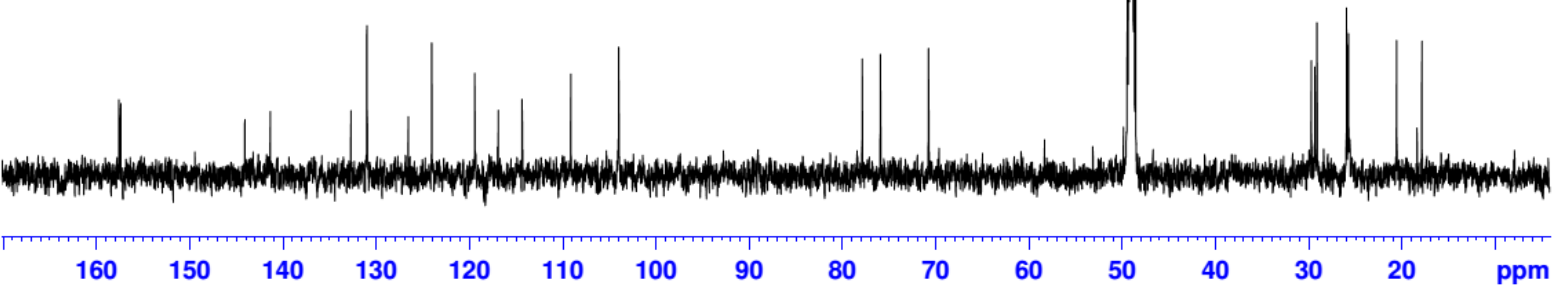


Figure S25. HSQC spectrum of daphnegiralin $\mathrm{B}_{1} / \mathrm{B}_{2}(\mathbf{2 a})$ in $\mathrm{CD}_{3} \mathrm{OD}$.

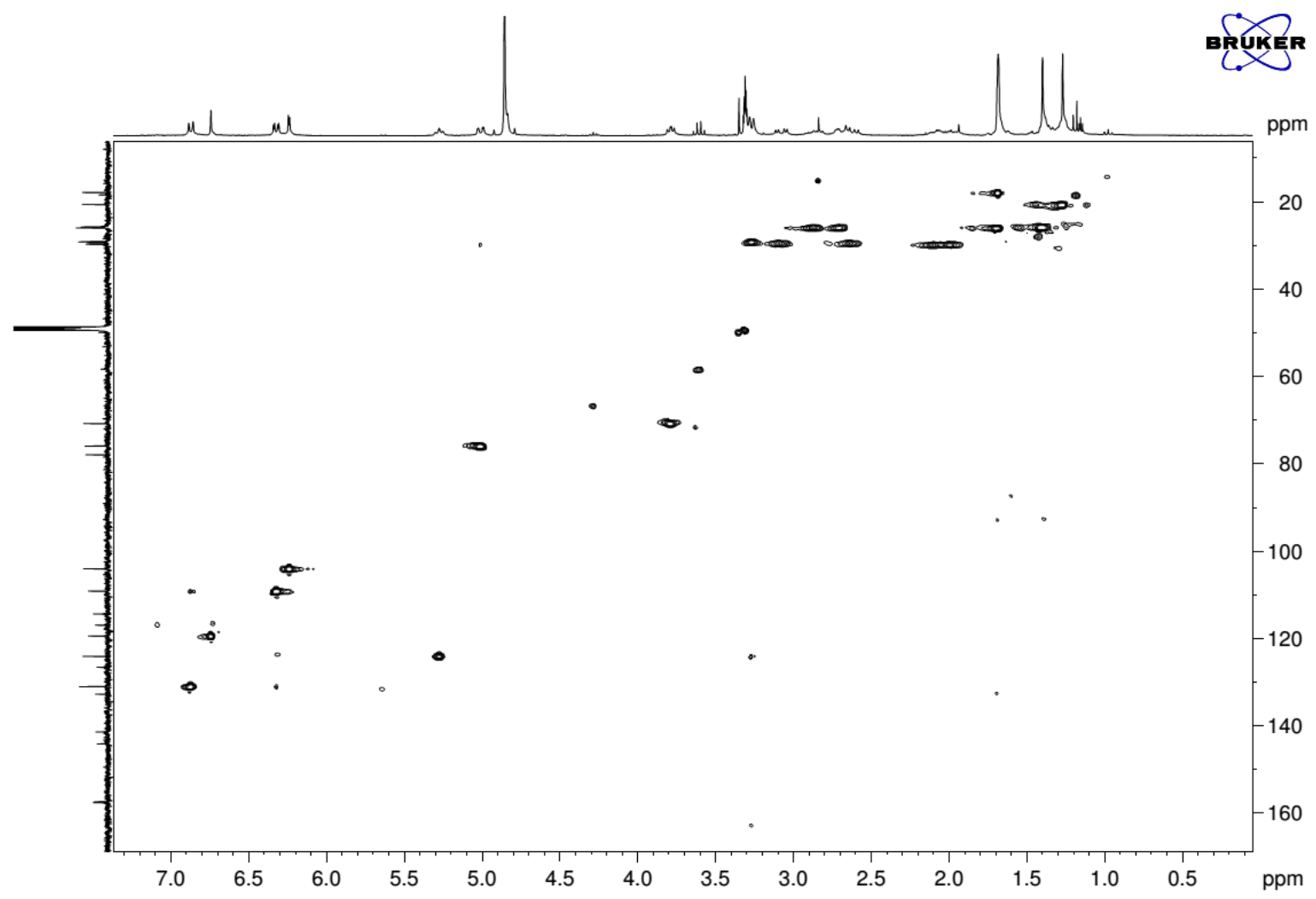

Figure S26. $\mathrm{HMBC}$ spectrum of daphnegiralin $\mathrm{B}_{1} / \mathrm{B}_{2}(\mathbf{2 a})$ in $\mathrm{CD}_{3} \mathrm{OD}$.

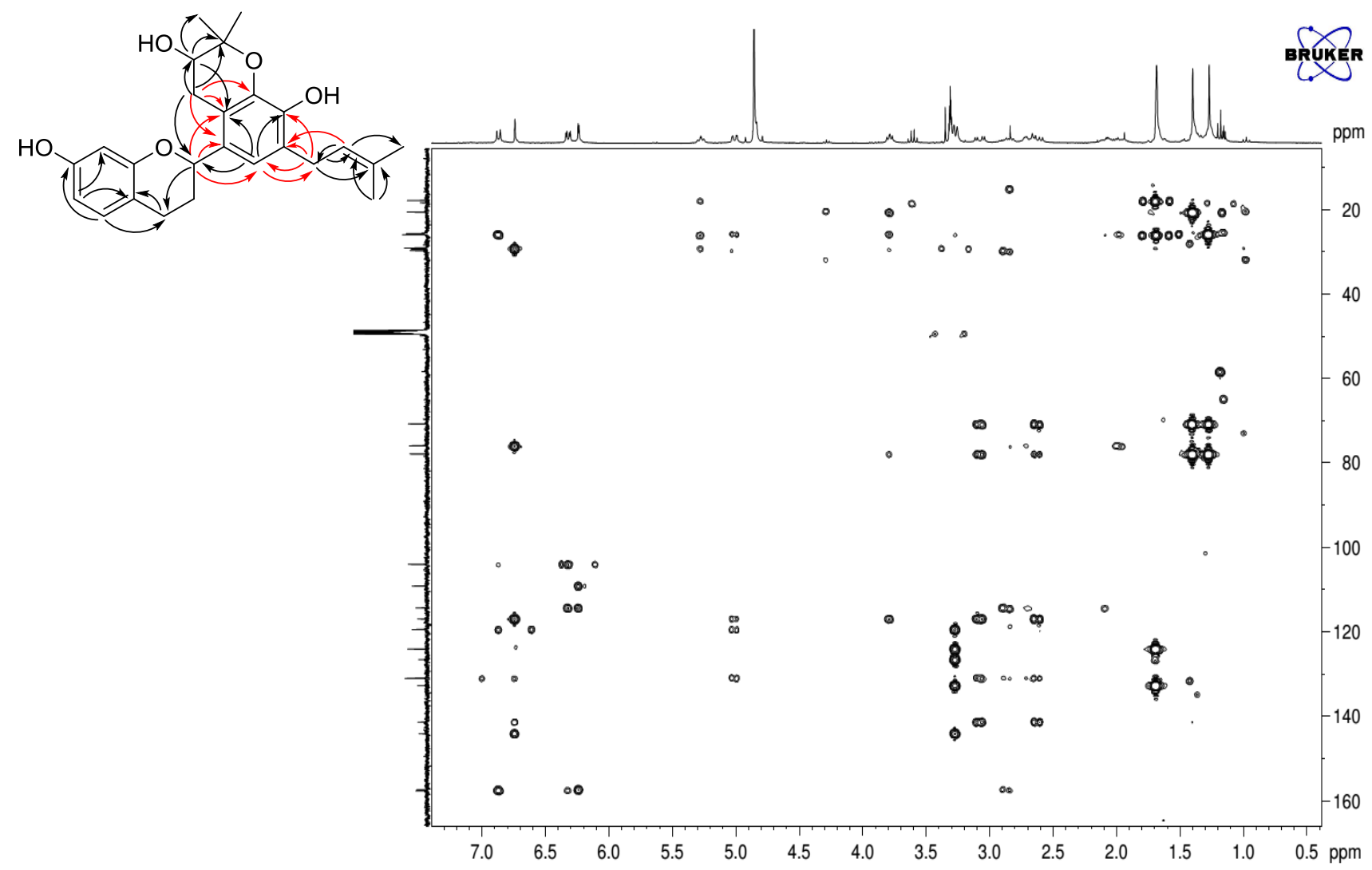


Figure S27. IR spectrum of daphnegiralin $\mathrm{B}_{1} / \mathrm{B}_{2}(\mathbf{2 a})$.

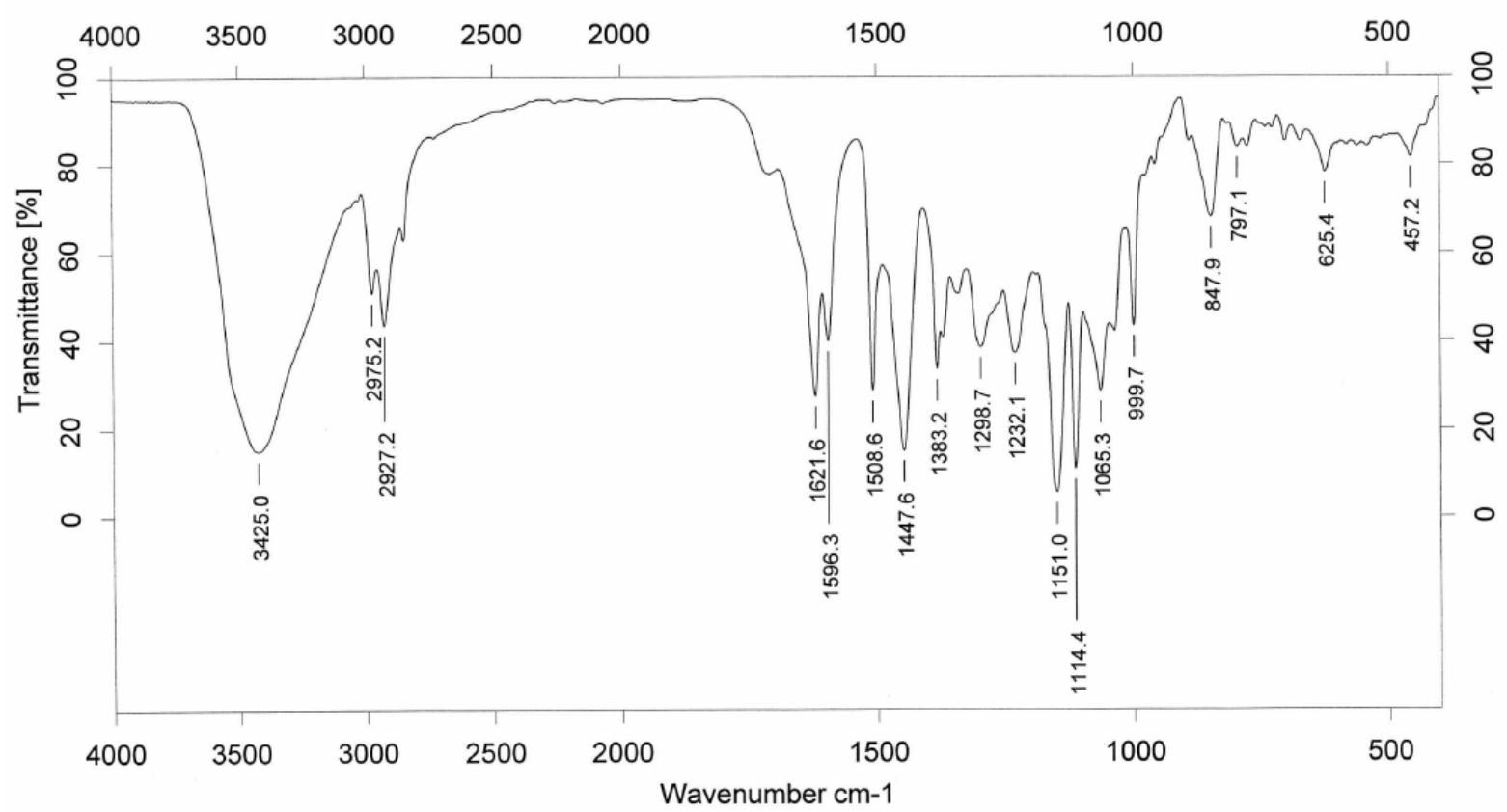

Figure S28. HRESIMS of daphnegiralin $\mathrm{B}_{1} / \mathrm{B}_{2}(\mathbf{2 a})$.

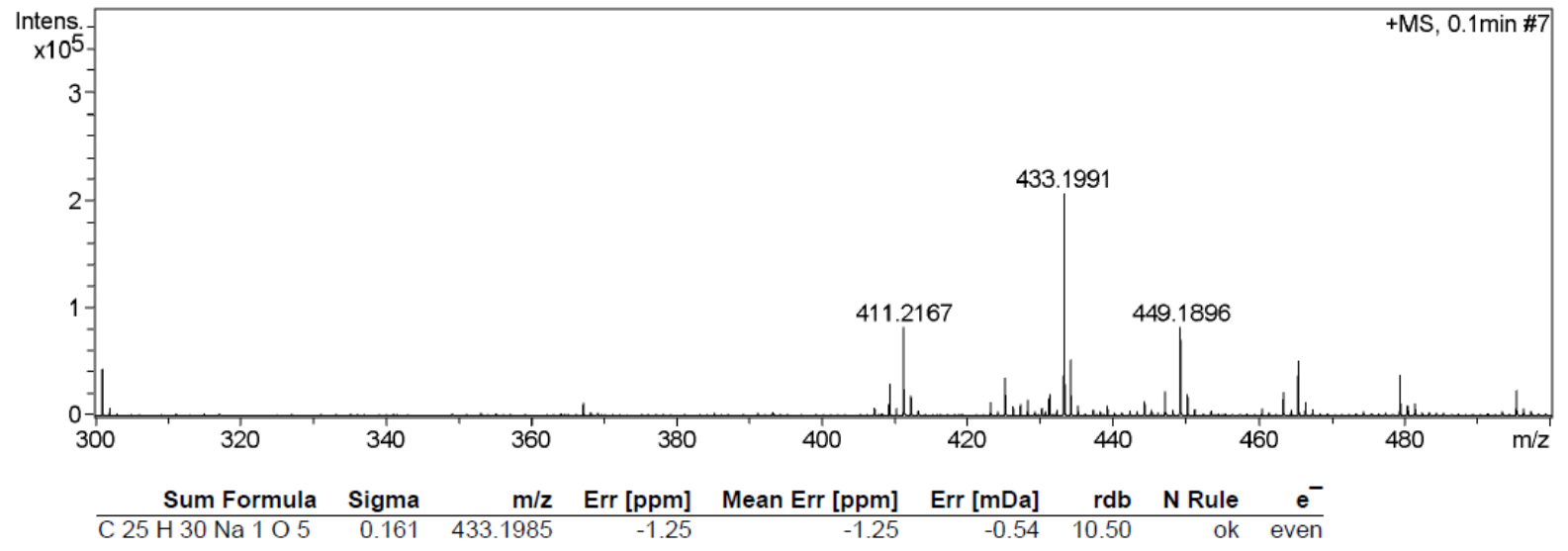

Figure S29. UV spectrum of daphnegiralin $\mathrm{B}_{1} / \mathrm{B}_{2}(\mathbf{2 a})$.

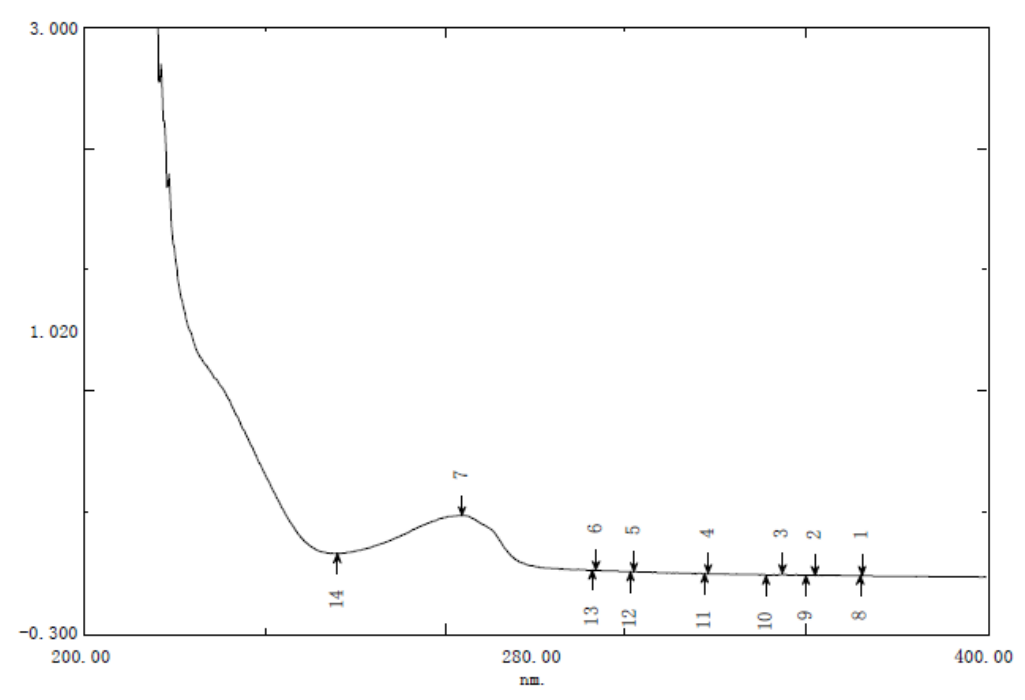


Figure S30. The ECD Spectrum of daphnegiralin $\mathrm{B}_{1} / \mathrm{B}_{2}(\mathbf{2 a})$.

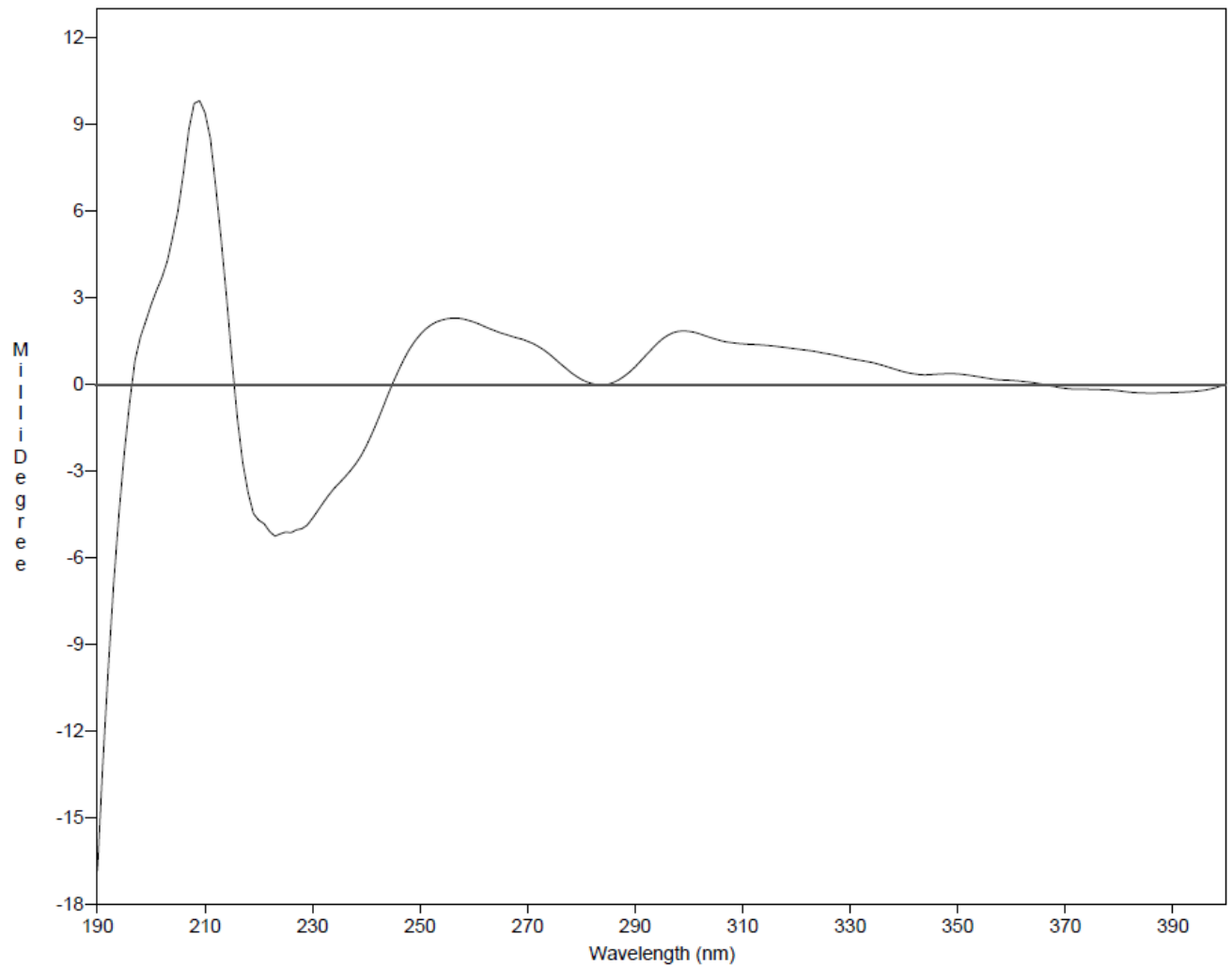

Figure S31. The ECD Spectrum of daphnegiralin $\mathrm{B}_{1}(\mathbf{2 a - 1})$.

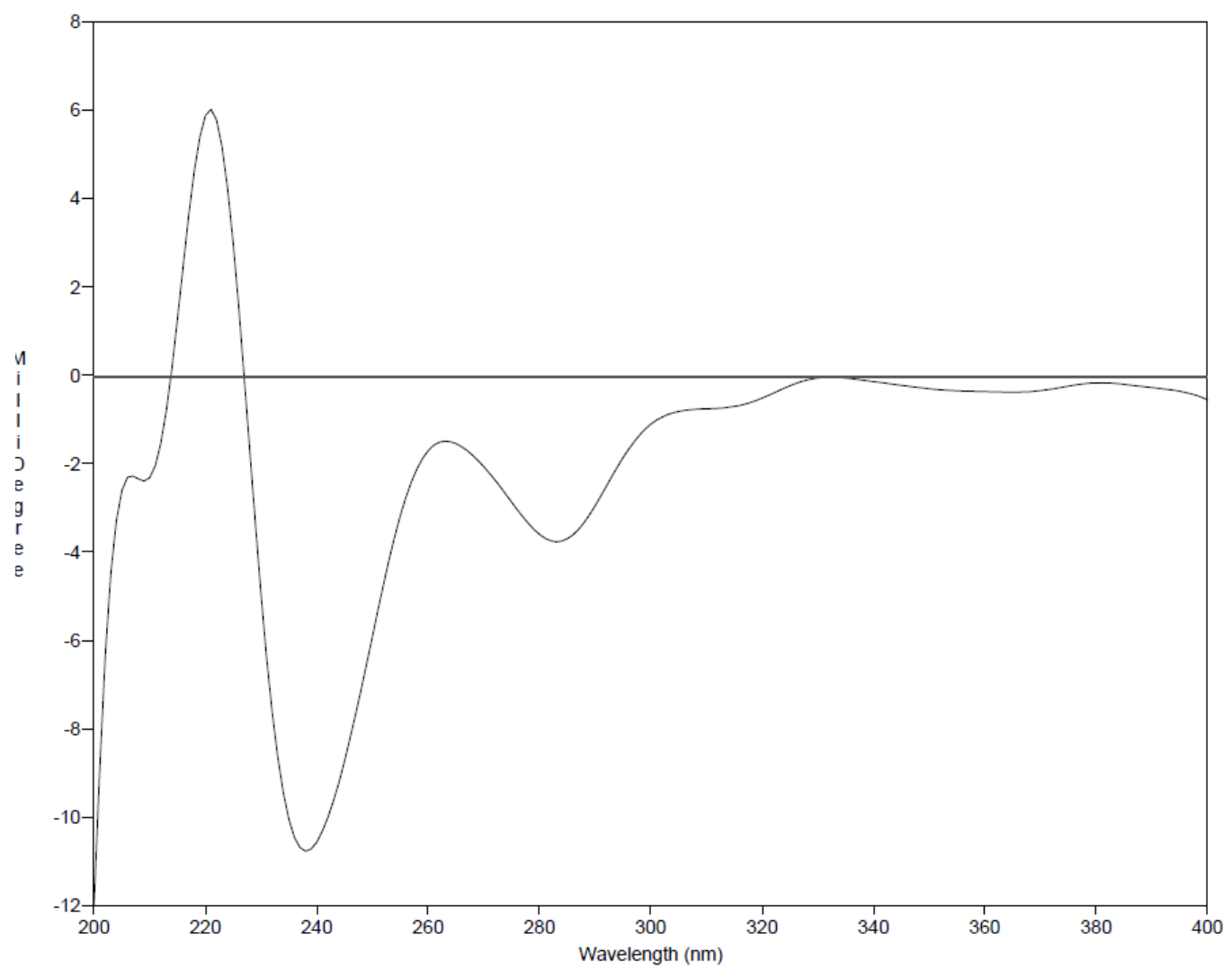


Figure S32. The ECD Spectrum of daphnegiralin $\mathrm{B}_{2}(\mathbf{2 a}-\mathbf{2})$.

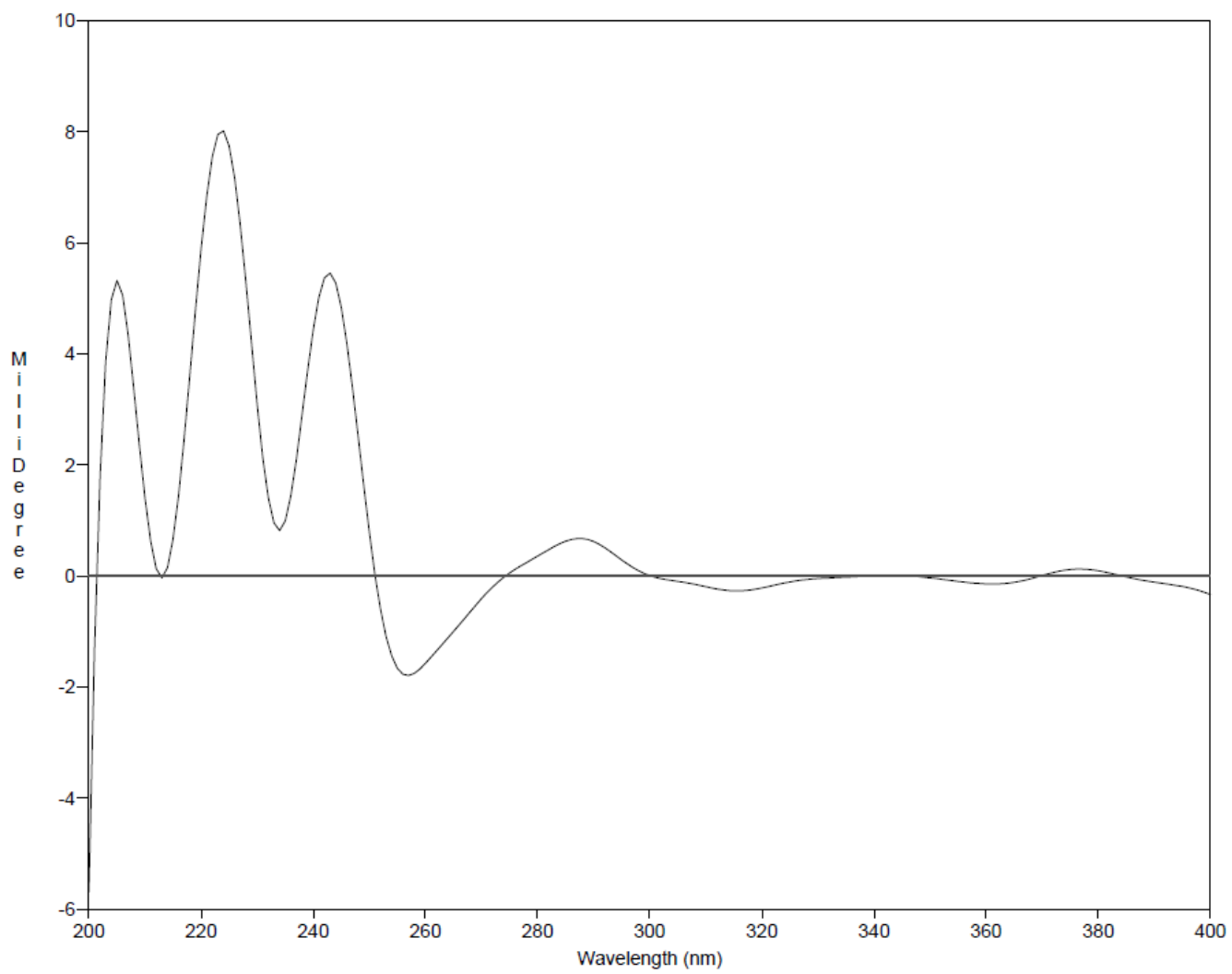

Figure S33. $\mathrm{Rh}_{2}\left(\mathrm{OCOCF}_{3}\right)_{4}$-ICD spectrum of daphnegiralin $\mathrm{B}_{1}(\mathbf{2 a - 1})$.

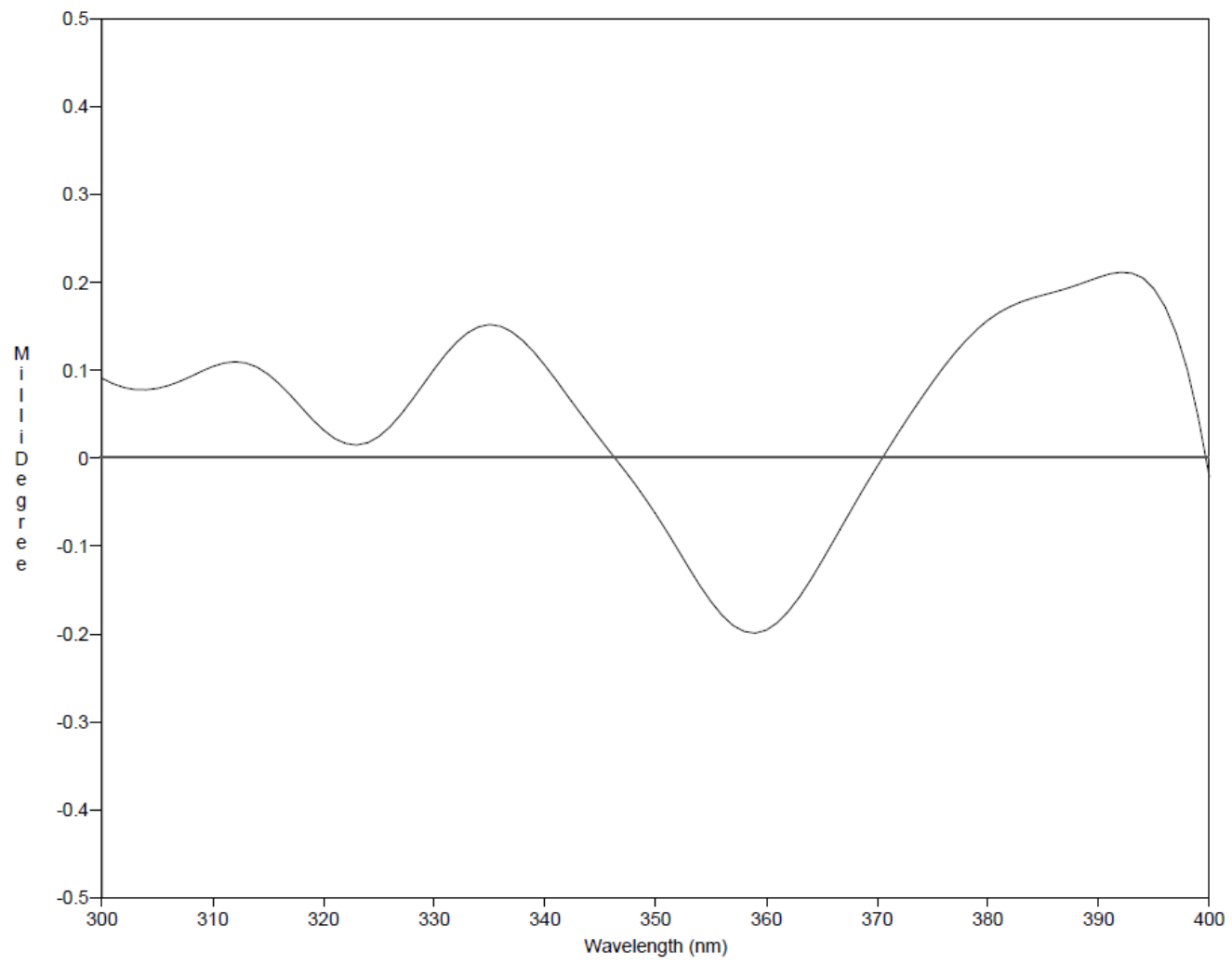


Figure S34. $\mathrm{Rh}_{2}\left(\mathrm{OCOCF}_{3}\right)_{4}$-ICD spectrum of daphnegiralin $\mathrm{B}_{2}(\mathbf{2 a - 2})$.

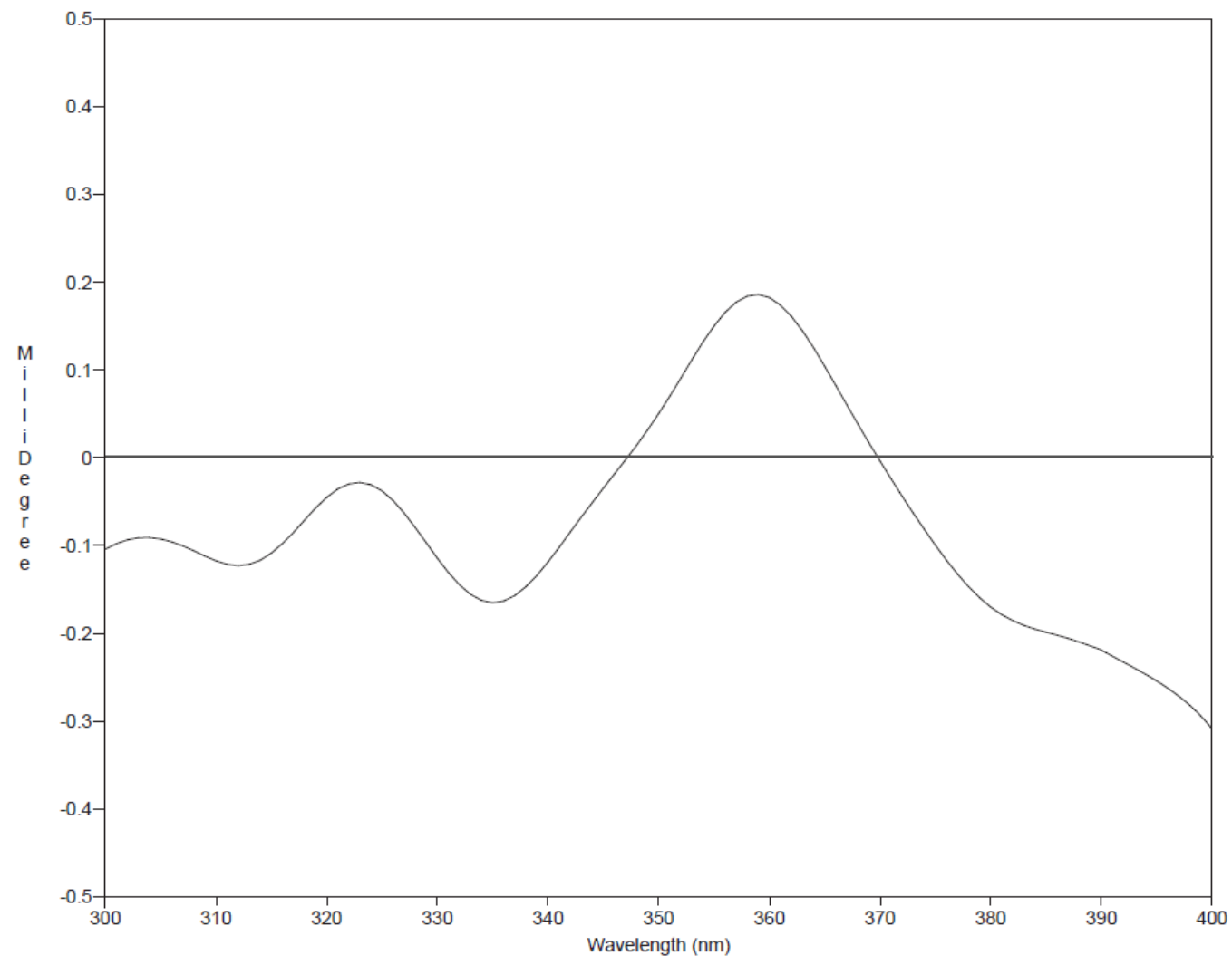

Figure S35. ${ }^{1} \mathrm{H}$ NMR spectrum of daphnegiralin $\mathrm{B}_{3} / \mathrm{B}_{4}(\mathbf{2 b})$ in $\mathrm{CD}_{3} \mathrm{OD}$.

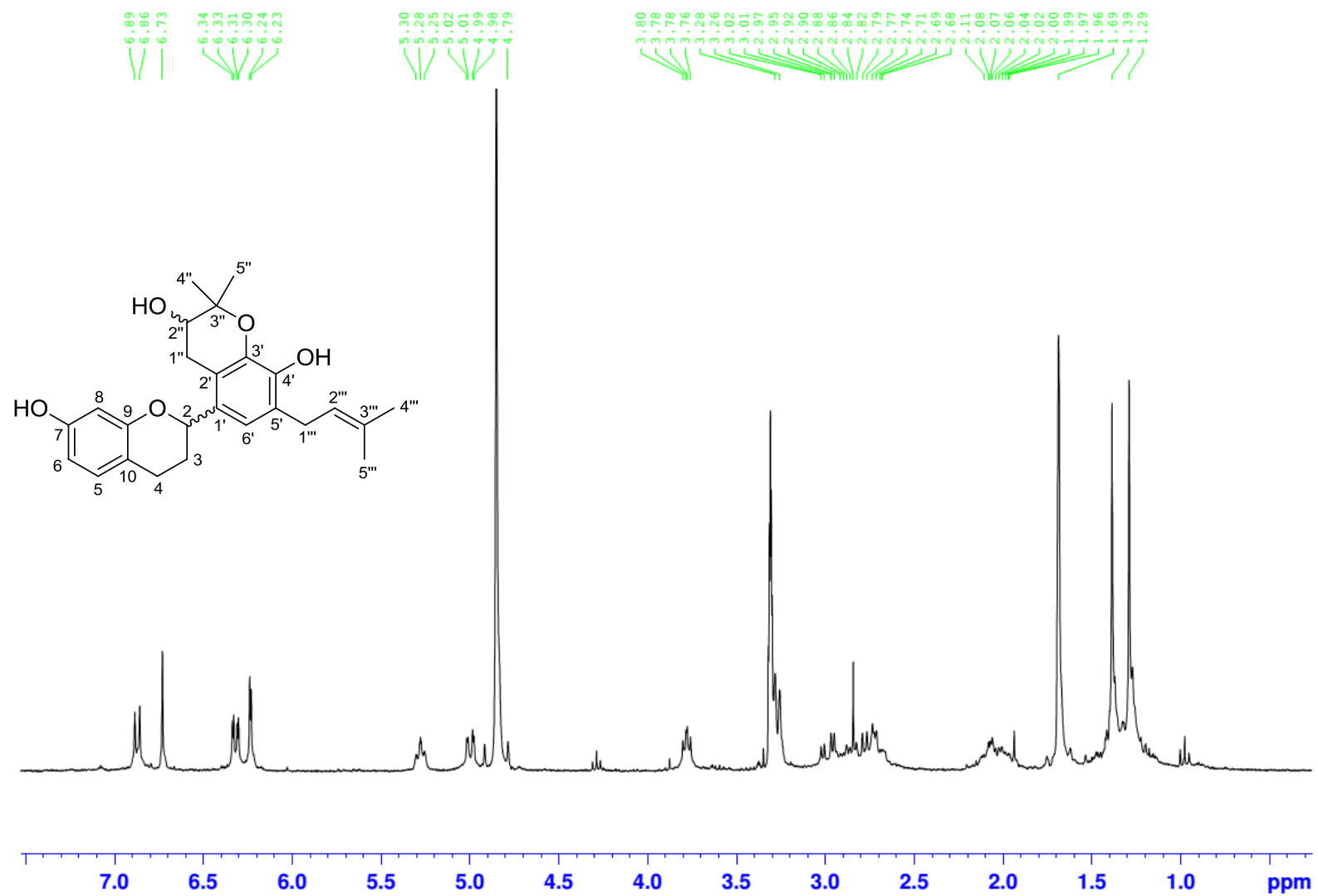


Figure S36. ${ }^{13} \mathrm{C}$ NMR spectrum of daphnegiralin $\mathrm{B}_{3} / \mathrm{B}_{4}(\mathbf{2 b})$ in $\mathrm{CD}_{3} \mathrm{OD}$.

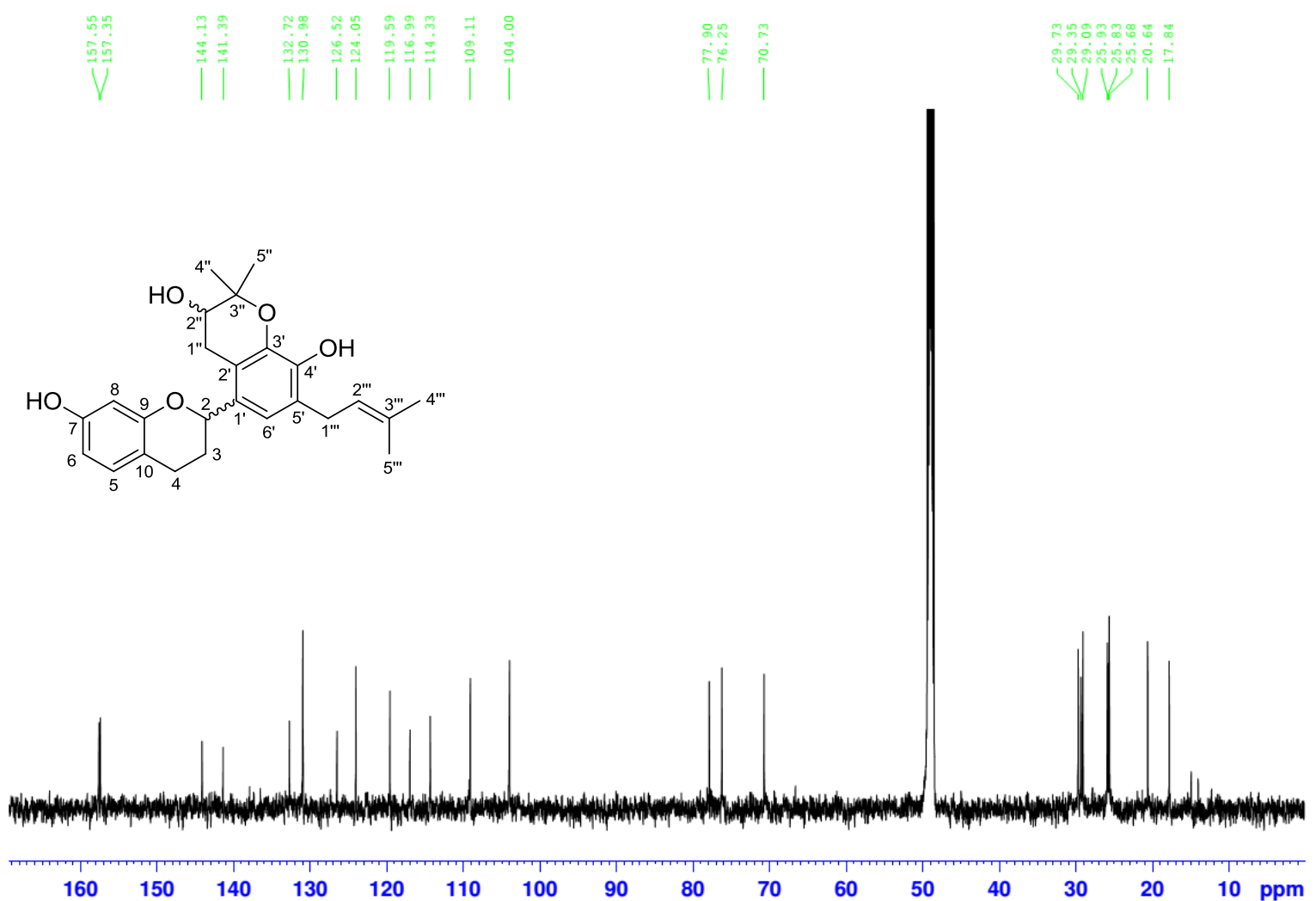

Figure S37. $\mathrm{HSQC}$ spectrum of daphnegiralin $\mathrm{B}_{3} / \mathrm{B}_{4}(\mathbf{2 b})$ in $\mathrm{CD}_{3} \mathrm{OD}$.

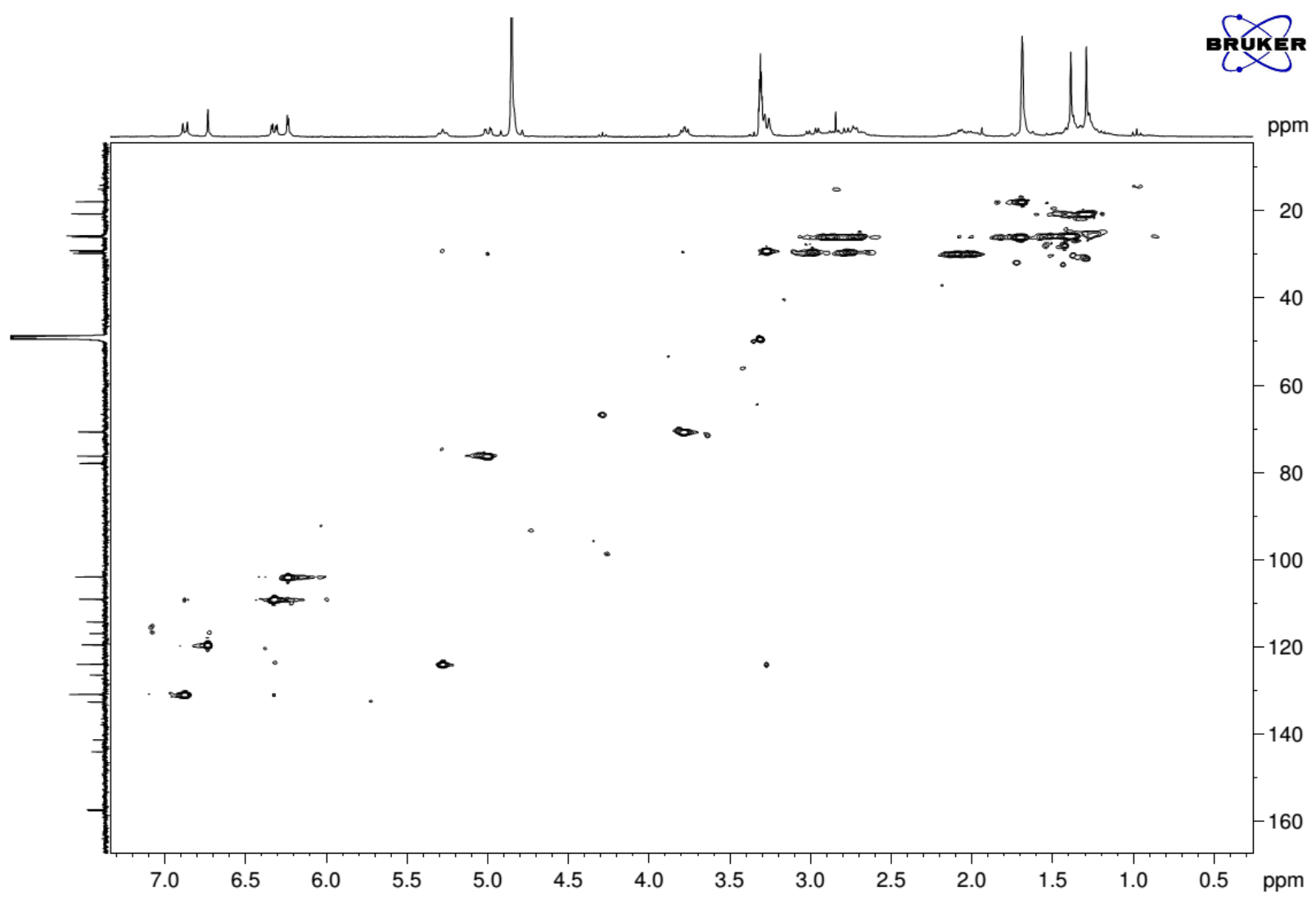


Figure S38. $\mathrm{HMBC}$ spectrum of daphnegiralin $\mathrm{B}_{3} / \mathrm{B}_{4}(\mathbf{2 b})$ in $\mathrm{CD}_{3} \mathrm{OD}$.

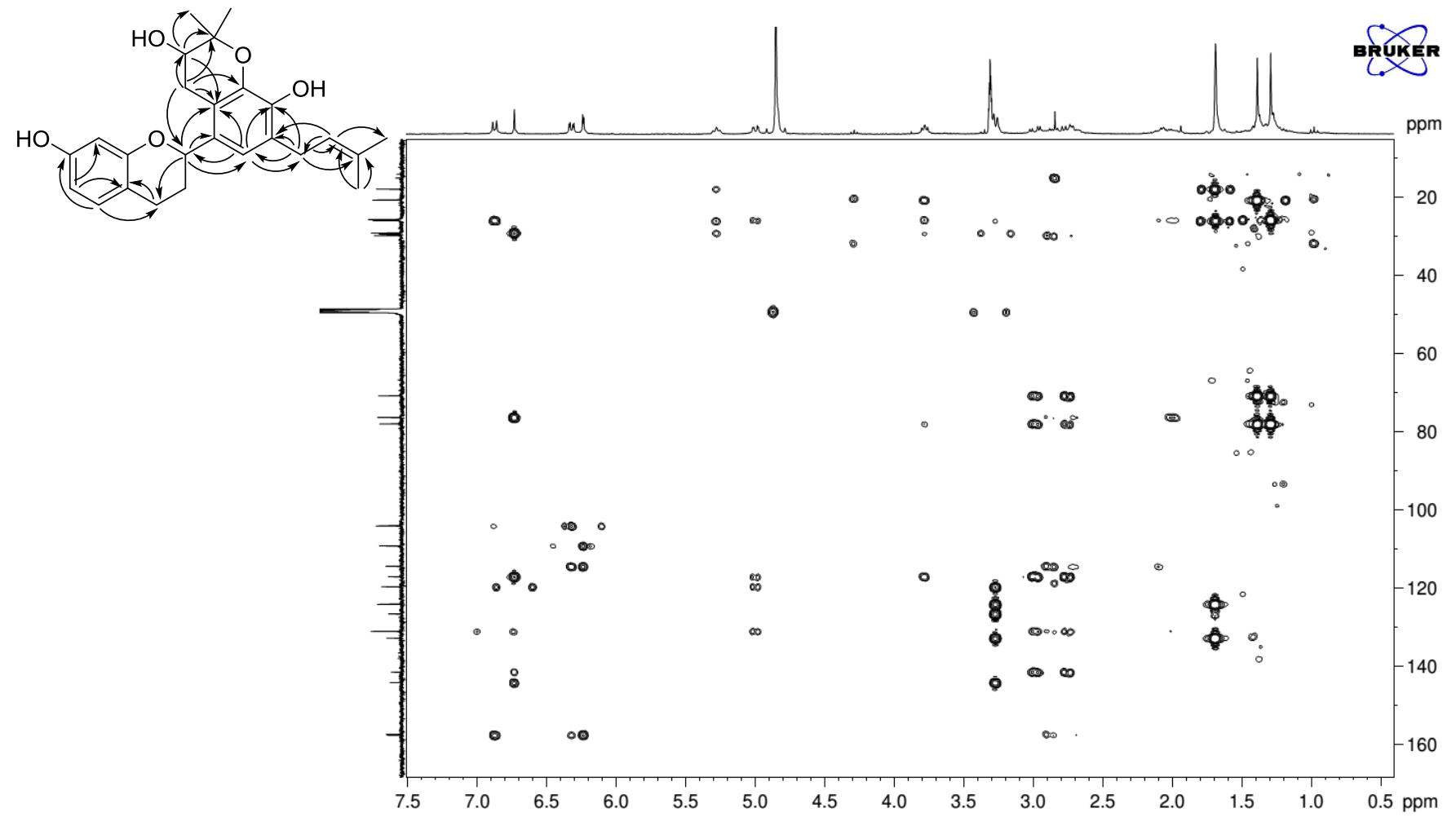

Figure S39. IR spectrum of daphnegiralin $\mathrm{B}_{3} / \mathrm{B}_{4}(\mathbf{2 b})$.

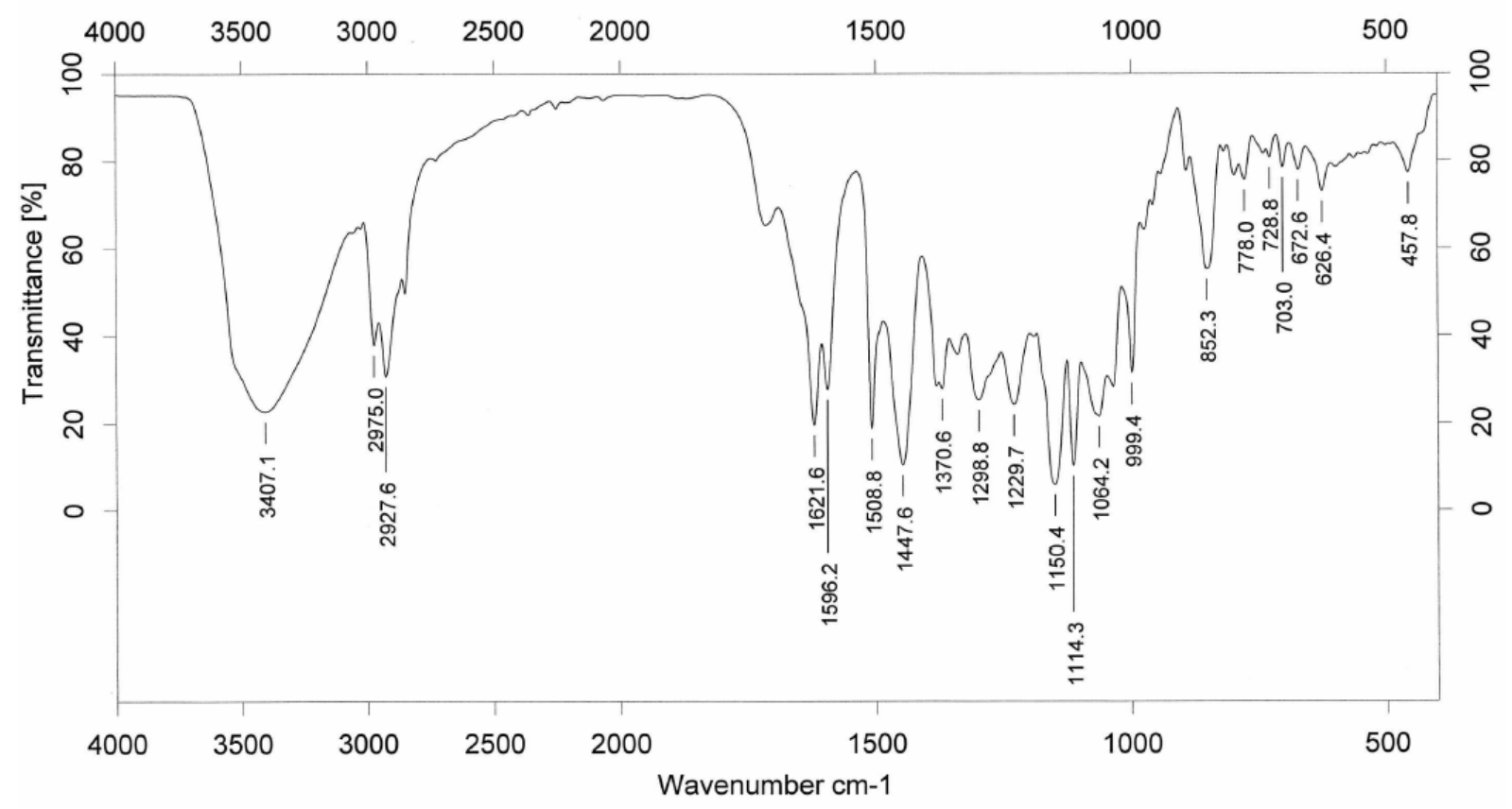


Figure S40. HRESIMS of daphnegiralin $\mathrm{B}_{3} / \mathrm{B}_{4}(\mathbf{2 b})$.

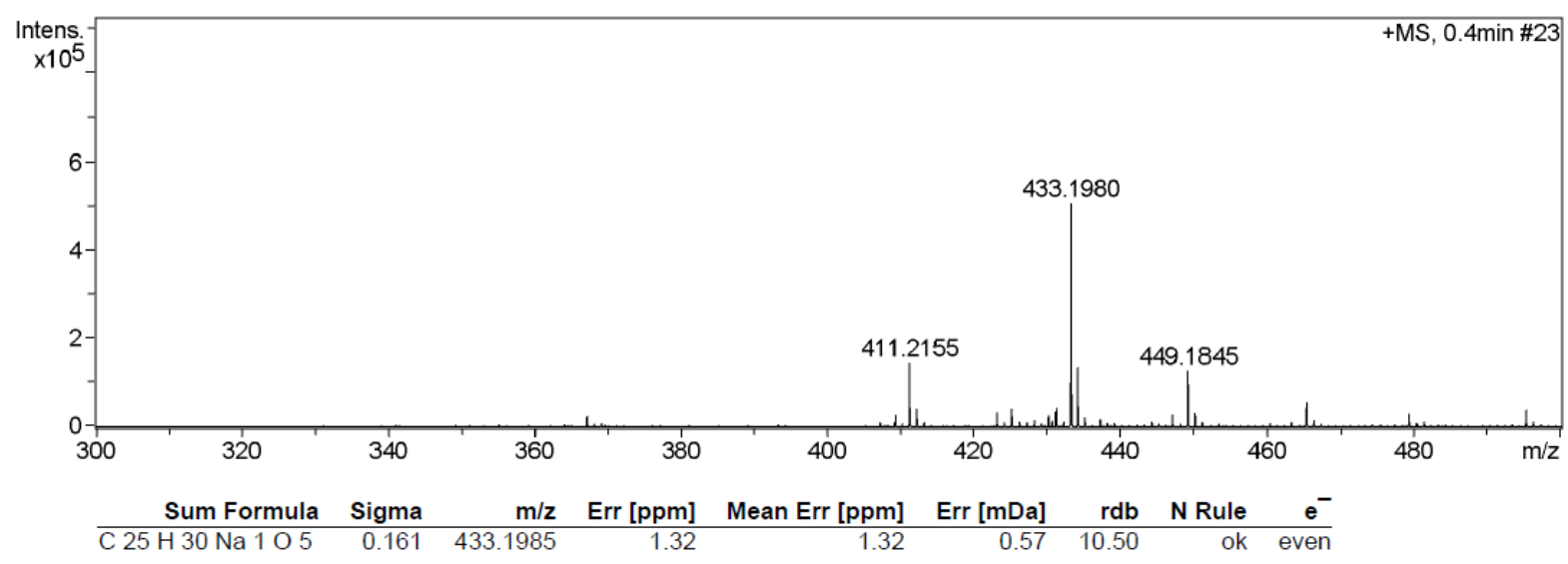

Figure S41. UV spectrum of daphnegiralin $\mathrm{B}_{3} / \mathrm{B}_{4}(\mathbf{2 b})$.

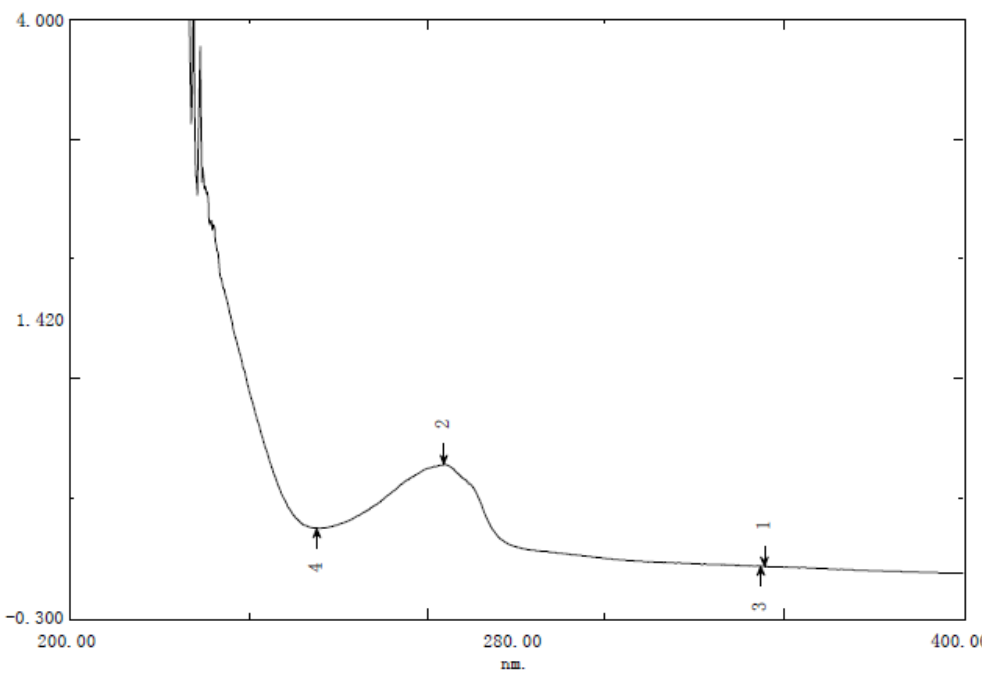

Figure $\mathbf{S 4 2}$. The ECD Spectrum of daphnegiralin $\mathrm{B}_{3} / \mathrm{B}_{4}(\mathbf{2 b})$.

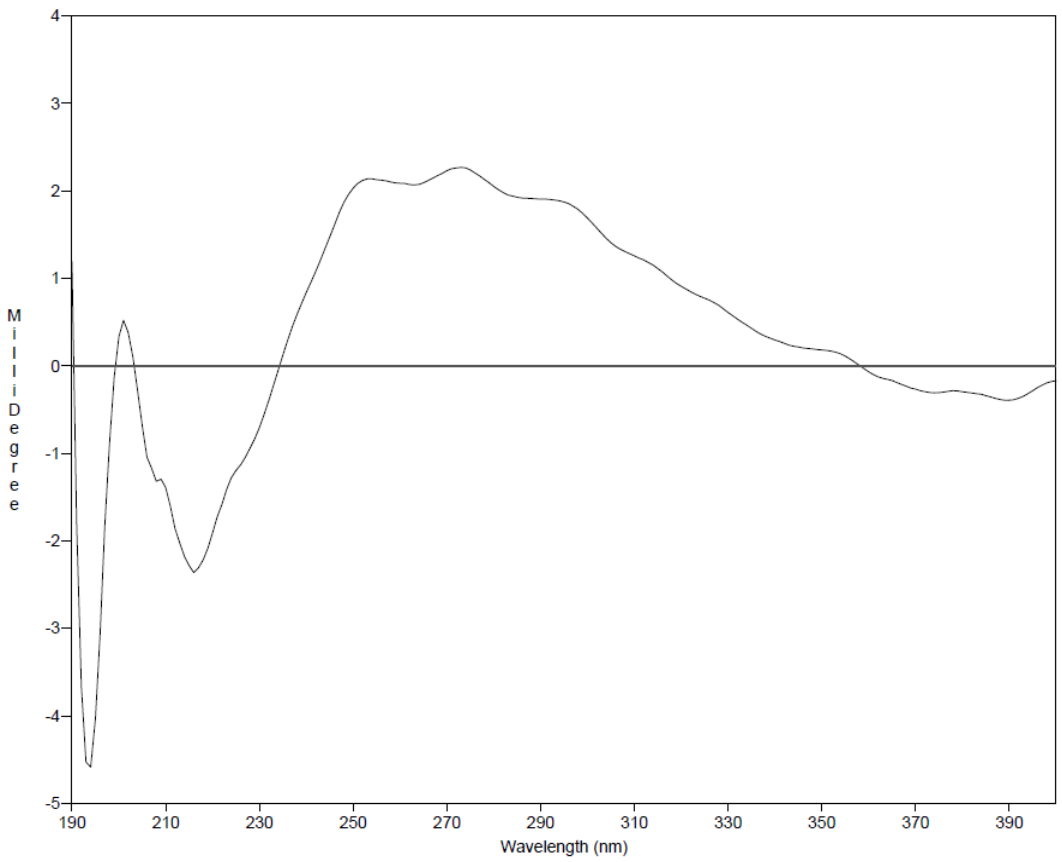


Figure S43. The ECD Spectrum of daphnegiralin $\mathrm{B}_{3}(\mathbf{2 b}-\mathbf{1})$.

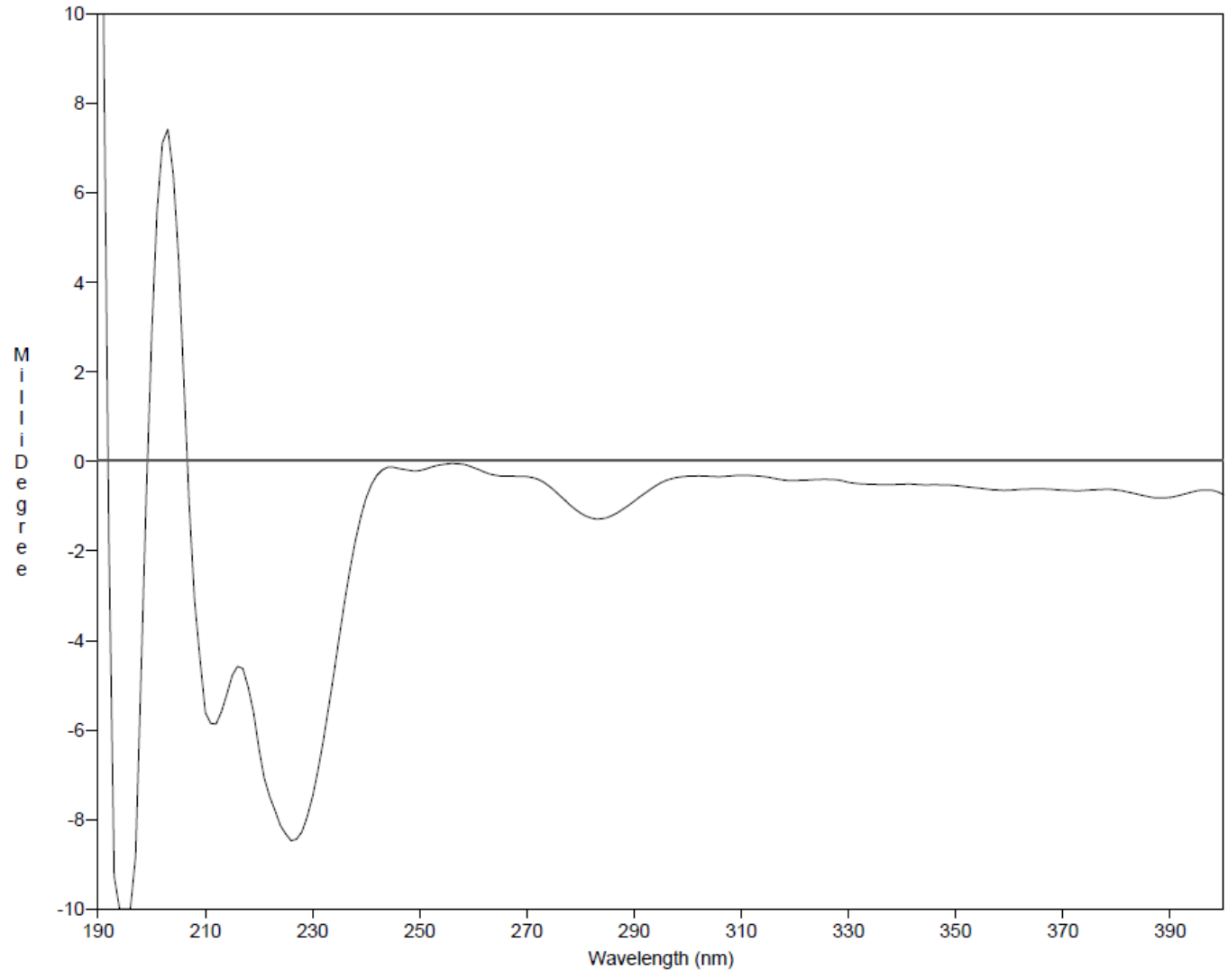

Figure S44. The ECD Spectrum of daphnegiralin $\mathrm{B}_{4}(\mathbf{2 b}-\mathbf{2})$.

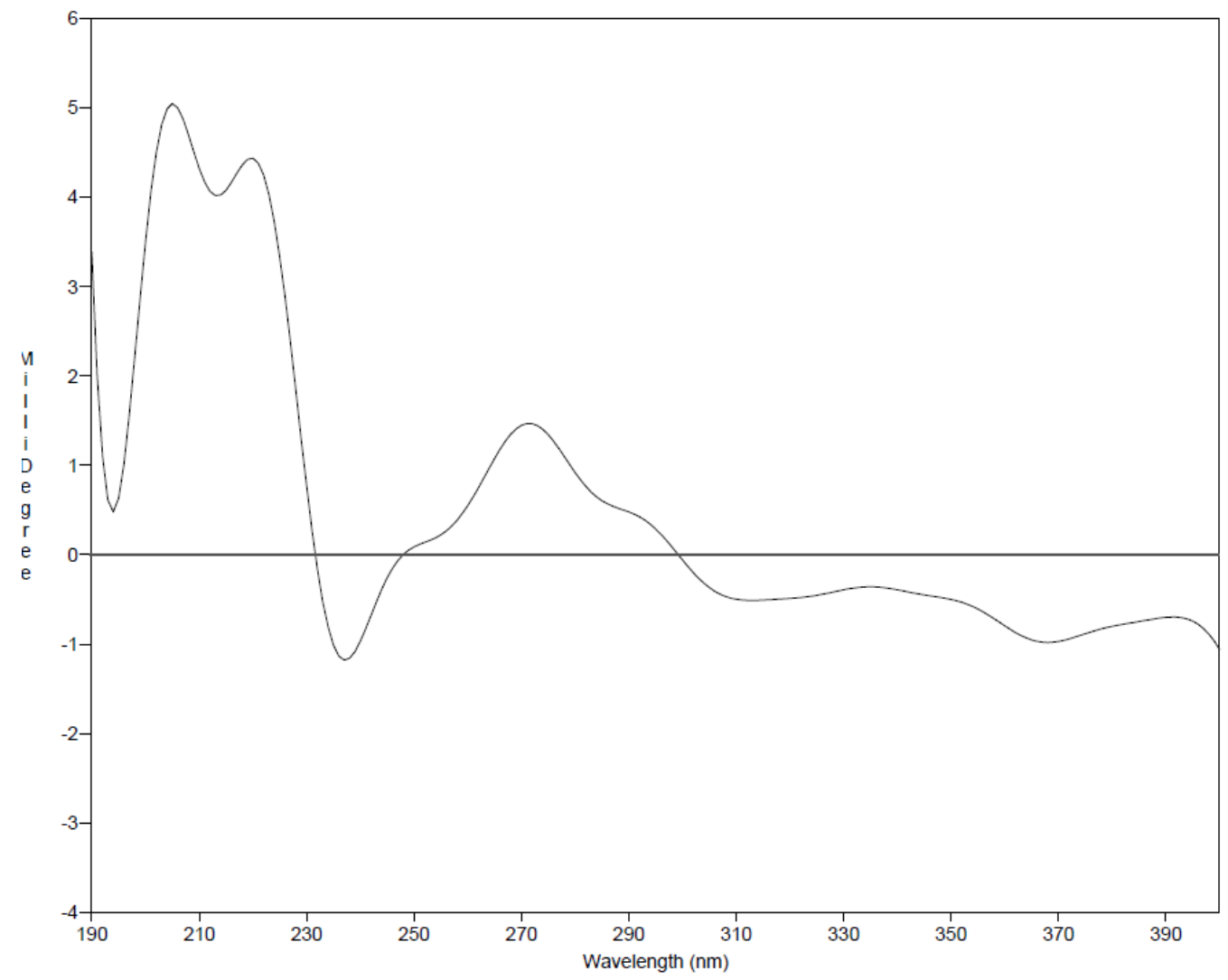


Figure $\mathbf{S 4 5} . \mathrm{Rh}_{2}\left(\mathrm{OCOCF}_{3}\right)_{4}$-ICD spectrum of daphnegiralin $\mathrm{B}_{3}(\mathbf{2 b}-\mathbf{1})$.

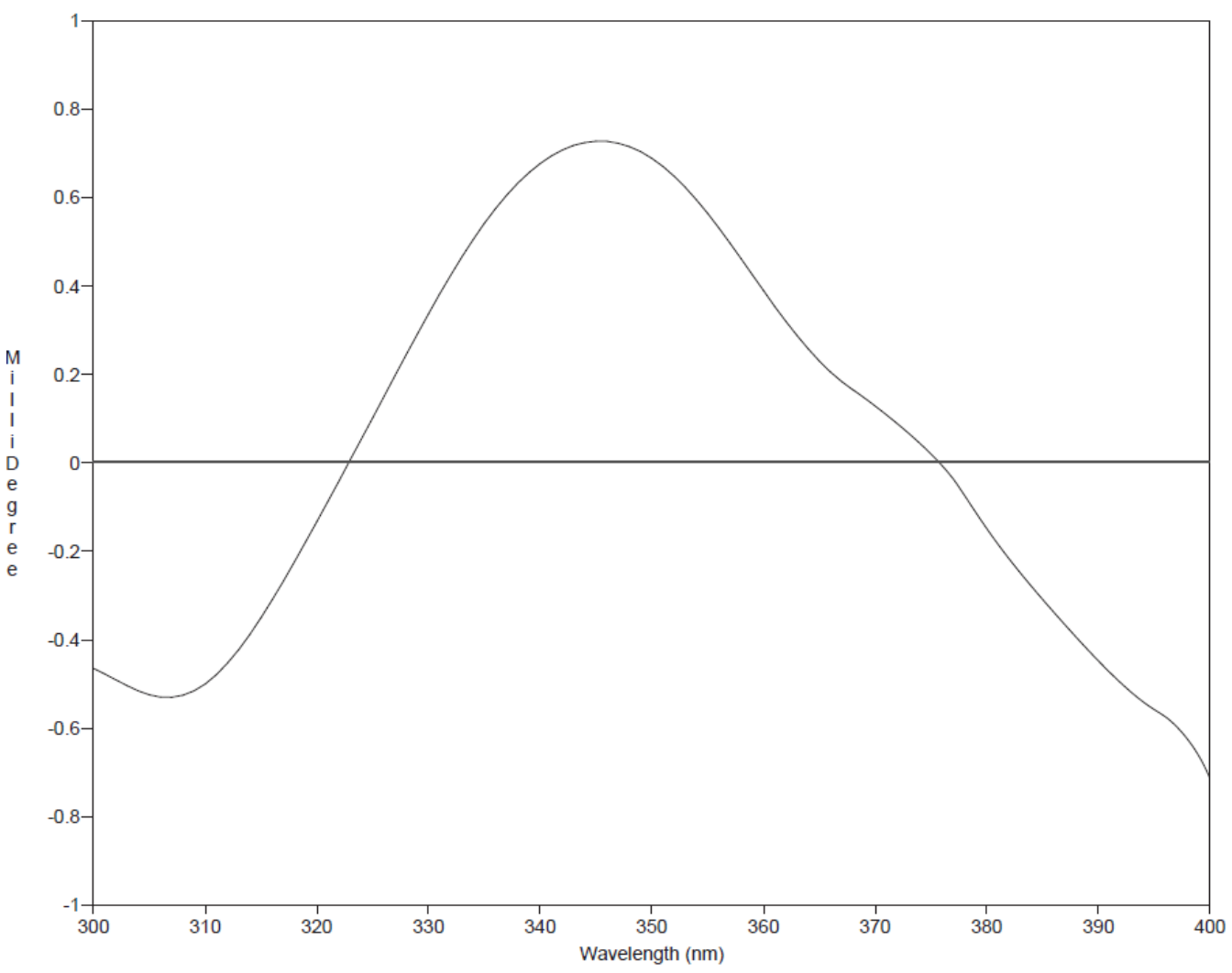

Figure S46. $\mathrm{Rh}_{2}\left(\mathrm{OCOCF}_{3}\right)_{4}-\mathrm{ICD}$ spectrum of daphnegiralin $\mathrm{B}_{4}(\mathbf{2 b}-\mathbf{2})$.

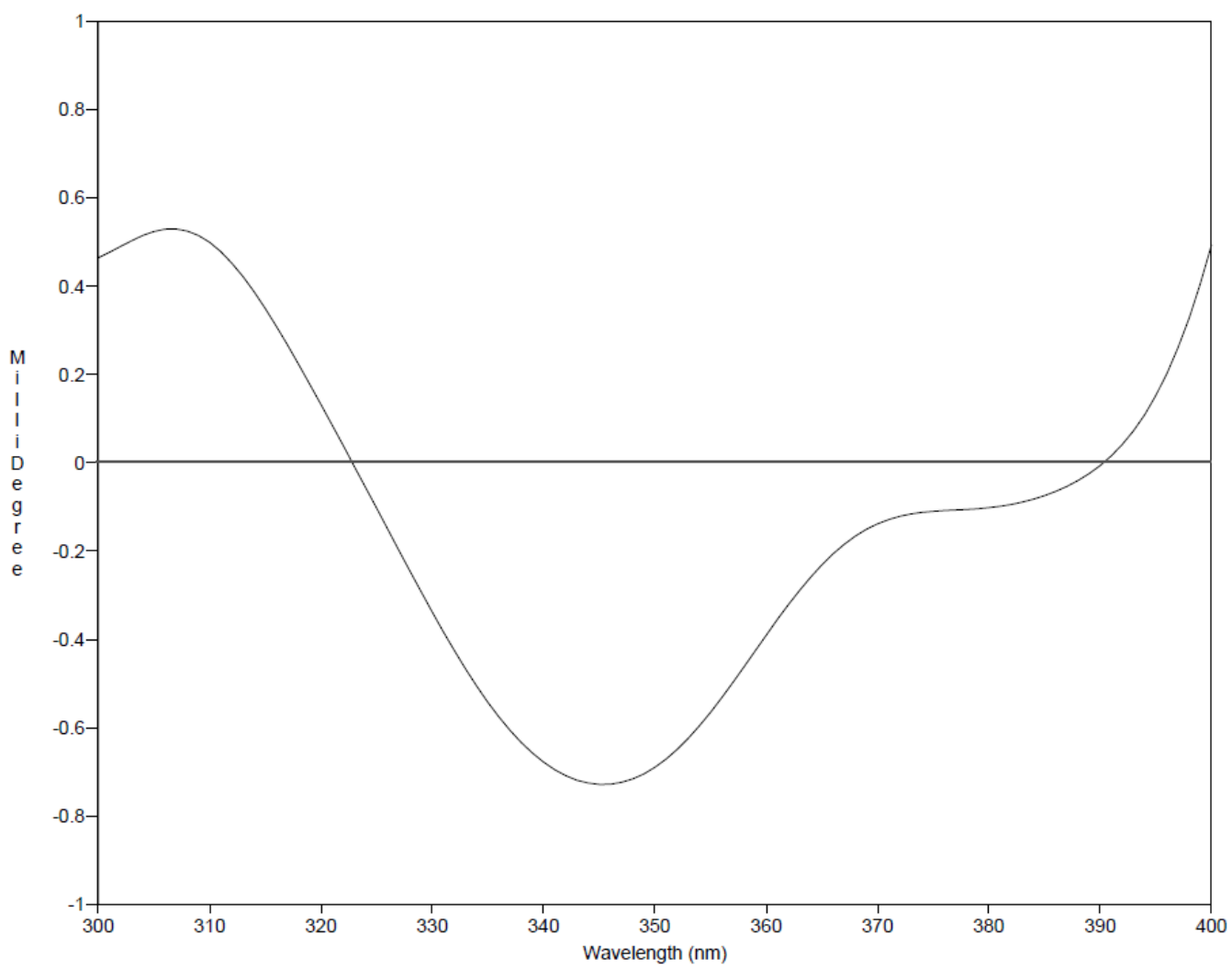


Figure S47. ${ }^{1} \mathrm{H}$ NMR spectrum of daphnegiralin $\mathrm{C}_{1}(\mathbf{3 a})$ in $\mathrm{CD}_{3} \mathrm{OD}$.

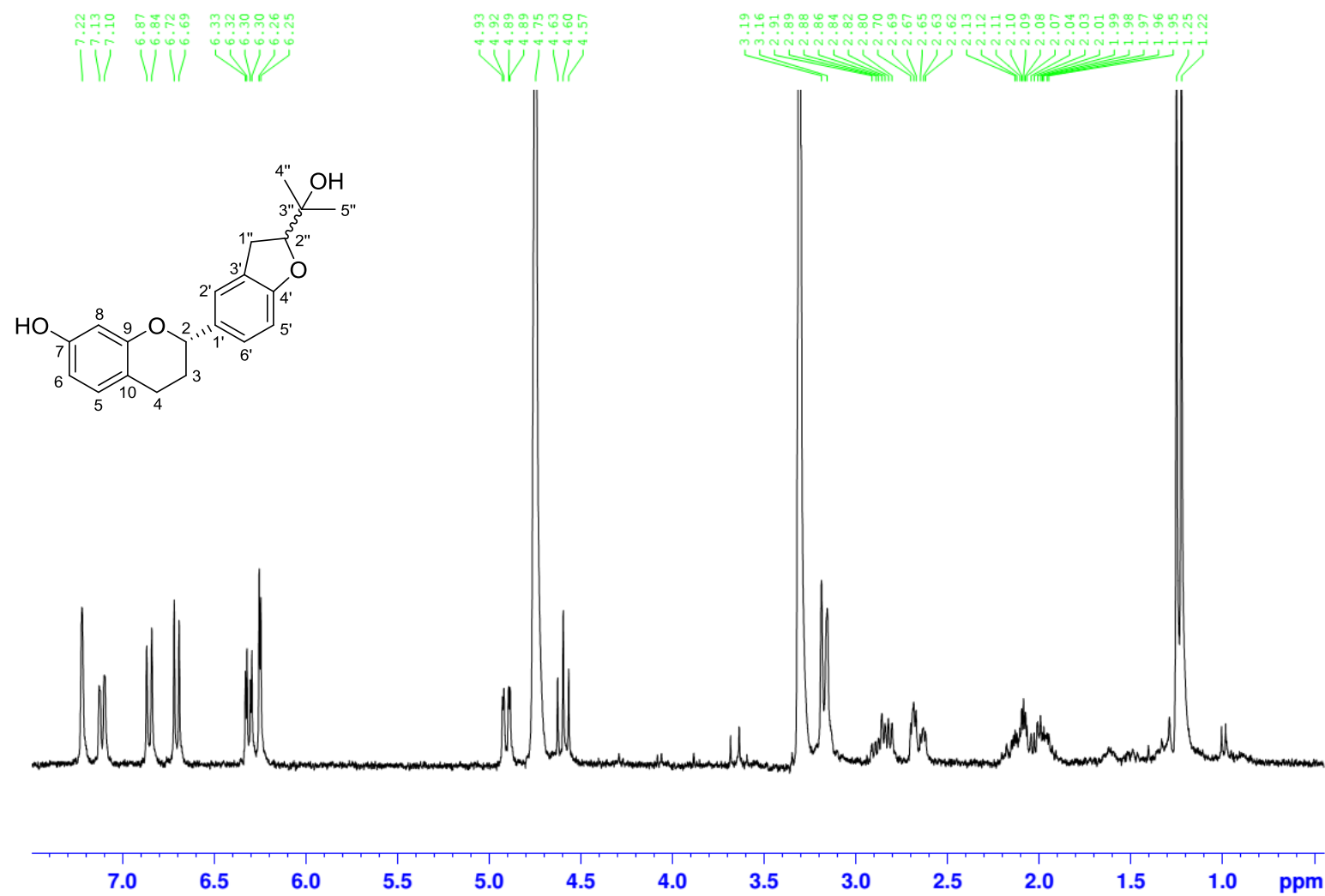

Figure S48. ${ }^{13} \mathrm{C}$ NMR spectrum of daphnegiralin $\mathrm{C}_{1}(\mathbf{3 a})$ in $\mathrm{CD}_{3} \mathrm{OD}$.

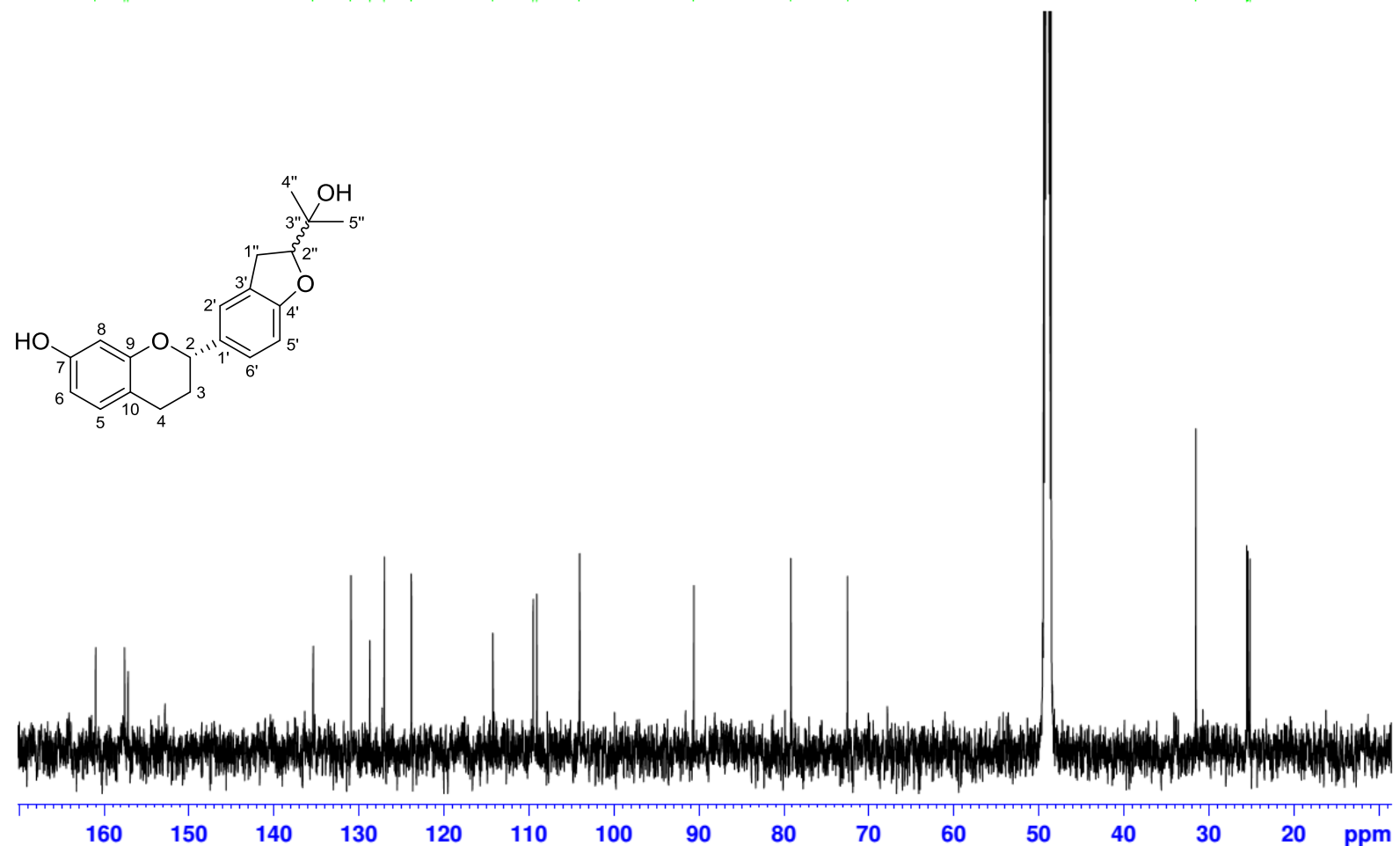


Figure S49. HSQC spectrum of daphnegiralin $\mathrm{C}_{1}(\mathbf{3 a})$ in $\mathrm{CD}_{3} \mathrm{OD}$.

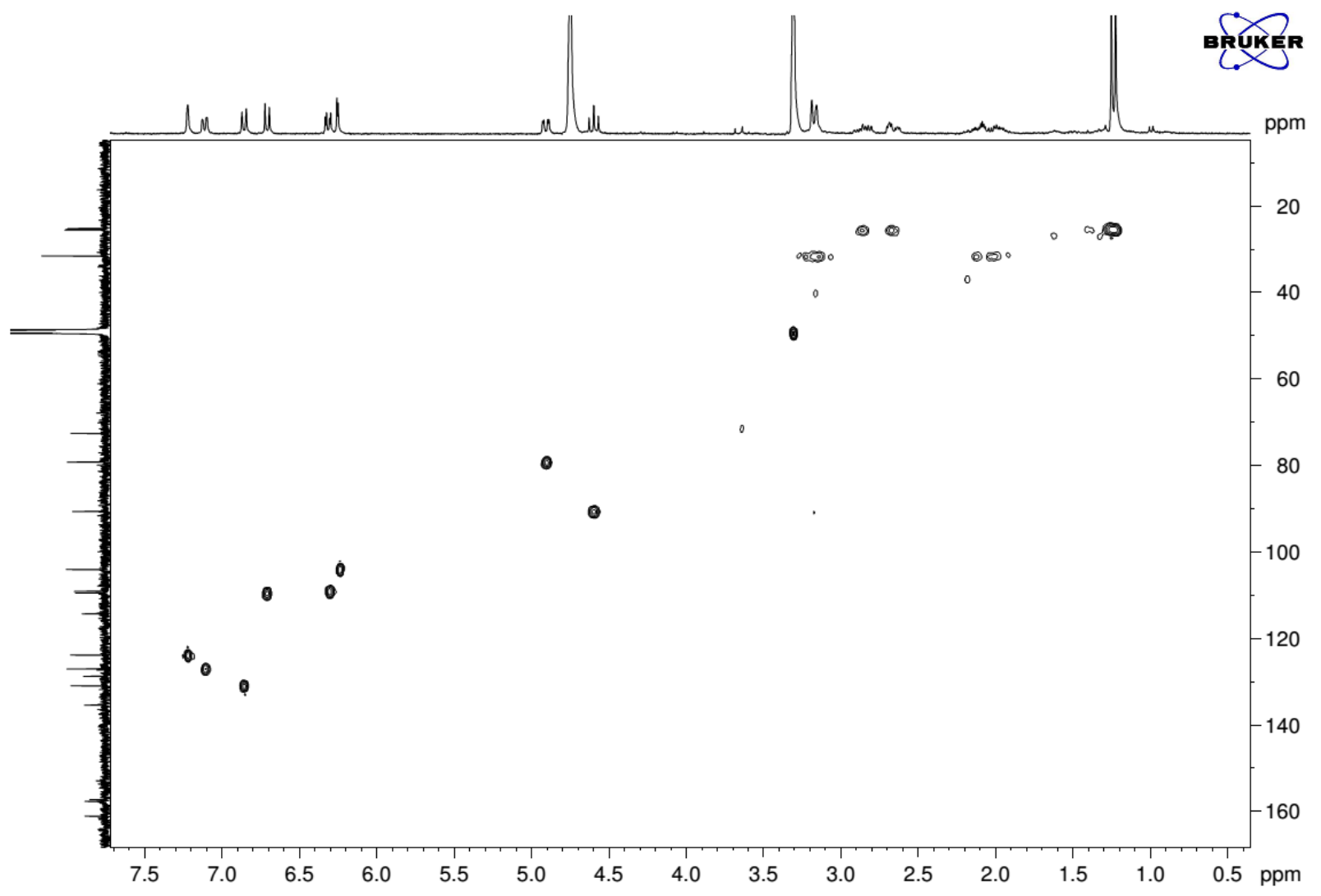

Figure S50. HMBC spectrum of daphnegiralin $\mathrm{C}_{1}(\mathbf{3 a})$ in $\mathrm{CD}_{3} \mathrm{OD}$.

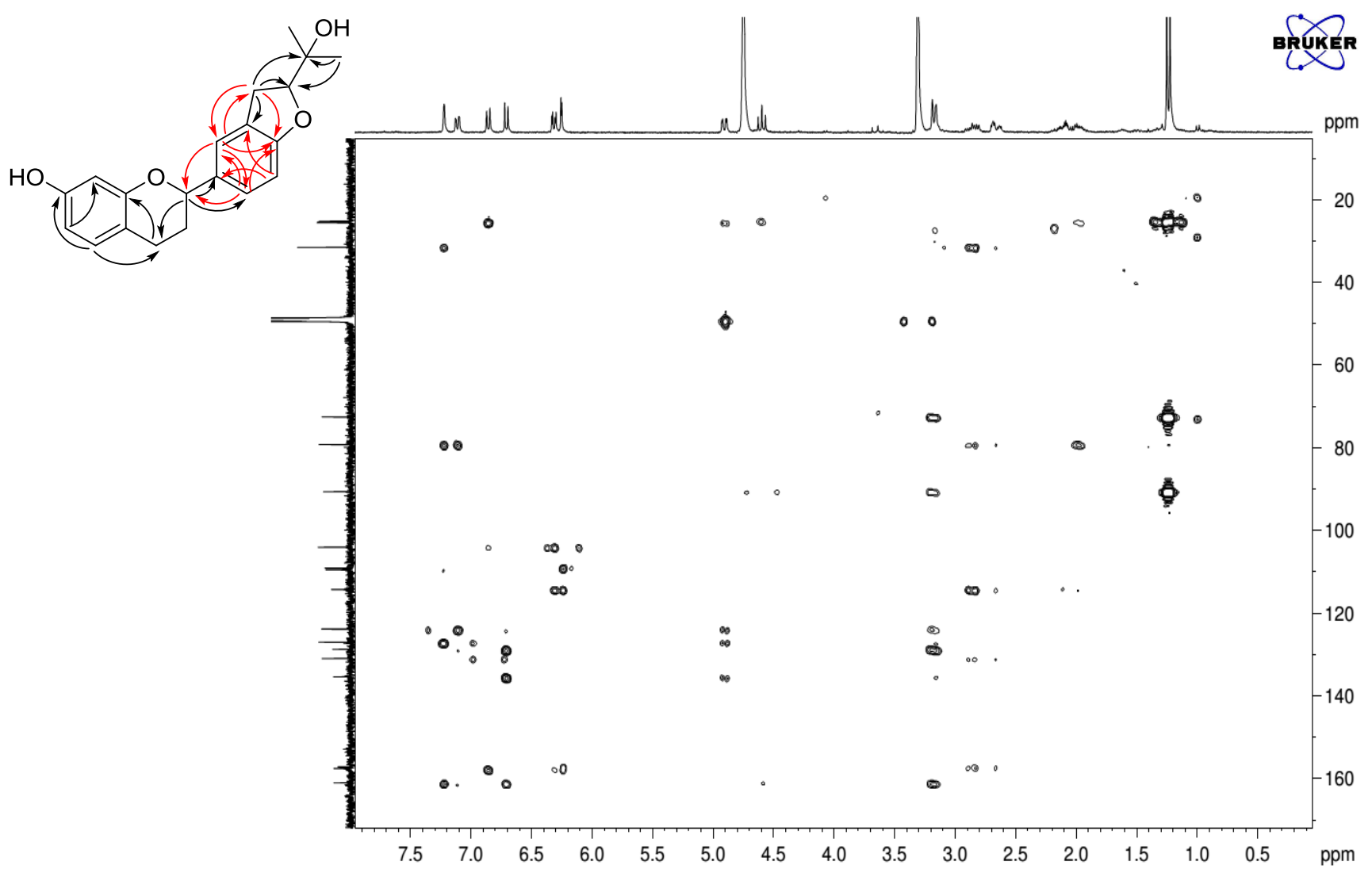


Figure S51. IR spectrum of daphnegiralin $C_{1}$ (3a).

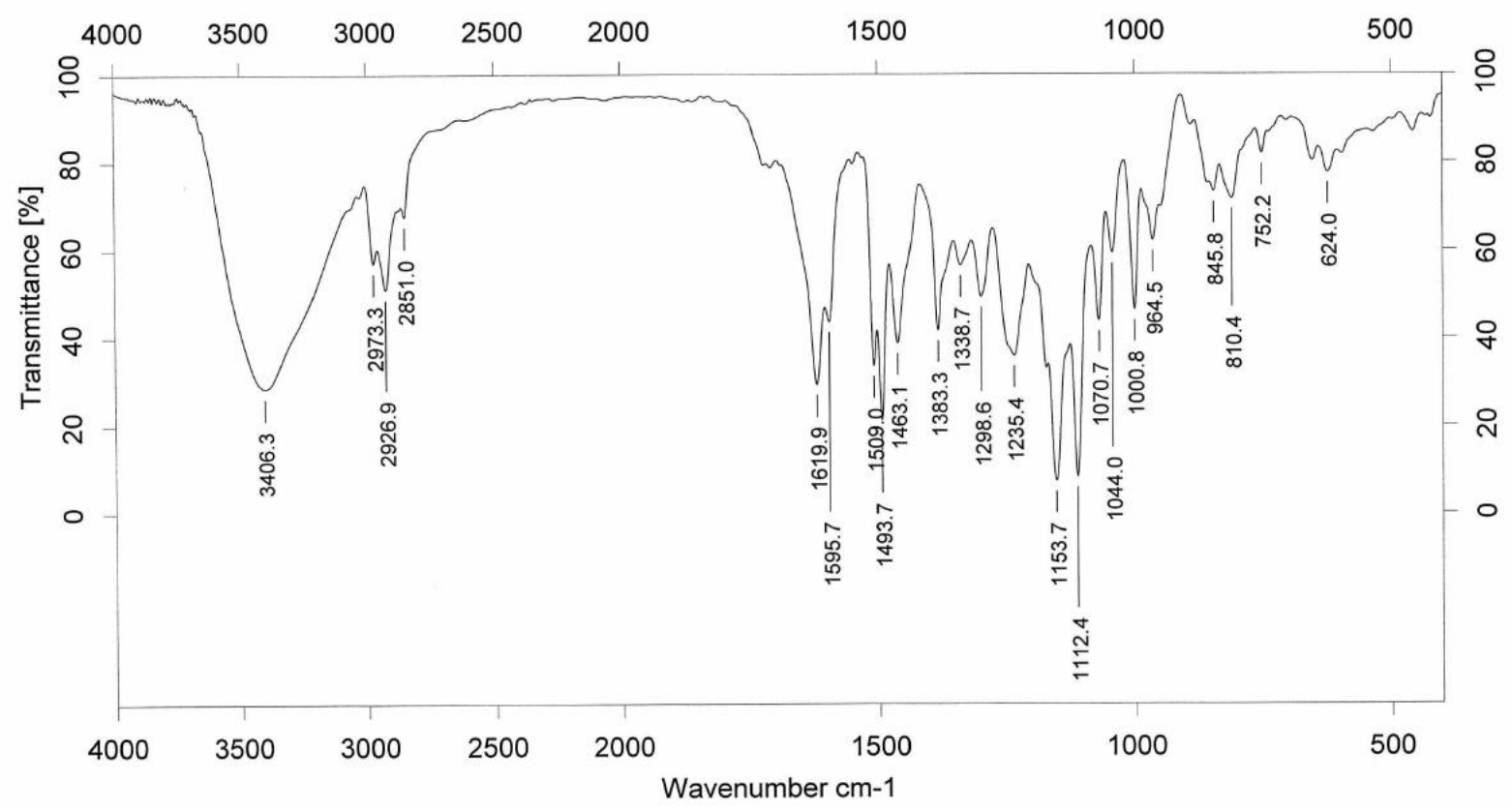

Figure S52. HRESIMS of daphnegiralin $\mathrm{C}_{1}$ (3a).

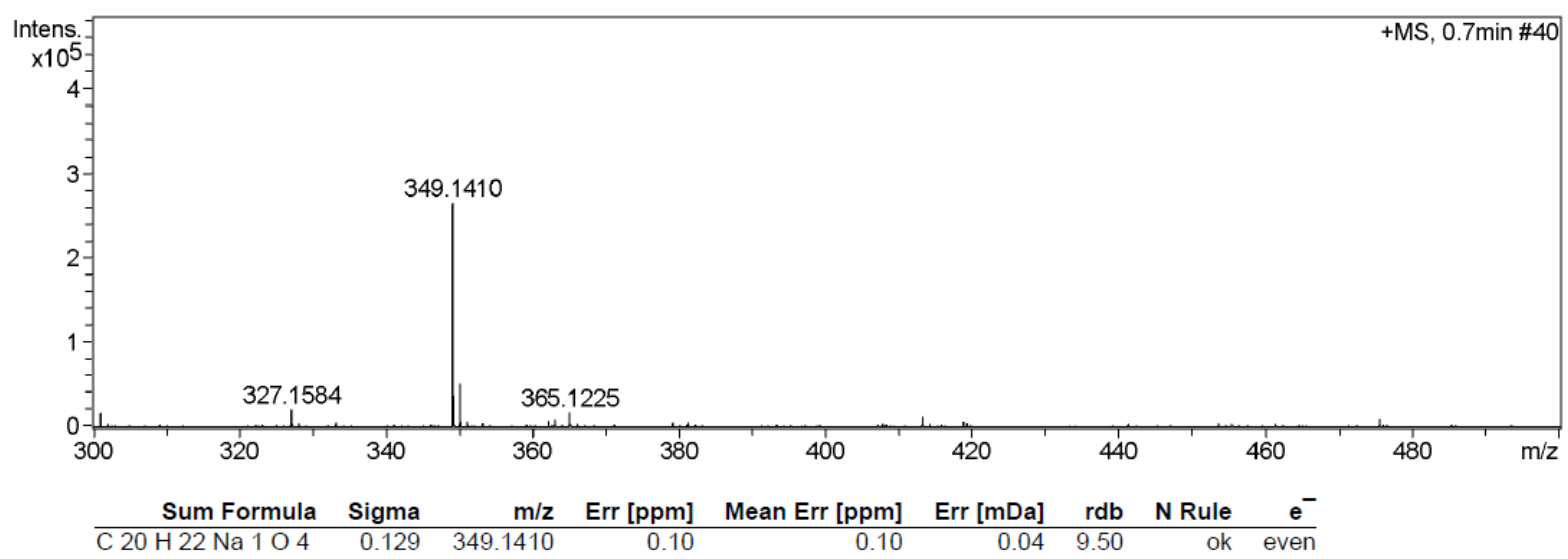

Figure S53. UV spectrum of daphnegiralin $C_{1}(3 \mathbf{a})$.

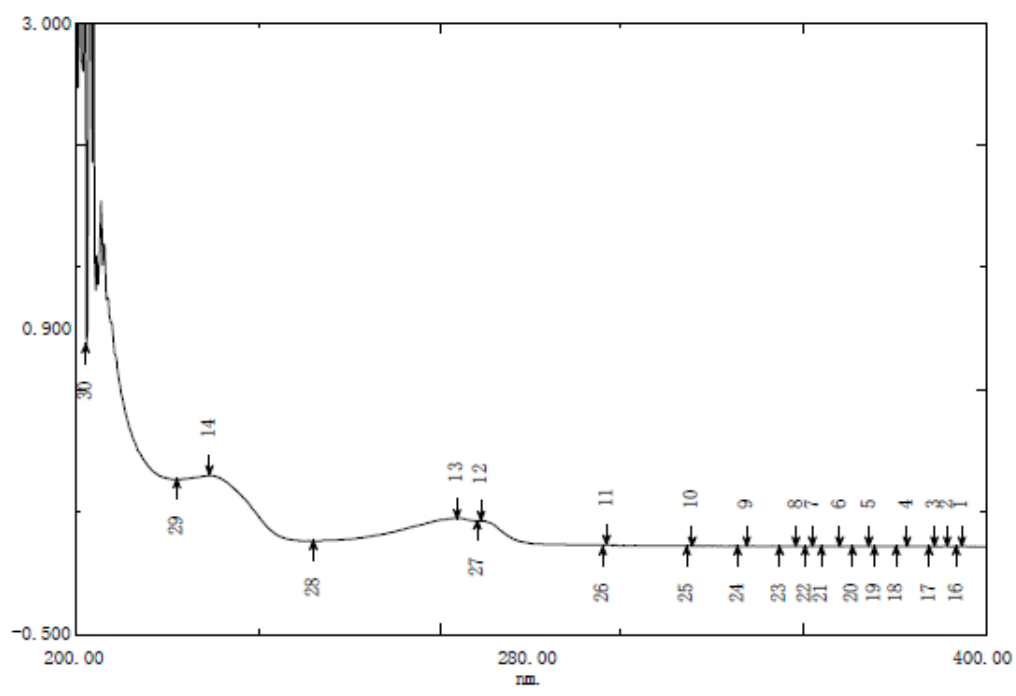


Figure S54. The ECD Spectrum of daphnegiralin $\mathrm{C}_{1}(\mathbf{3 a})$.

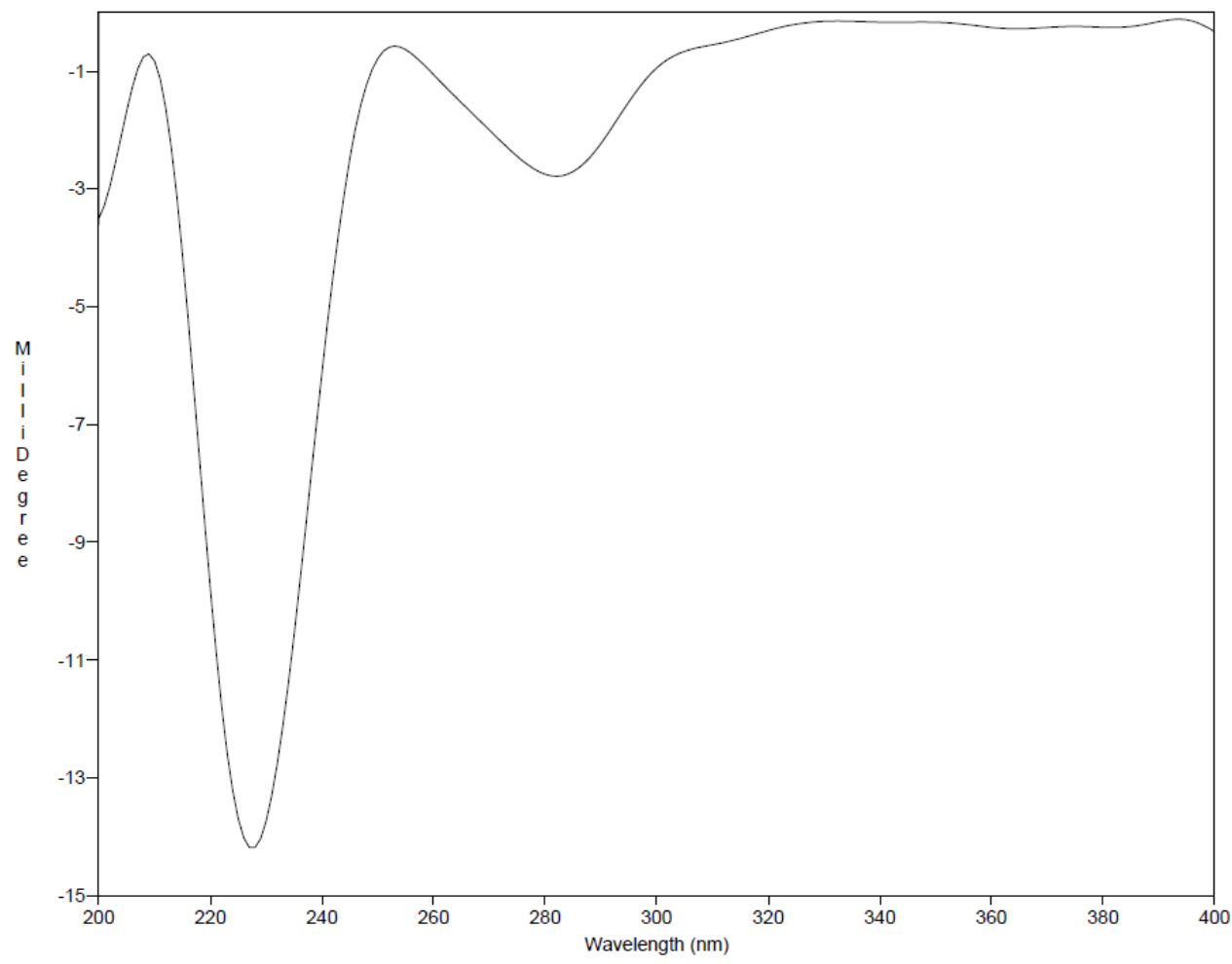

Figure S55. ${ }^{1} \mathrm{H}$ NMR spectrum of daphnegiralin $\mathrm{C}_{2}(\mathbf{3 b})$ in $\mathrm{CD}_{3} \mathrm{OD}$.<smiles>CC[C@@H]1Oc2cc(O)ccc2OC2(C(C)(C)O)Cc3ccc1cc3[I-]2</smiles>

$\begin{array}{llllllllllllllllll}9.0 & 8.5 & 8.0 & 7.5 & 7.0 & 6.5 & 6.0 & 5.5 & 5.0 & 4.5 & 4.0 & 3.5 & 3.0 & 2.5 & 2.0 & 1.5 & 1.0 & \mathrm{ppm}\end{array}$ 
Figure S56. ${ }^{13} \mathrm{C}$ NMR spectrum of daphnegiralin $\mathrm{C}_{2}(\mathbf{3 b})$ in $\mathrm{CD}_{3} \mathrm{OD}$.

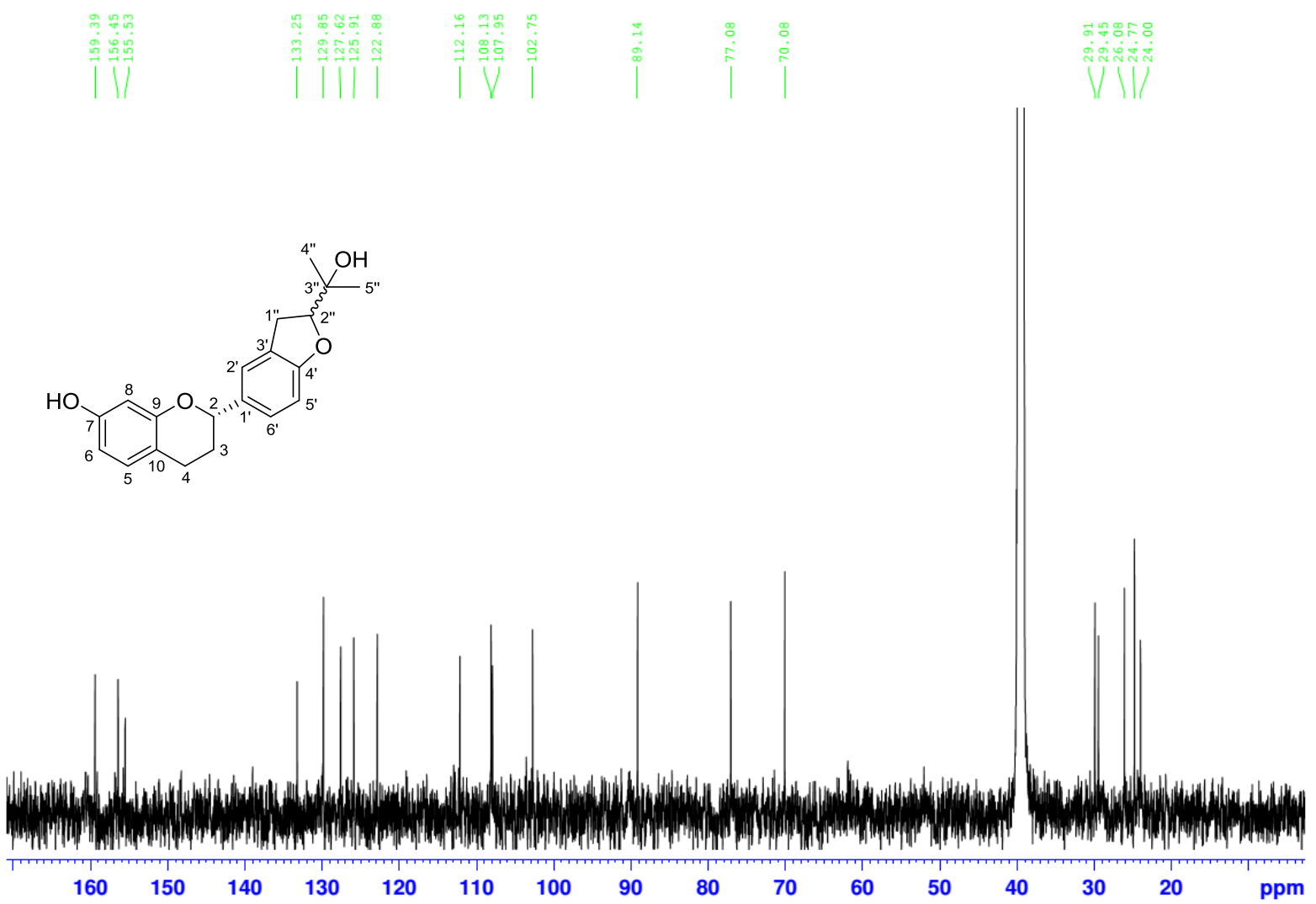

Figure S57. $\mathrm{HSQC}$ spectrum of daphnegiralin $\mathrm{C}_{2}(\mathbf{3 b})$ in $\mathrm{CD}_{3} \mathrm{OD}$.

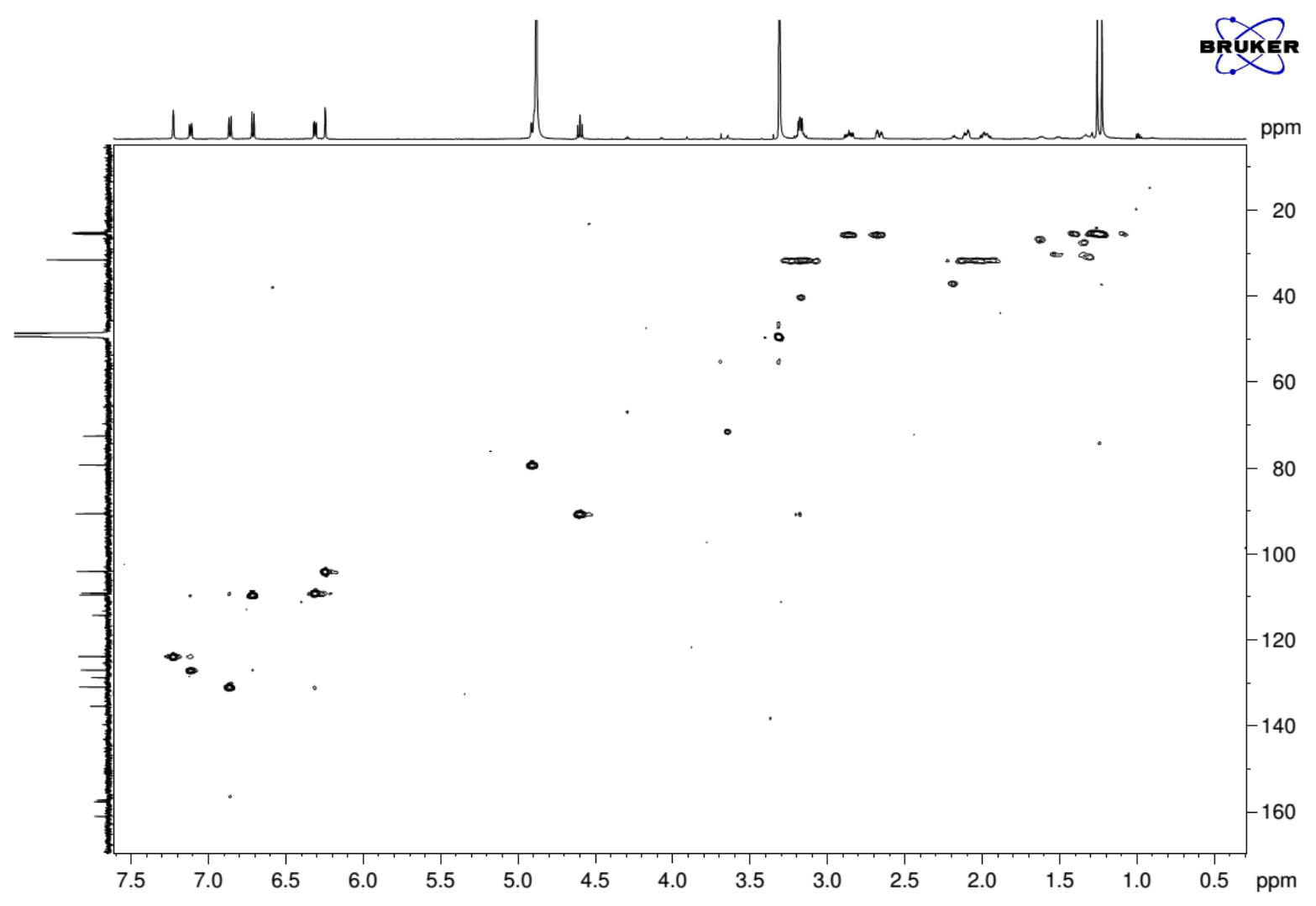


Figure S58. $\mathrm{HMBC}$ spectrum of daphnegiralin $\mathrm{C}_{2}(\mathbf{3 b})$ in $\mathrm{CD}_{3} \mathrm{OD}$.

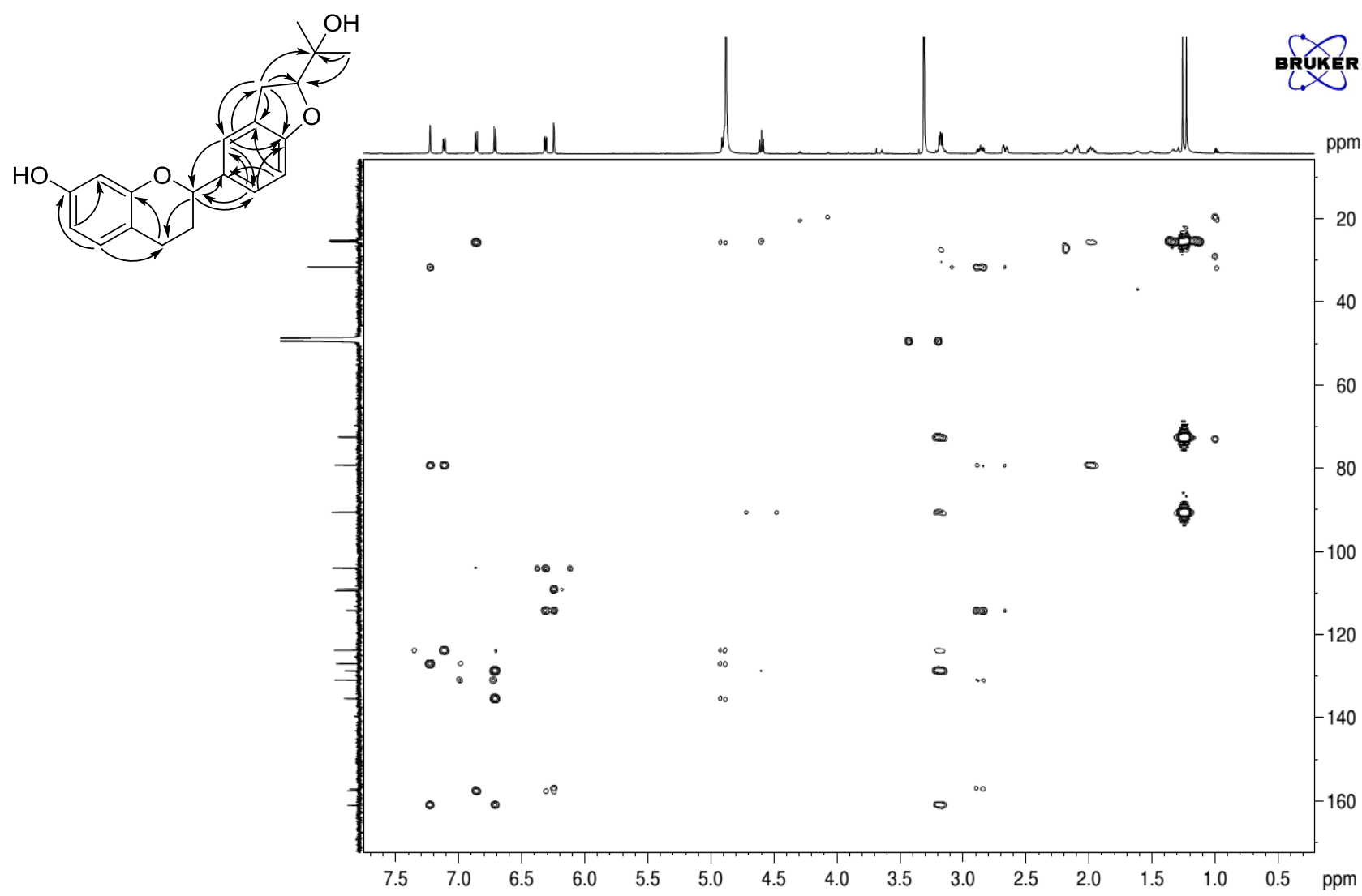

Figure S59. IR spectrum of daphnegiralin $C_{2}(3 b)$.

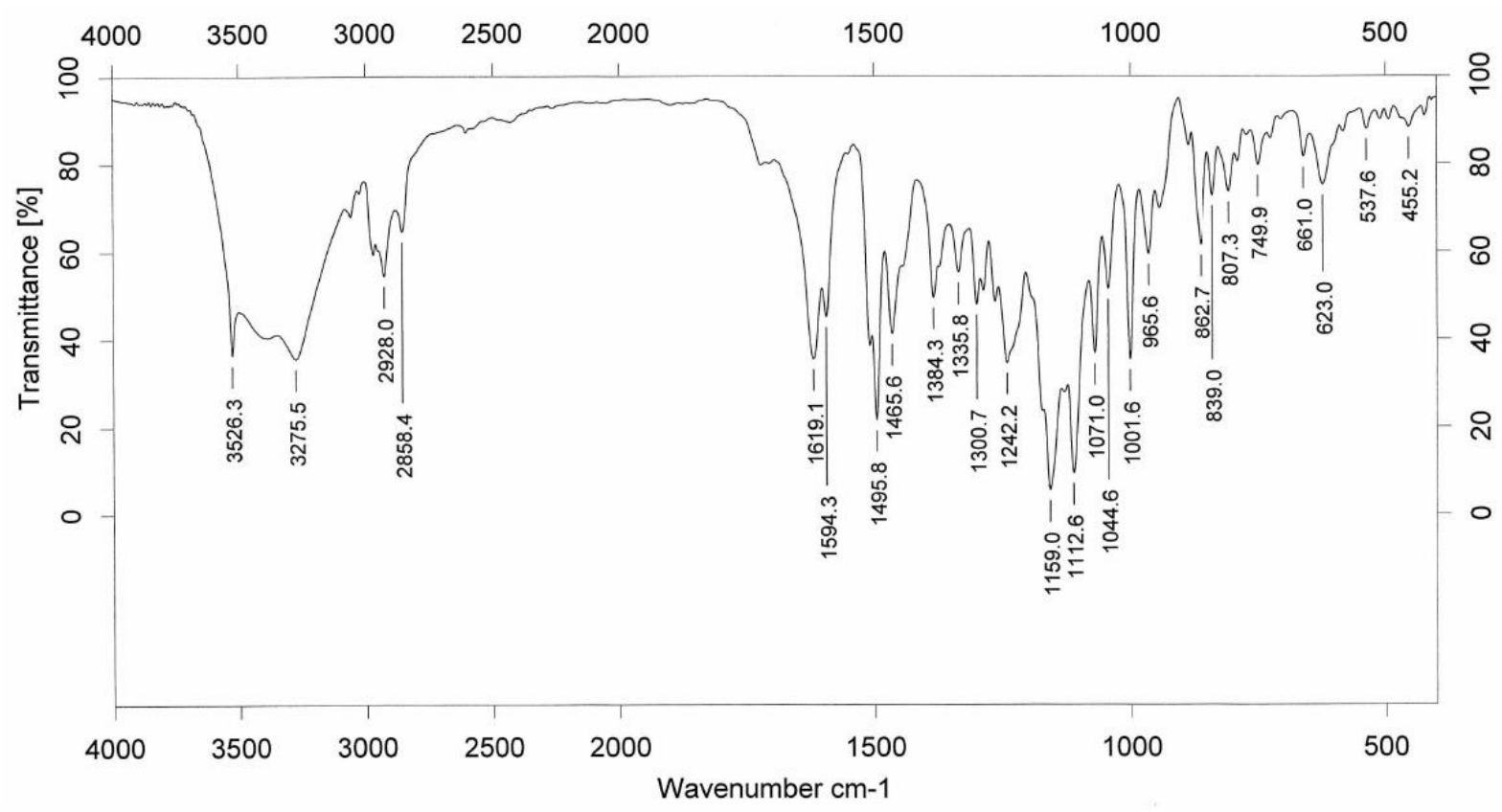


Figure S60. HRESIMS of daphnegiralin $\mathrm{C}_{2}(\mathbf{3 b})$.

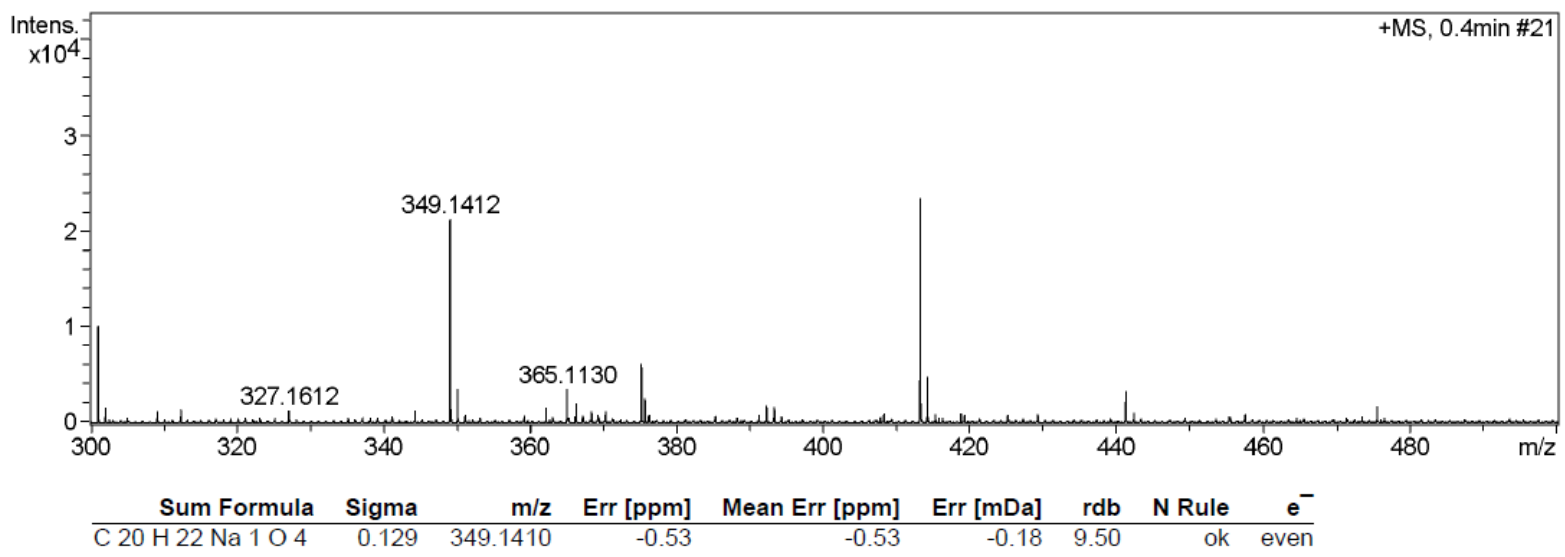

Figure S61. UV spectrum of daphnegiralin $C_{2}(\mathbf{3 b})$.

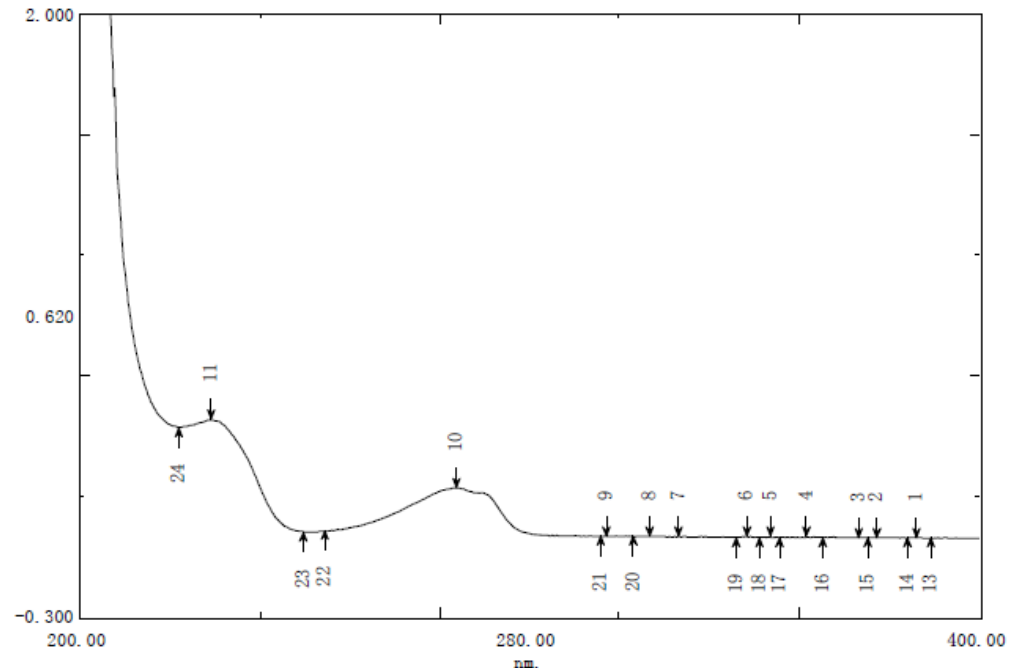

Figure S62. The ECD Spectrum of daphnegiralin $\mathrm{C}_{2}(\mathbf{3 b})$.

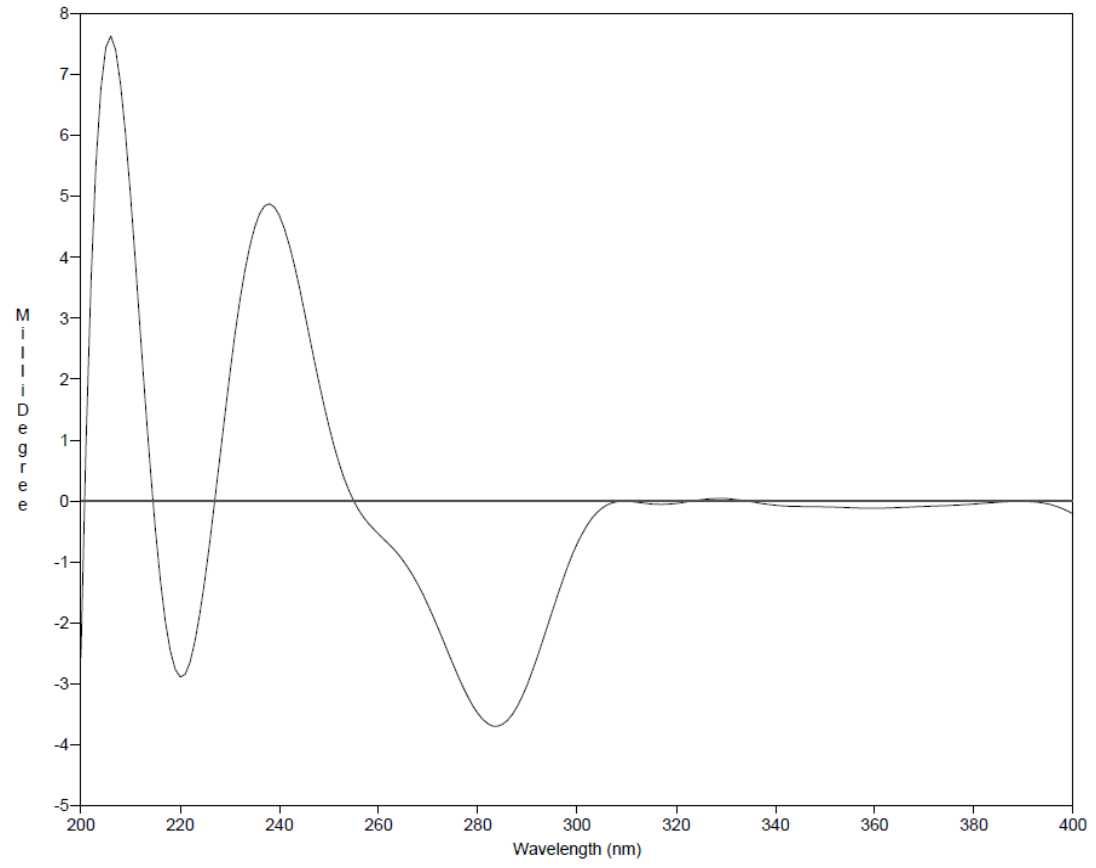


Figure S63. ${ }^{1} \mathrm{H}$ NMR spectrum of daphnegiralin $\mathrm{D}_{1}(\mathbf{4 a})$ in $\mathrm{CD}_{3} \mathrm{OD}$.
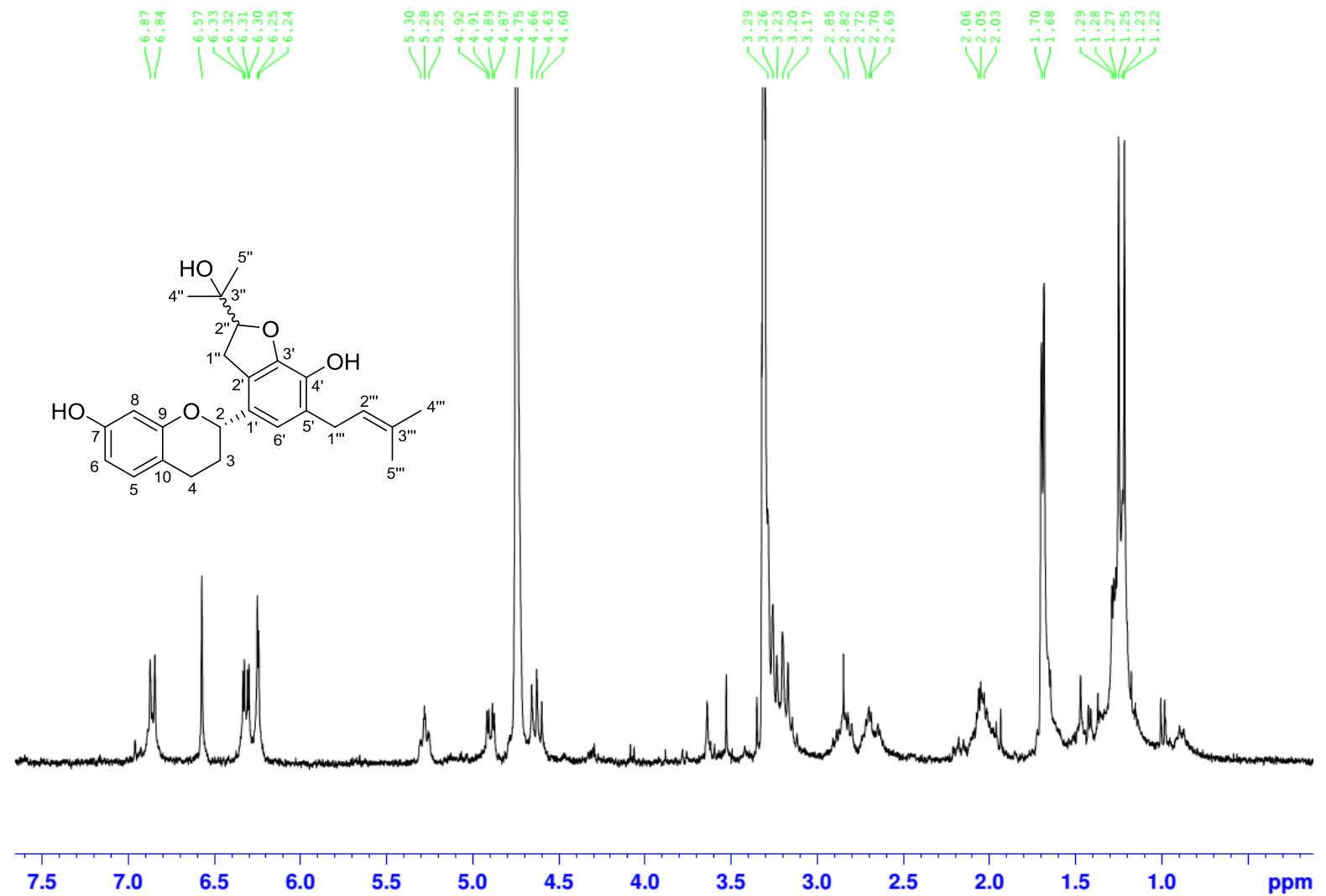

Figure S64. ${ }^{13} \mathrm{C}$ NMR spectrum of daphnegiralin $\mathrm{D}_{1}(\mathbf{4 a})$ in $\mathrm{CD}_{3} \mathrm{OD}$.

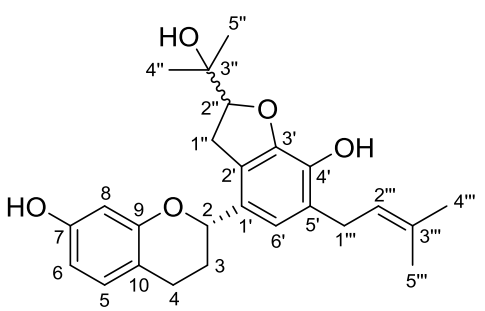

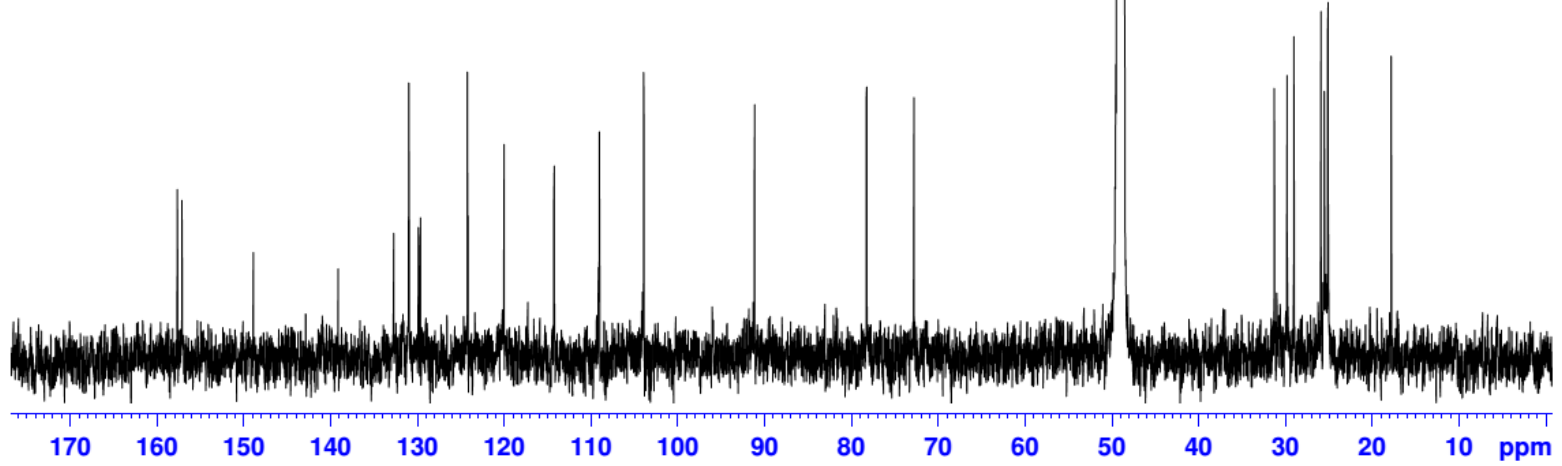


Figure S65. HSQC spectrum of daphnegiralin $\mathrm{D}_{1}(\mathbf{4 a})$ in $\mathrm{CD}_{3} \mathrm{OD}$.

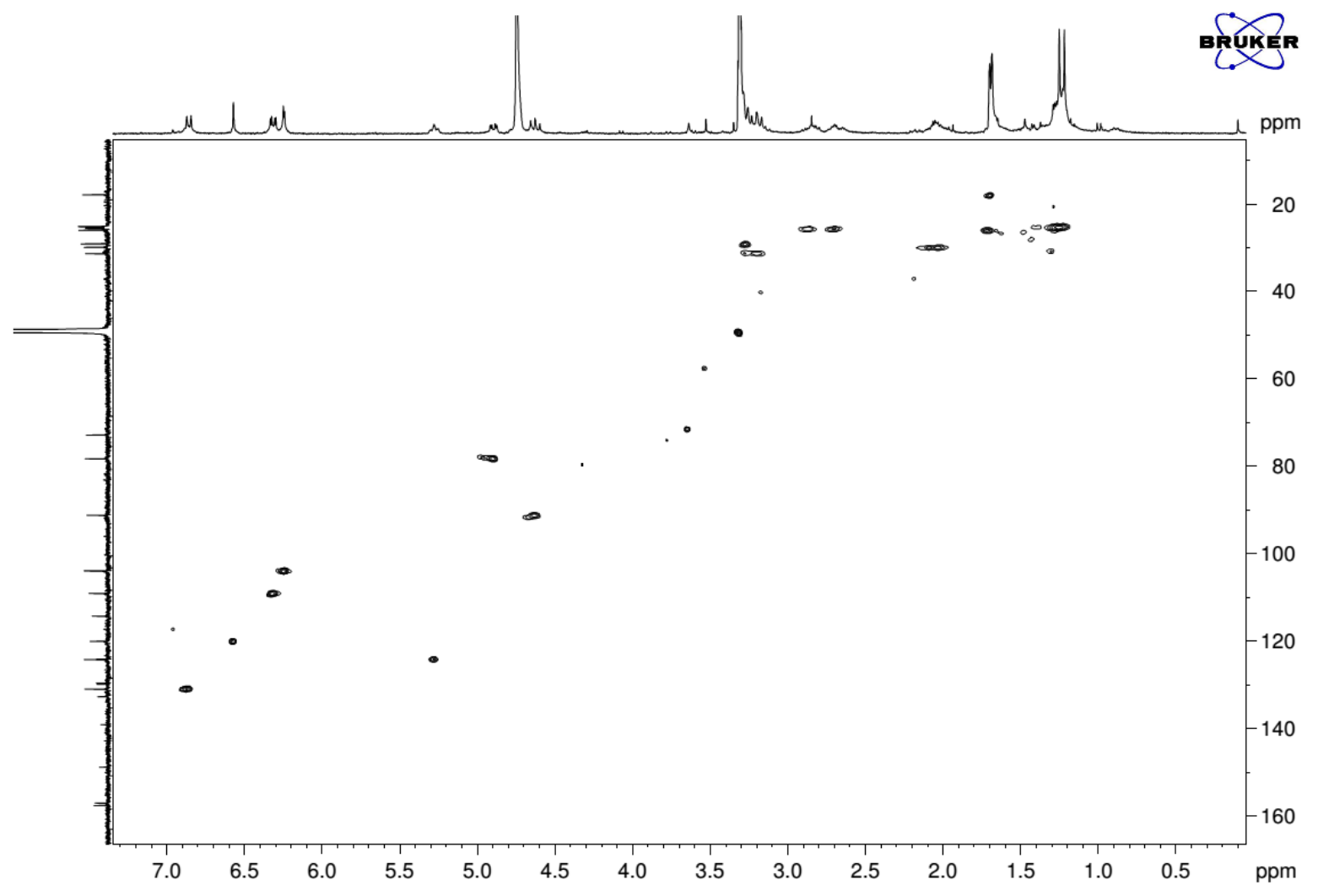

Figure S66. $\mathrm{HMBC}$ spectrum of daphnegiralin $\mathrm{D}_{1}(\mathbf{4 a})$ in $\mathrm{CD}_{3} \mathrm{OD}$.

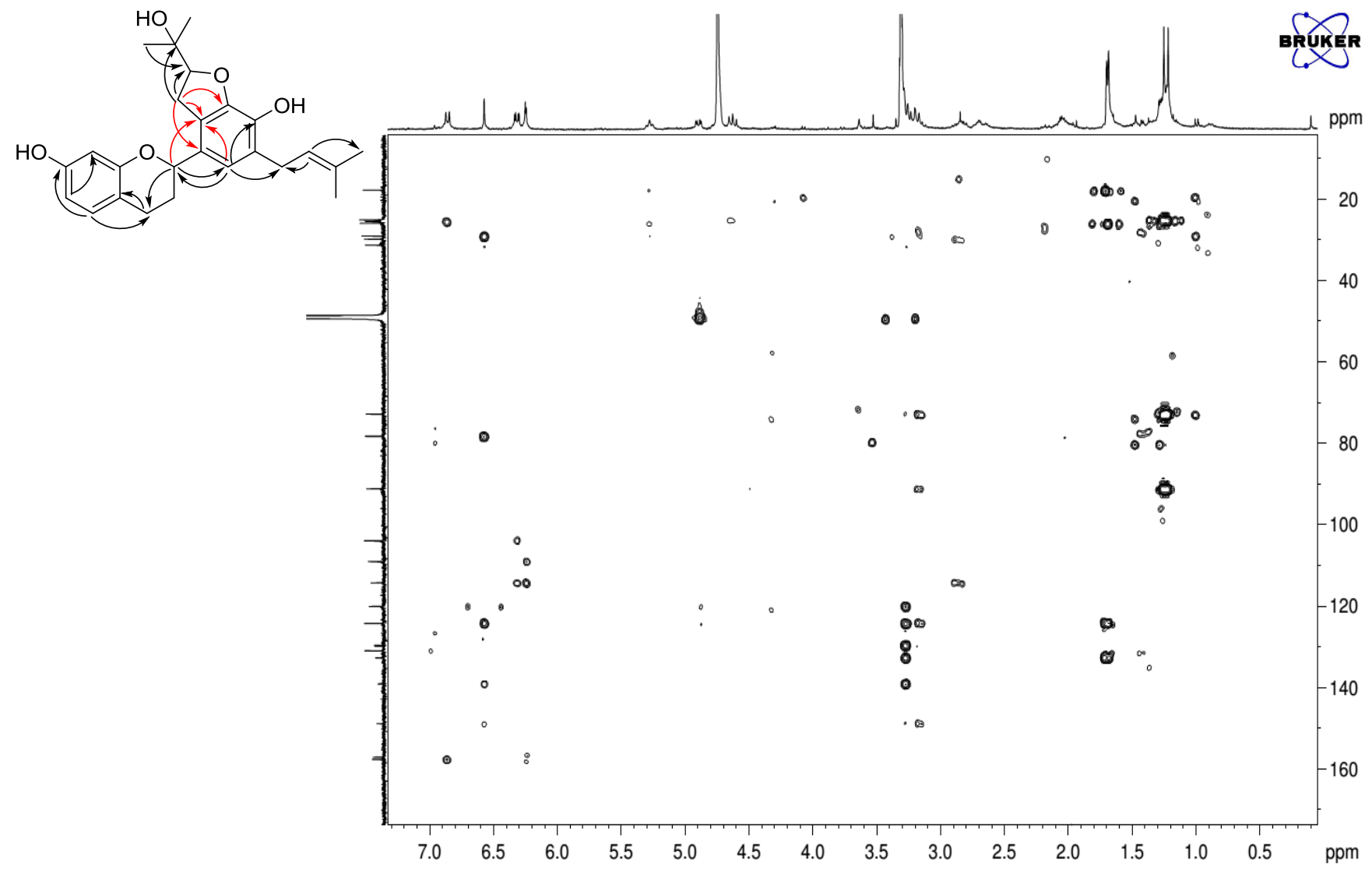


Figure S67. IR spectrum of daphnegiralin $\mathrm{D}_{1}(\mathbf{4 a})$.

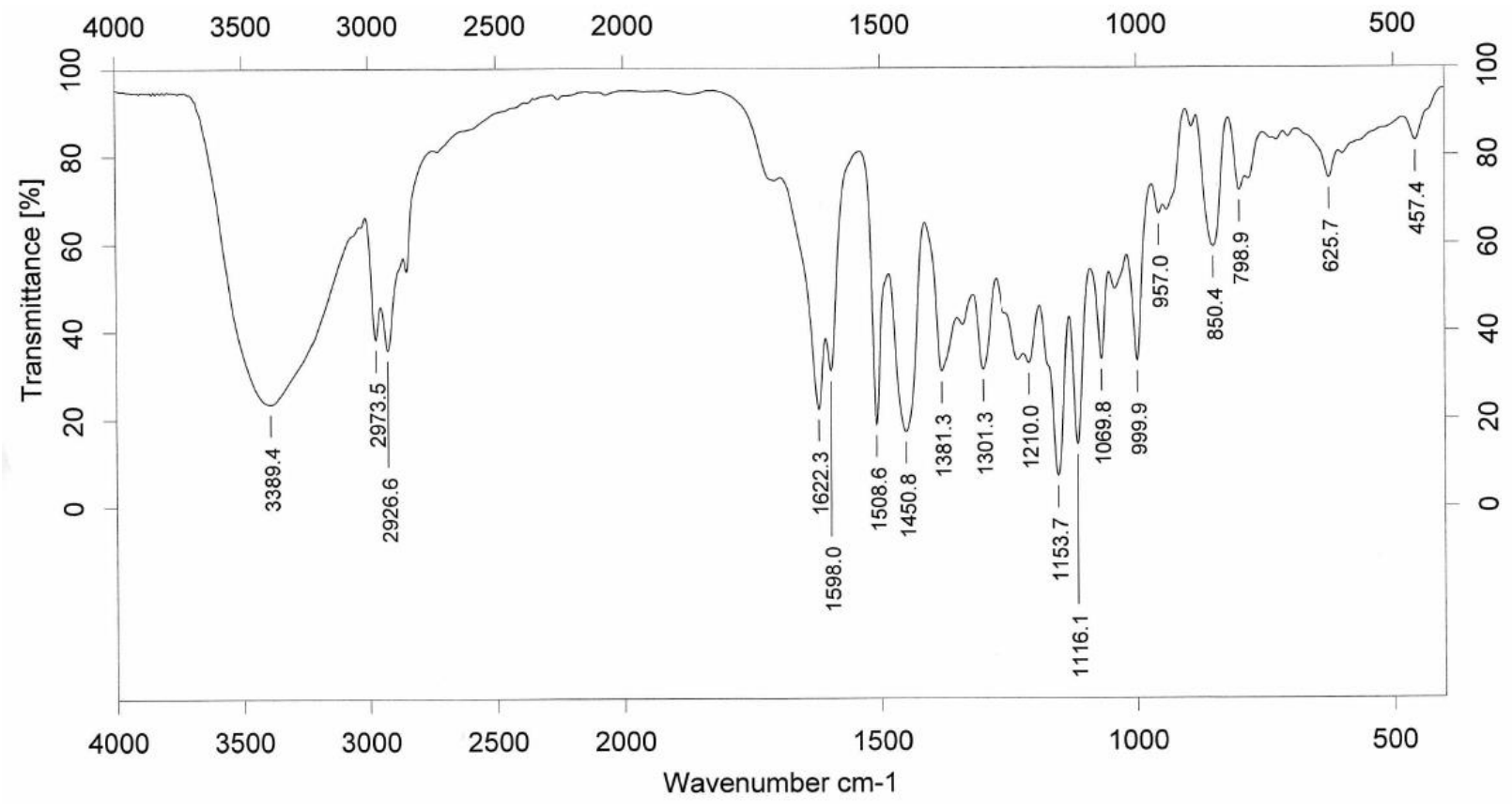

Figure S68. HRESIMS of daphnegiralin $\mathrm{D}_{1}(\mathbf{4 a})$.

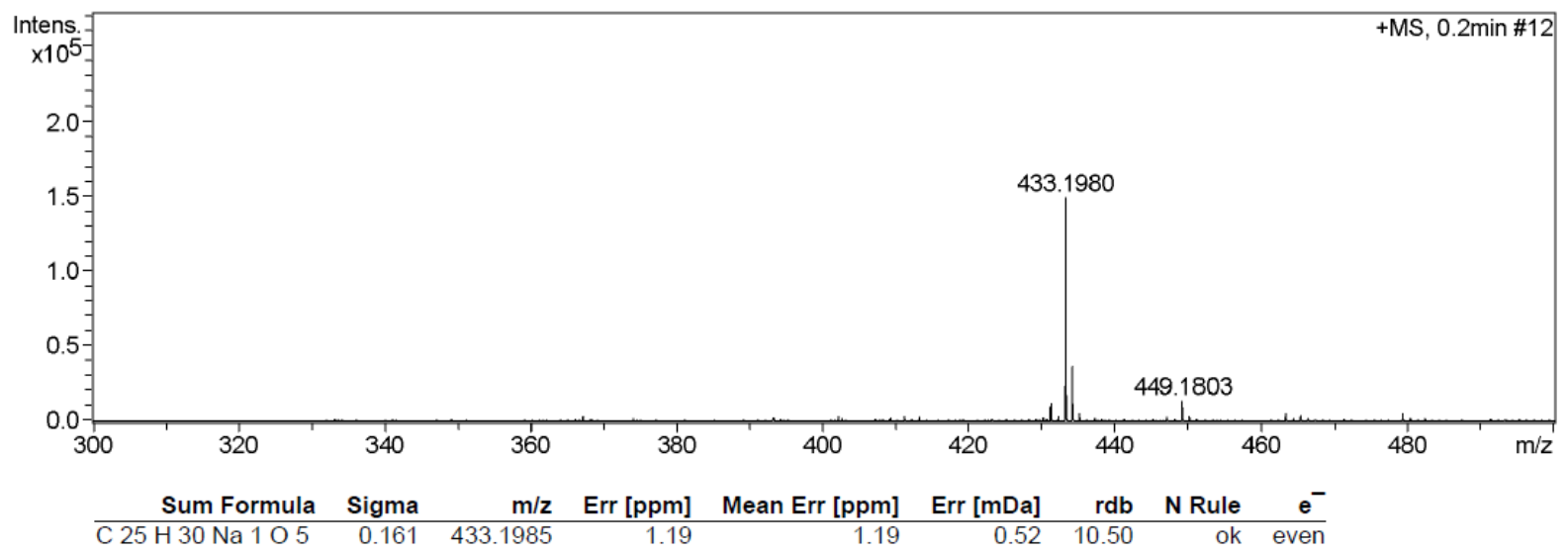

Figure S69. UV spectrum of daphnegiralin $\mathrm{D}_{1}(\mathbf{4 a})$.

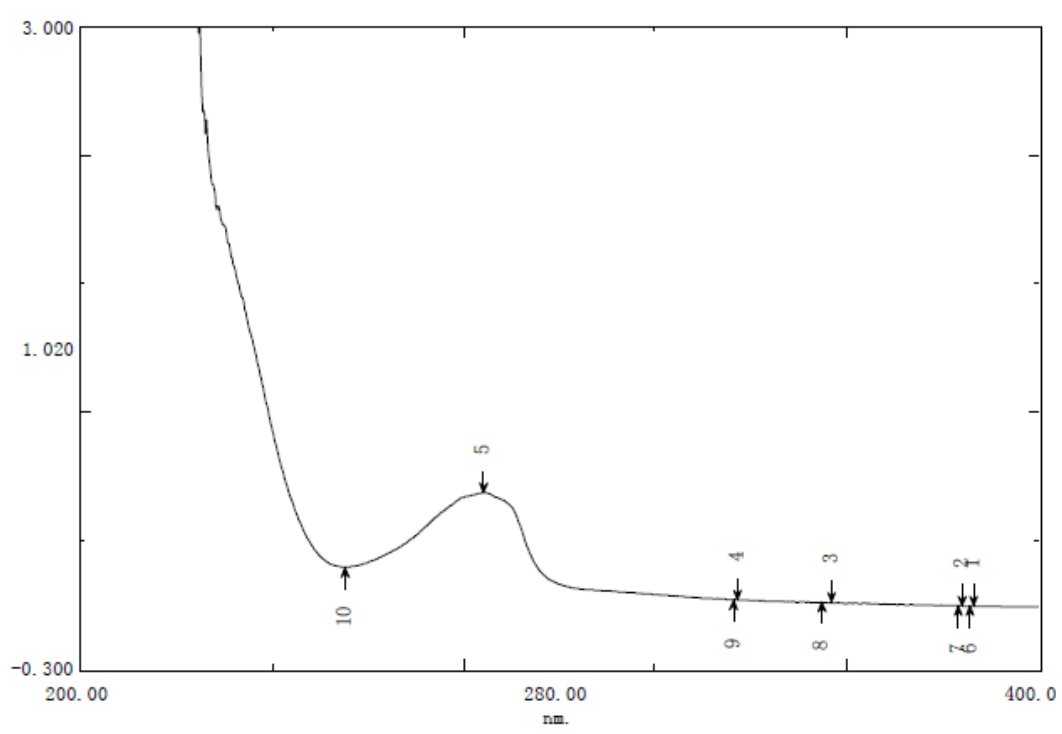


Figure S70. The ECD Spectrum of daphnegiralin $\mathrm{D}_{1}(\mathbf{4 a})$.

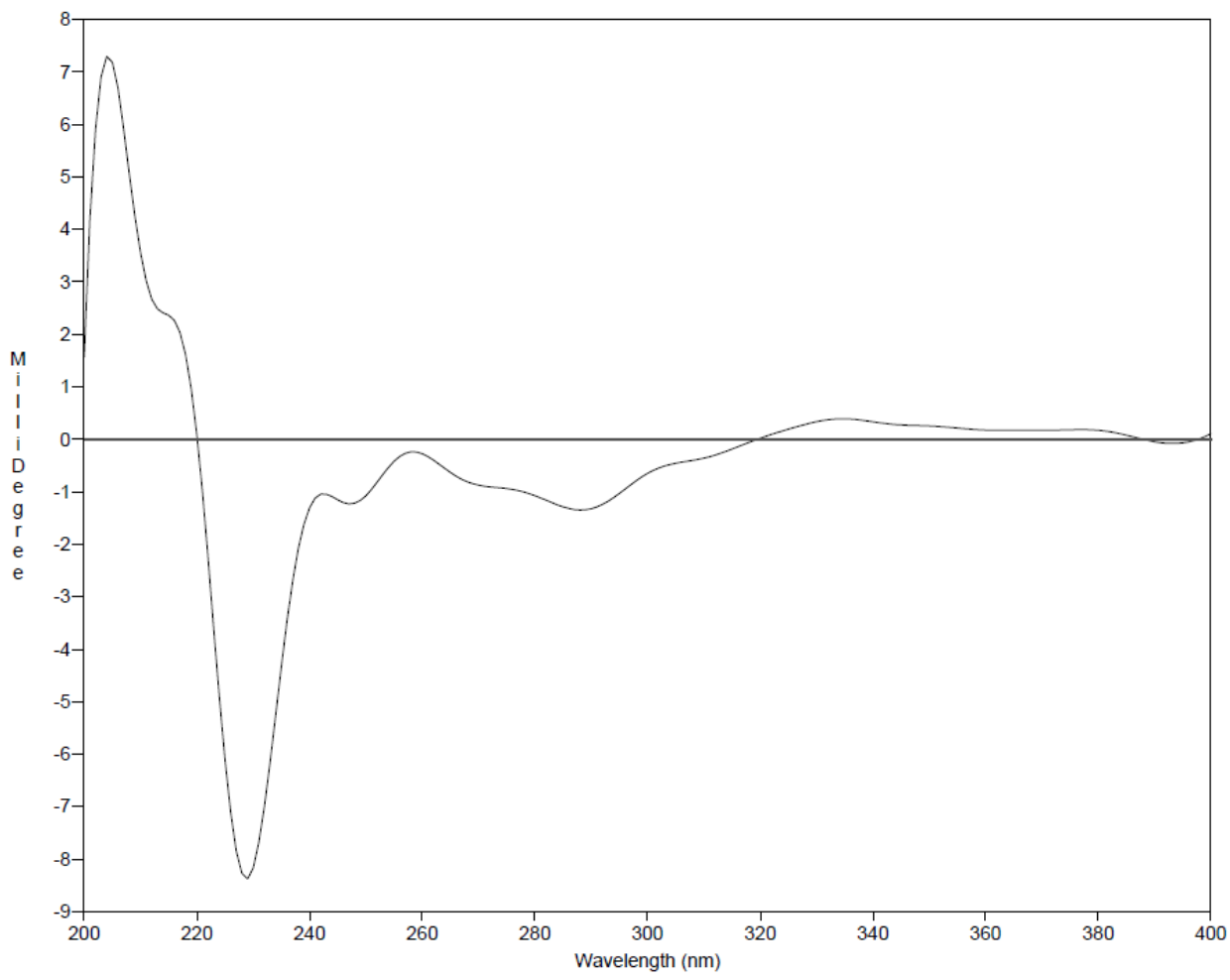

Figure S71. ${ }^{1} \mathrm{H}$ NMR spectrum of daphnegiralin $\mathrm{D}_{2}(\mathbf{4 b})$ in $\mathrm{CD}_{3} \mathrm{OD}$.

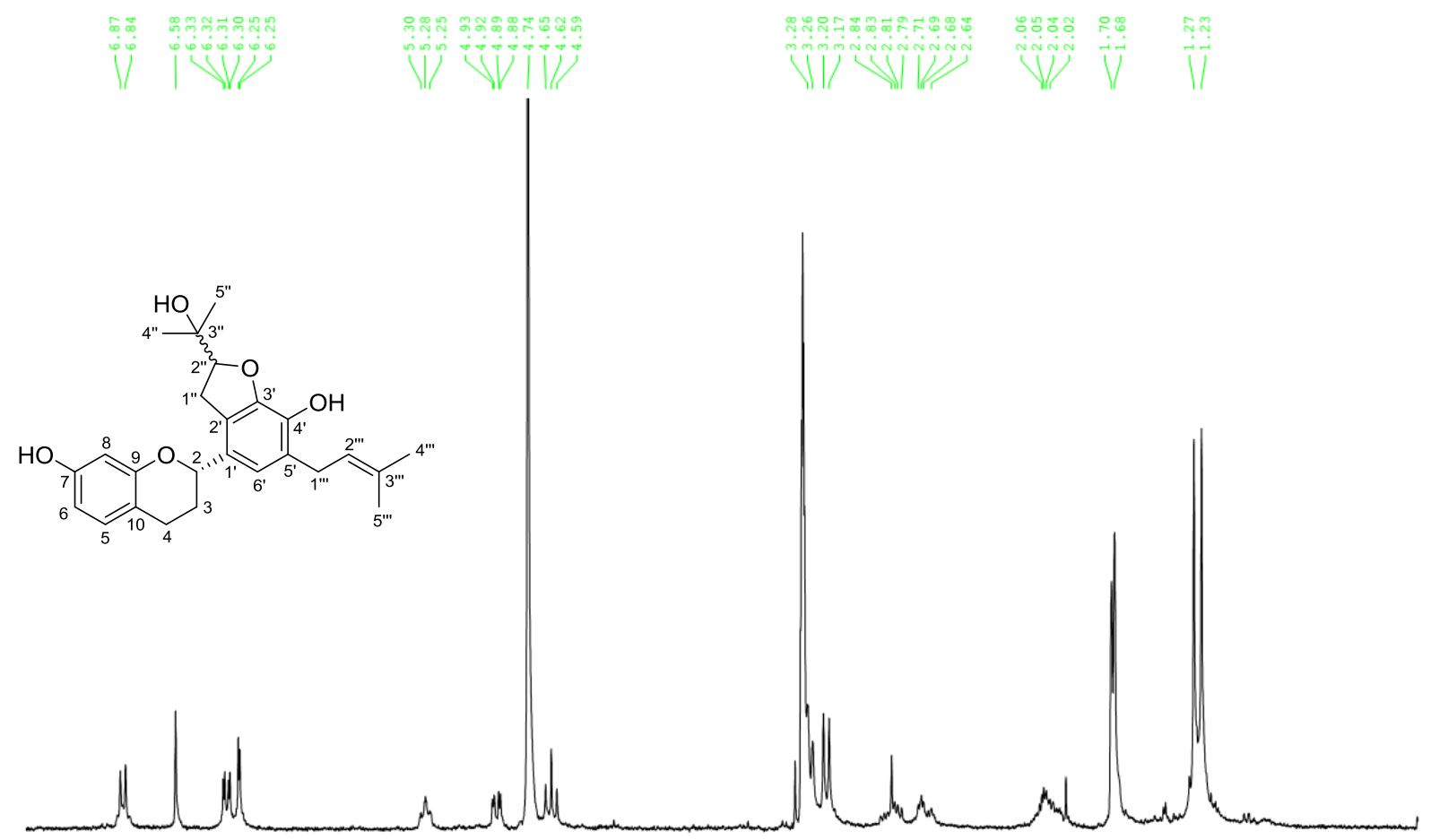

$\begin{array}{llllllllllllllll}7.0 & 6.5 & 6.0 & 5.5 & 5.0 & 4.5 & 4.0 & 3.5 & 3.0 & 2.5 & 2.0 & 1.5 & 1.0 & 0.5 \mathrm{ppm}\end{array}$ 
Figure S72. ${ }^{13} \mathrm{C}$ NMR spectrum of daphnegiralin $\mathrm{D}_{2}(\mathbf{4 b})$ in $\mathrm{CD}_{3} \mathrm{OD}$.

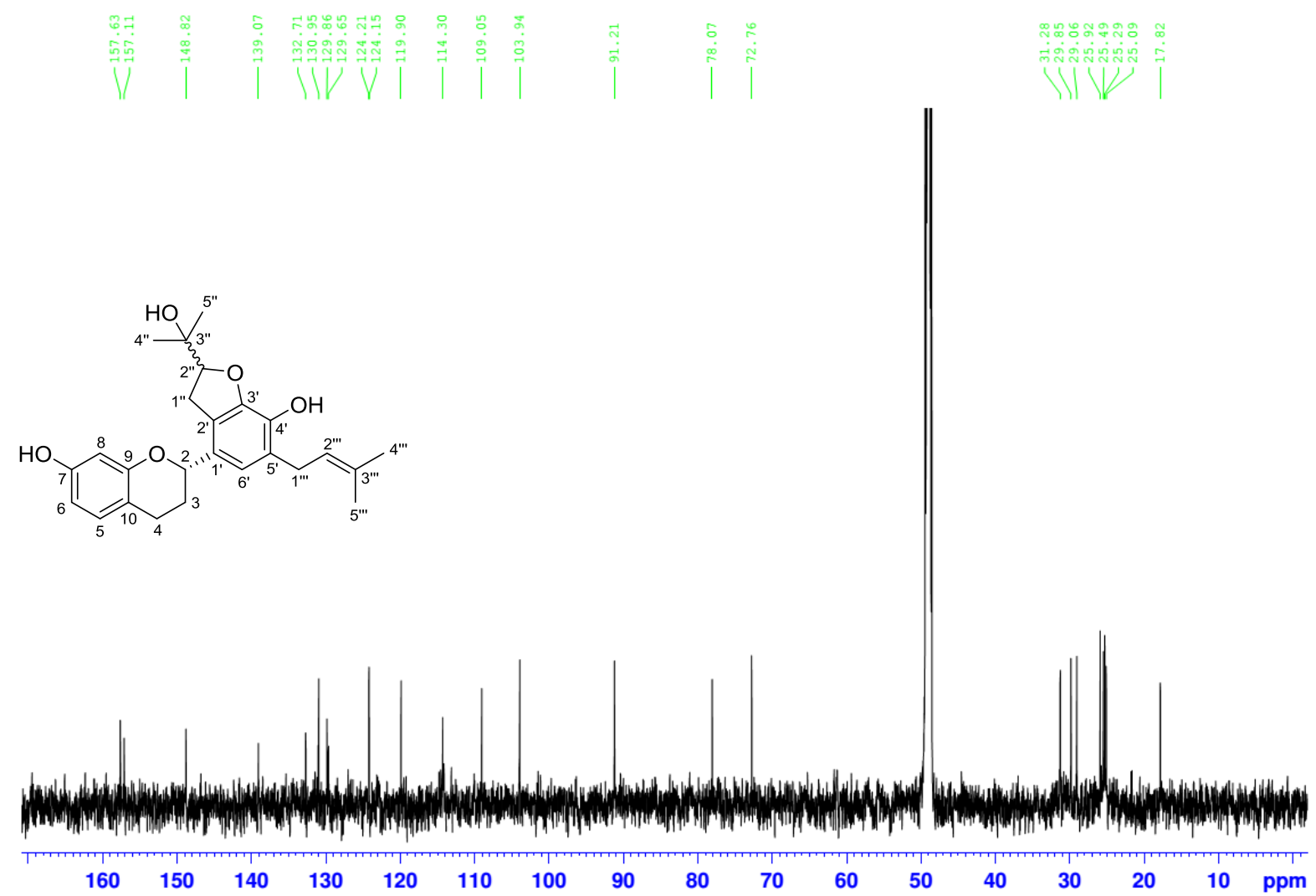

Figure S73. $\mathrm{HSQC}$ spectrum of daphnegiralin $\mathrm{D}_{2}(\mathbf{4 b})$ in $\mathrm{CD}_{3} \mathrm{OD}$.

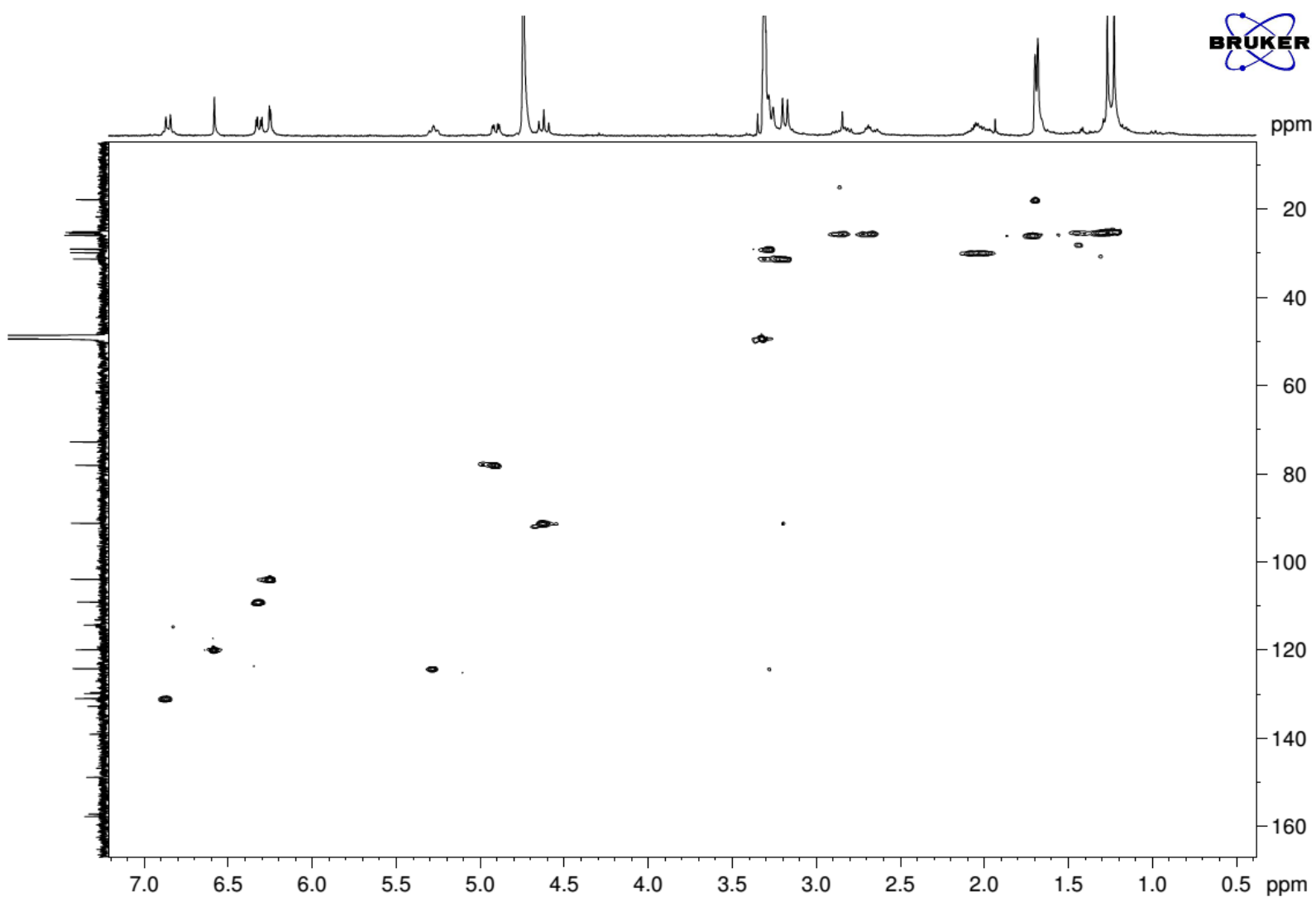


Figure S74. $\mathrm{HMBC}$ spectrum of daphnegiralin $\mathrm{D}_{2}(\mathbf{4 b})$ in $\mathrm{CD}_{3} \mathrm{OD}$.

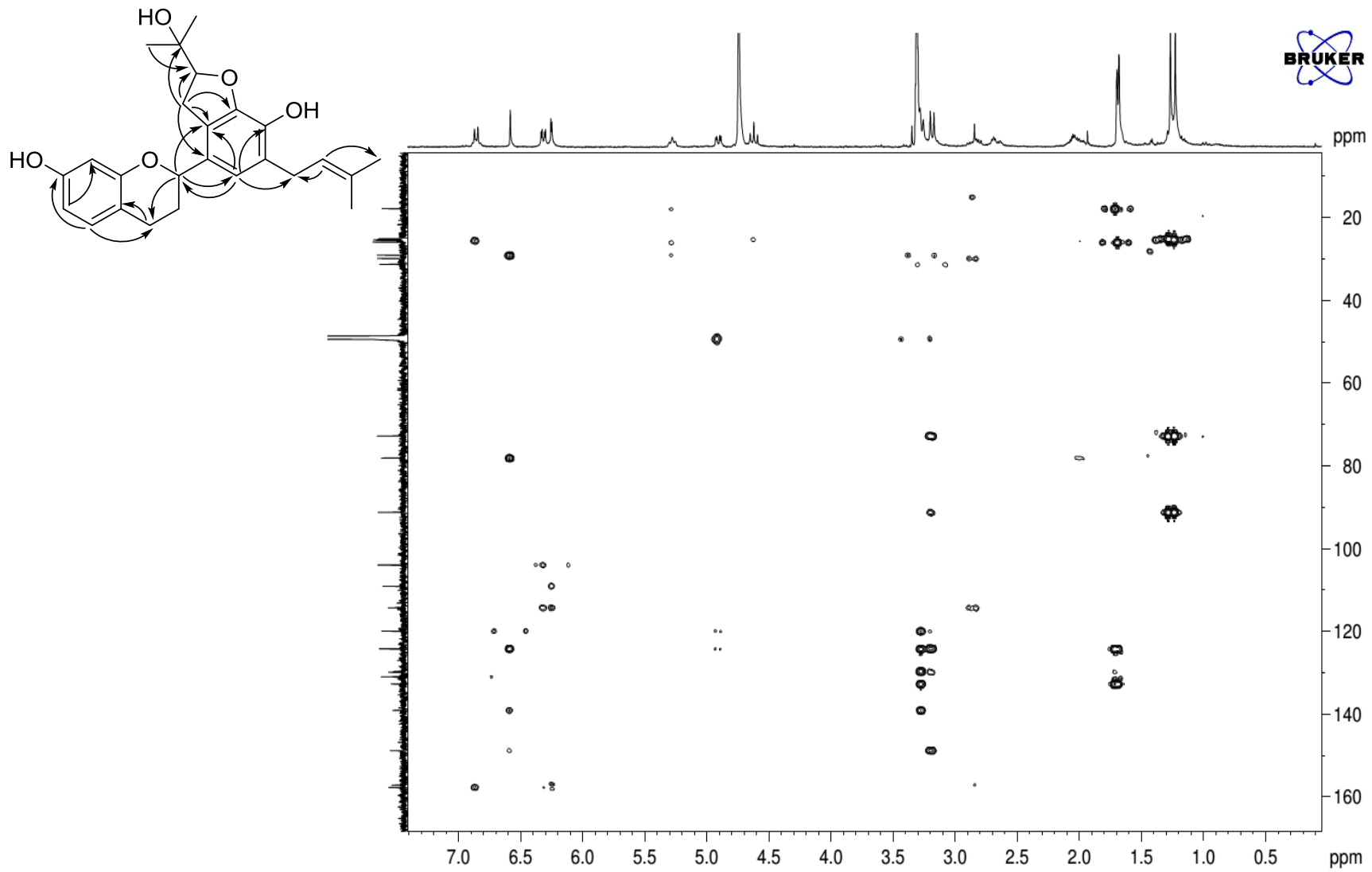

Figure S75. IR spectrum of daphnegiralin $\mathrm{D}_{2}(\mathbf{4 b})$.

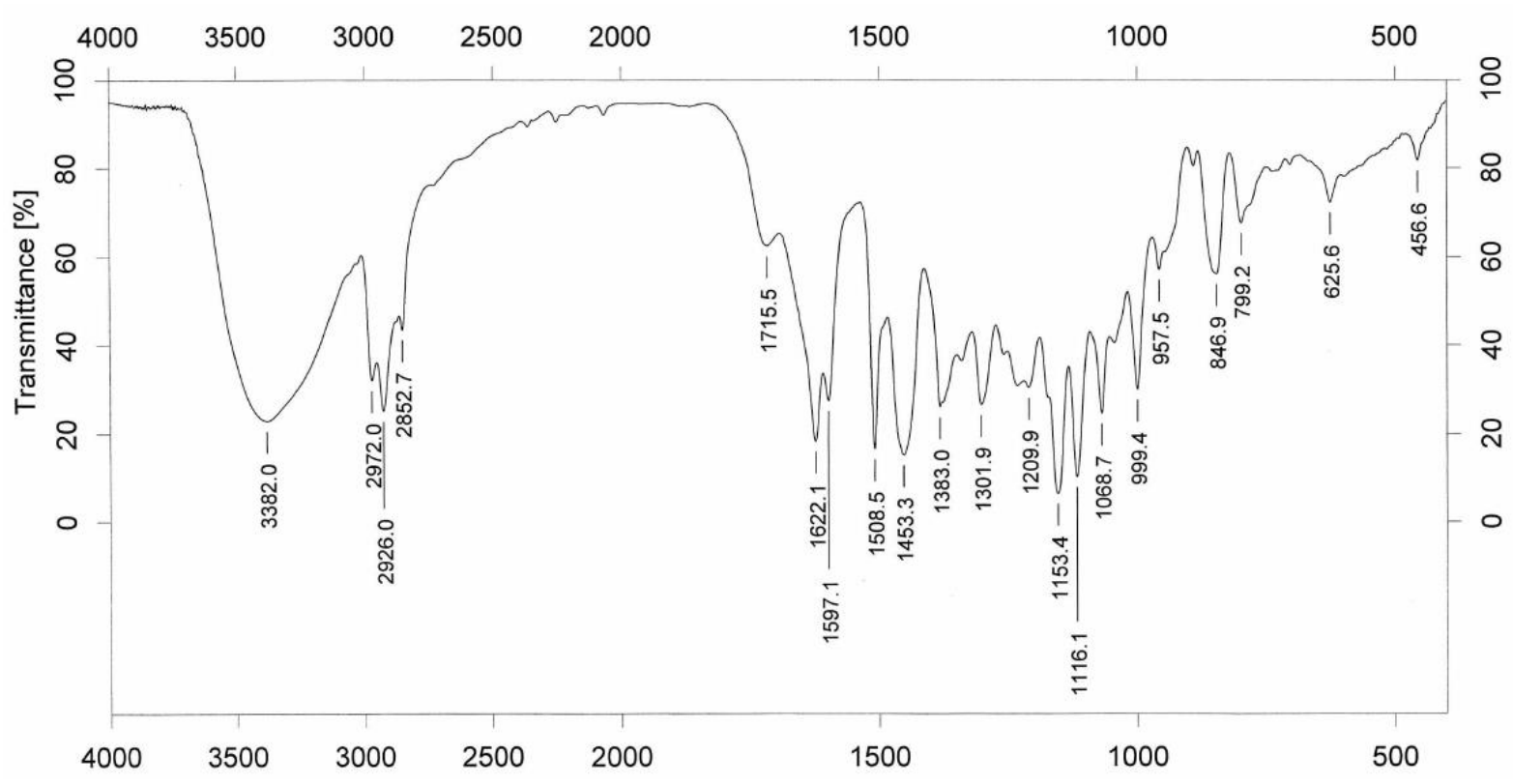


Figure S76. HRESIMS of daphnegiralin $\mathrm{D}_{2}(\mathbf{4 b})$.

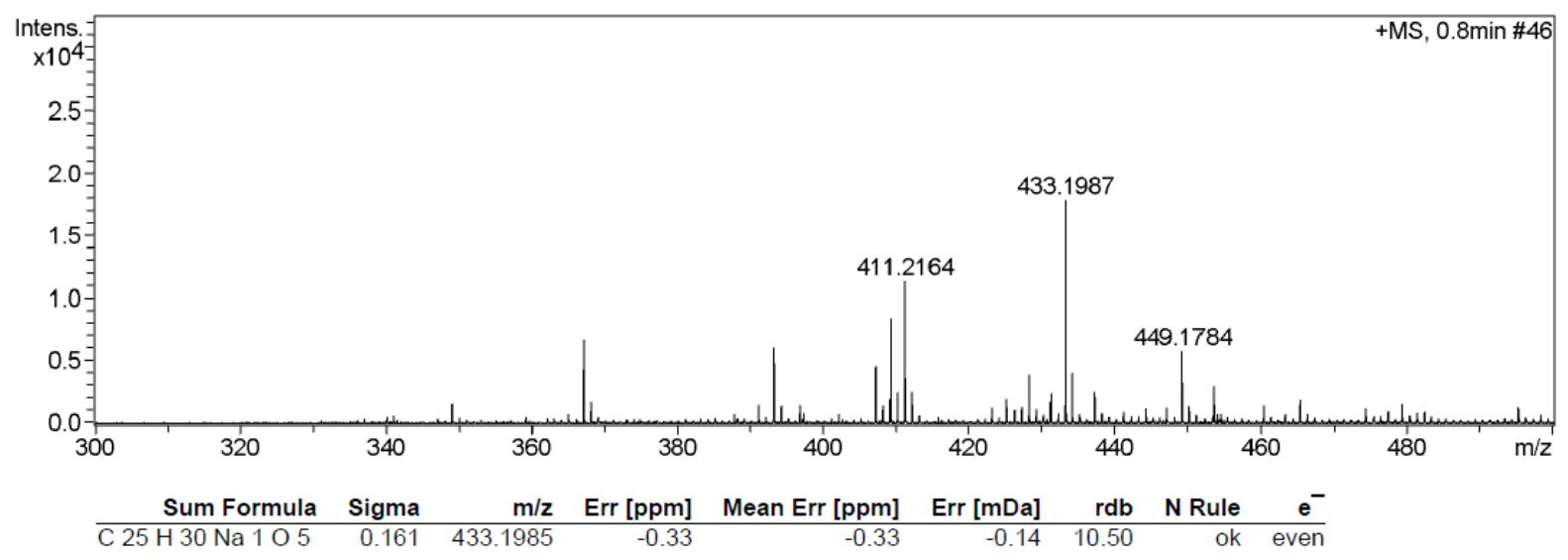

Figure S77. UV spectrum of daphnegiralin $\mathrm{D}_{2}(\mathbf{4 b})$.

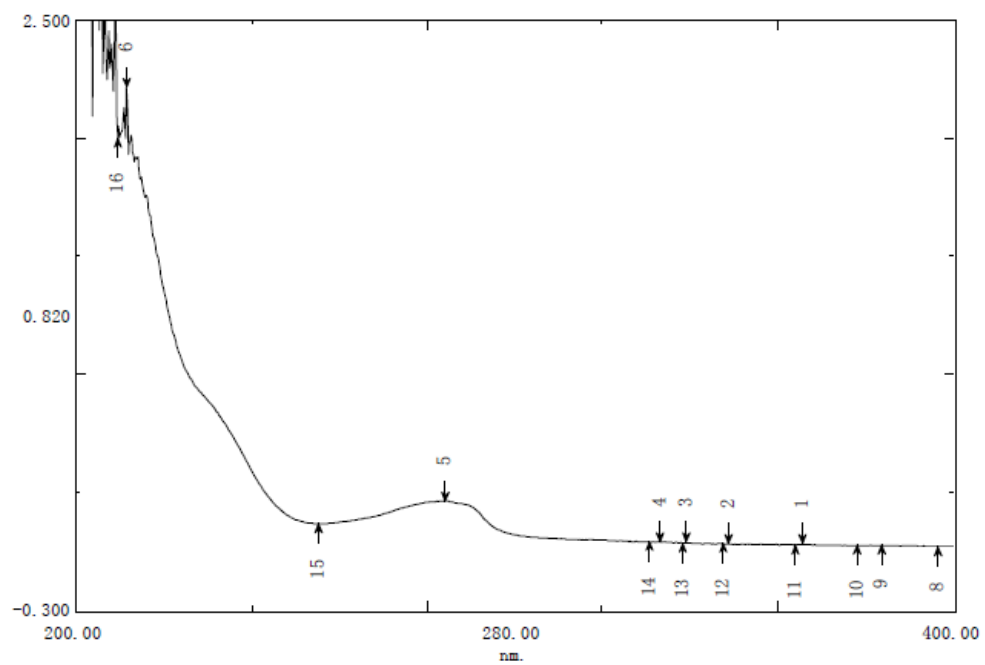

Figure S78. The ECD Spectrum of daphnegiralin $\mathrm{D}_{2}(\mathbf{4 b})$.

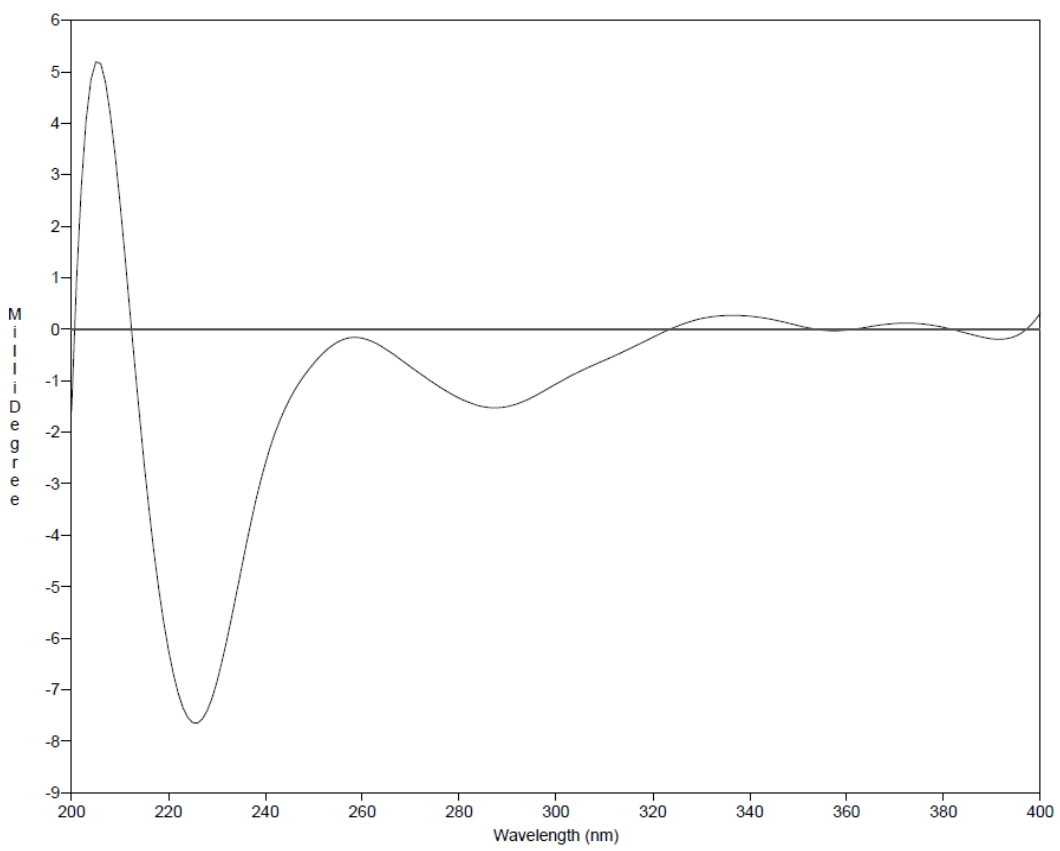


Figure S79. Computational methods for ECD spectra and Optical Rotation

The conformational analyses of ECD spectra were carried out for compounds $\mathbf{3 a} / \mathbf{3 b}$ using BALLOON and CONFAB programs. The conformations generated by both programs were subjected to semi-empirical PM3 quantum mechanical geometry optimizations using the Gaussian 09 program. The duplicated conformations were removed in which the root-mean-square (RMS) distance was less than $0.5 \AA$ A. The remaining conformations were further optimised at the B3LYP/6-31G(d) level of theory in MeOH solvent with the IEFPCM solvation model using the Gaussian 09 program, and the duplicated conformations emerging after these calculations were removed according to the same RMS criteria above. The harmonic vibrational frequencies were performed to confirm the stability of the obtained conformers (Table S1 and S3). The oscillator strengths and rotational strengths of the 20 weakest electronic excitations of each conformer were calculated using the TDDFT methodology at the B3LYP/6-311++G(2d,p) level of theory with methanol as the solvent by the IEFPCM solvation model implemented in the Gaussian 09 program. The ECD spectra with a bandwidth $\sigma$ of $0.4570 \mathrm{eV}$ for each conformer were then simulated using a Gaussian function. The calculated spectra for were combined after Boltzmann weighting according to their population contribution (Table S2 and S4).

The conformational search of OR was carried out for compounds $\mathbf{3 a / 3 b - 4 a / 4 b}$ in a similar fashion as in ECD calculations. All conformations were optimized at B3LYP/6-31G(d) level. The optical rotation for each conformation was calculated at B3LYP/6-311++G(2d,p) level with methanol as the solvent using PCM model. The overall OR was then calculated in Boltzmann-averaging manner. All calculations were performed using Gaussian 09.

Table S1. The conformations of daphnegiralin $\mathrm{C}_{1}(\mathbf{3 a})$ were obtained after the optimization

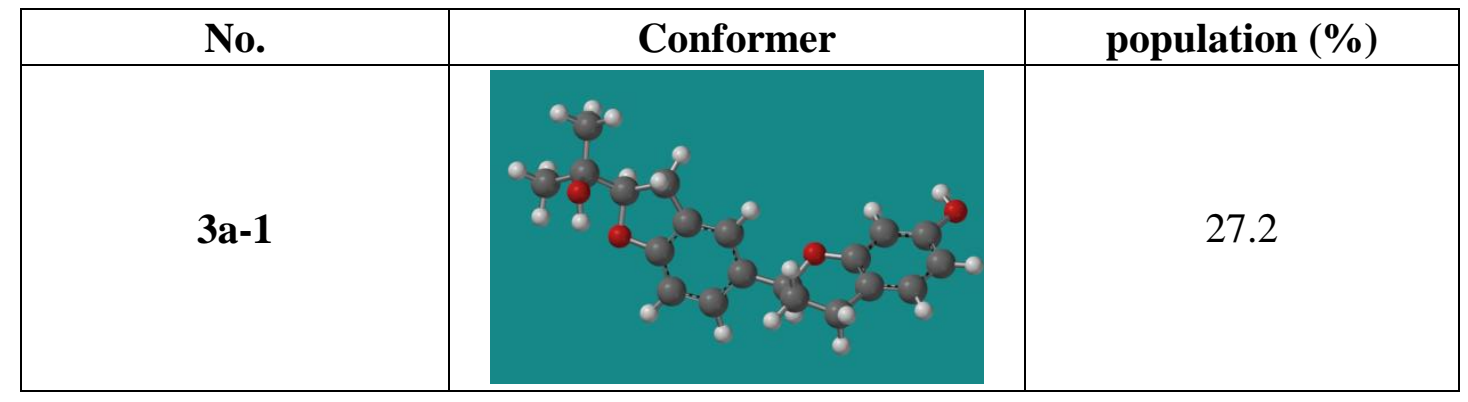




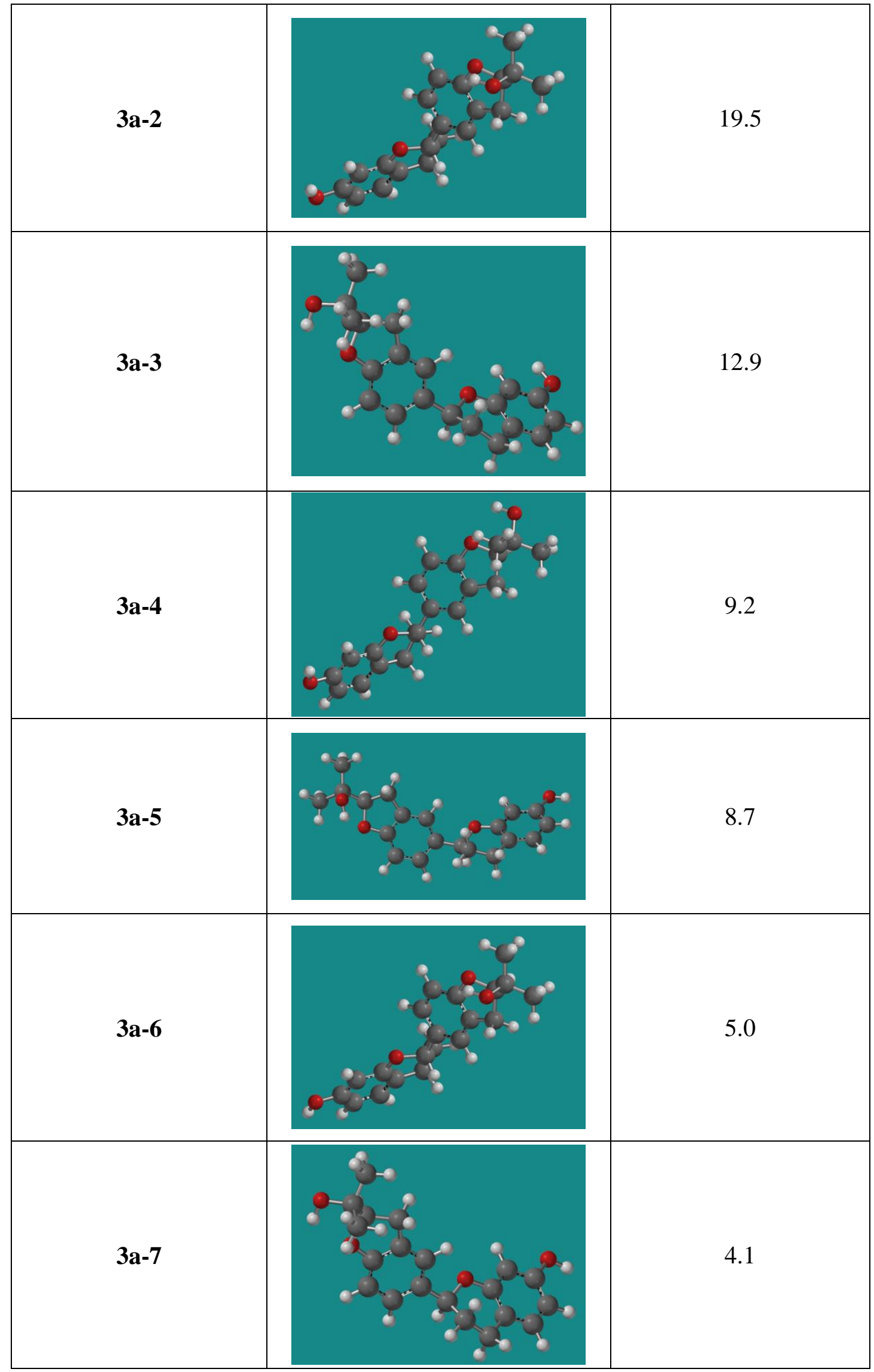




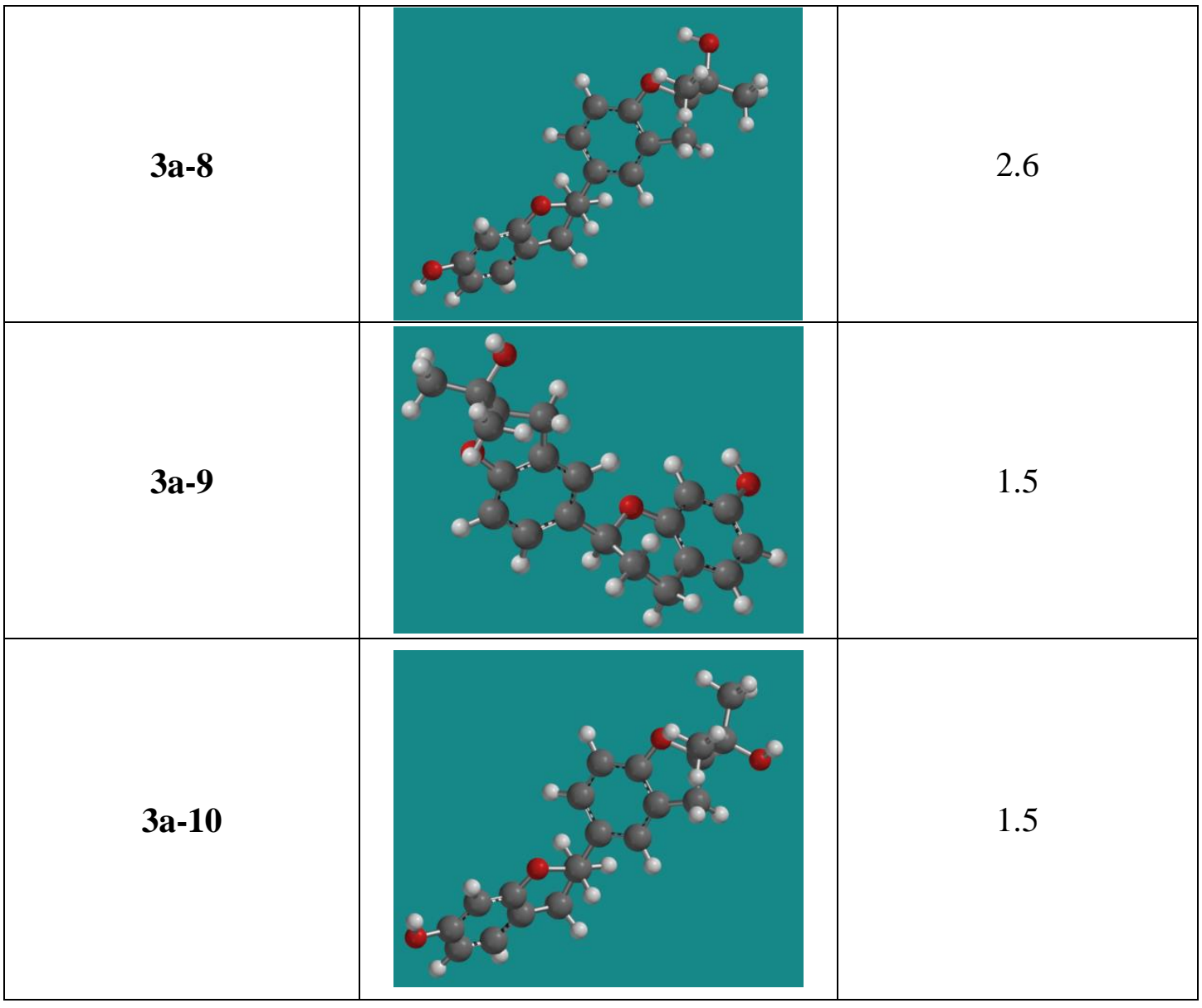

Table S2. The computational results for ECD of daphnegiralin $\mathrm{C}_{1}(\mathbf{3 a})\left(2 S, 2^{\prime \prime} R\right)$ Standard orientation:

\begin{tabular}{cccccc} 
Center & Atomic & Atomic & \multicolumn{3}{c}{ Coordinates (Angstroms) } \\
Number & Number & Type & $\mathrm{X}$ & $\mathrm{Y}$ & $\mathrm{Z}$ \\
\hline 1 & 1 & 0 & -3.734429 & -1.360769 & -1.897927 \\
2 & 6 & 0 & -3.817409 & -0.889677 & -0.923991 \\
3 & 6 & 0 & -4.016490 & 0.336531 & 1.560227 \\
4 & 6 & 0 & -2.916779 & 0.116051 & -0.557465 \\
5 & 6 & 0 & -4.817132 & -1.281203 & -0.033487 \\
6 & 6 & 0 & -4.921597 & -0.667945 & 1.221882 \\
7 & 6 & 0 & -2.999073 & 0.750927 & 0.694312 \\
8 & 1 & 0 & -5.702014 & -0.967526 & 1.916810 \\
9 & 1 & 0 & -4.103837 & 0.820935 & 2.530421 \\
10 & 6 & 0 & -2.020431 & 1.847716 & 1.047205 \\
11 & 1 & 0 & -2.513305 & 2.615553 & 1.654610 \\
12 & 1 & 0 & -1.197630 & 1.449016 & 1.657237 \\
13 & 6 & 0 & -1.451324 & 2.464664 & -0.233280 \\
14 & 1 & 0 & -0.643228 & 3.167512 & -0.008566
\end{tabular}




$\begin{array}{rrrrrr}15 & 1 & 0 & -2.233721 & 3.023712 & -0.761149 \\ 16 & 6 & 0 & -0.927612 & 1.367039 & -1.172049 \\ 17 & 1 & 0 & -0.675628 & 1.821632 & -2.136725 \\ 18 & 8 & 0 & -1.977124 & 0.435467 & -1.505852 \\ 19 & 6 & 0 & 0.308495 & 0.646121 & -0.640874 \\ 20 & 6 & 0 & 2.600509 & -0.613694 & 0.308790 \\ 21 & 6 & 0 & 1.499502 & 1.380003 & -0.473690 \\ 22 & 6 & 0 & 0.304123 & -0.720016 & -0.334931 \\ 23 & 6 & 0 & 1.448166 & -1.371020 & 0.146512 \\ 24 & 6 & 0 & 2.639167 & 0.748426 & 0.002107 \\ 25 & 1 & 0 & 1.528930 & 2.438479 & -0.723272 \\ 26 & 1 & 0 & -0.602219 & -1.296705 & -0.481295 \\ 27 & 1 & 0 & 1.436609 & -2.431011 & 0.379602 \\ 28 & 6 & 0 & 4.028320 & 1.266691 & 0.296382 \\ 29 & 1 & 0 & 4.030756 & 1.985392 & 1.123571 \\ 30 & 1 & 0 & 4.484121 & 1.766281 & -0.567210 \\ 31 & 6 & 0 & 4.793641 & -0.029701 & 0.667539 \\ 32 & 1 & 0 & 5.281233 & 0.027175 & 1.644177 \\ 33 & 8 & 0 & 3.792313 & -1.098338 & 0.777405 \\ 34 & 6 & 0 & 5.802502 & -0.469819 & -0.386759 \\ 35 & 1 & 0 & 6.623291 & 0.253524 & -0.432508 \\ 36 & 1 & 0 & 5.309613 & -0.486978 & -1.372365 \\ 37 & 8 & 0 & 6.375588 & -1.730575 & -0.072217 \\ 38 & 1 & 0 & 5.626479 & -2.340035 & 0.040585 \\ 39 & 8 & 0 & -5.669135 & -2.271390 & -0.444416 \\ 40 & 1 & 0 & -6.307639 & -2.454064 & 0.264066 \\ -----------------------------------------------------------------------------\end{array}$

Table S3. The conformations of daphnegiralin $\mathrm{C}_{2}(\mathbf{3 b})$ were obtained after the optimization

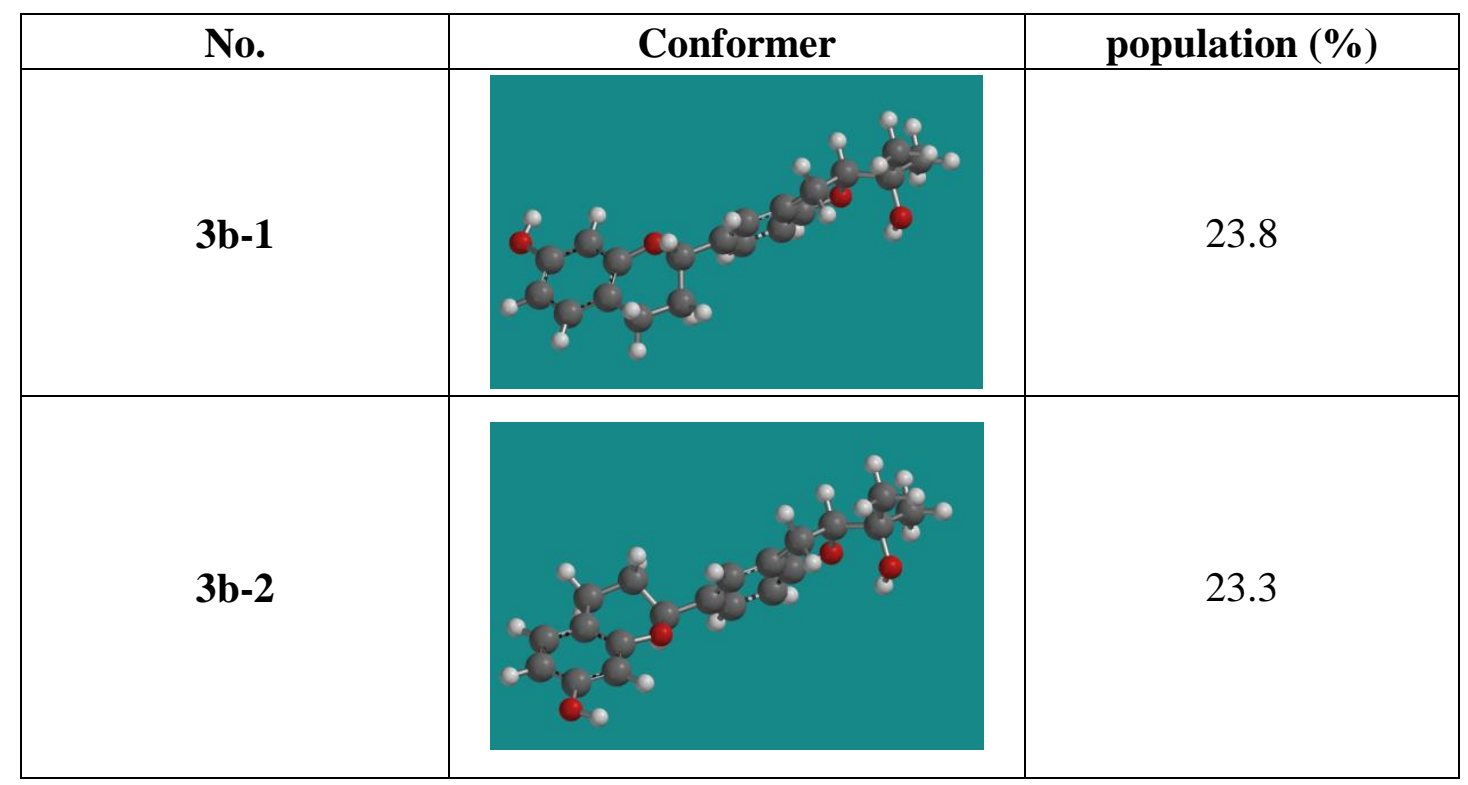




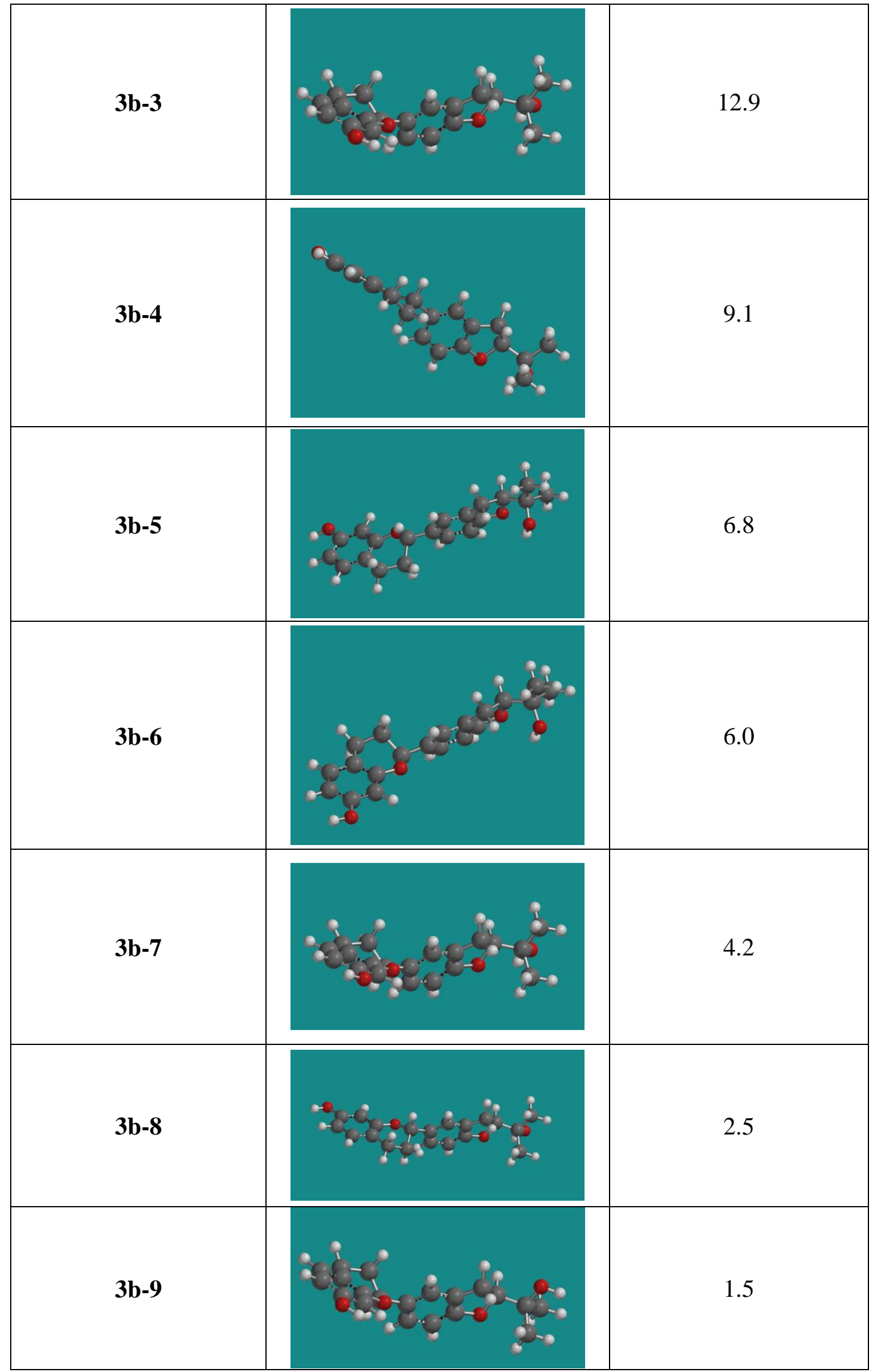




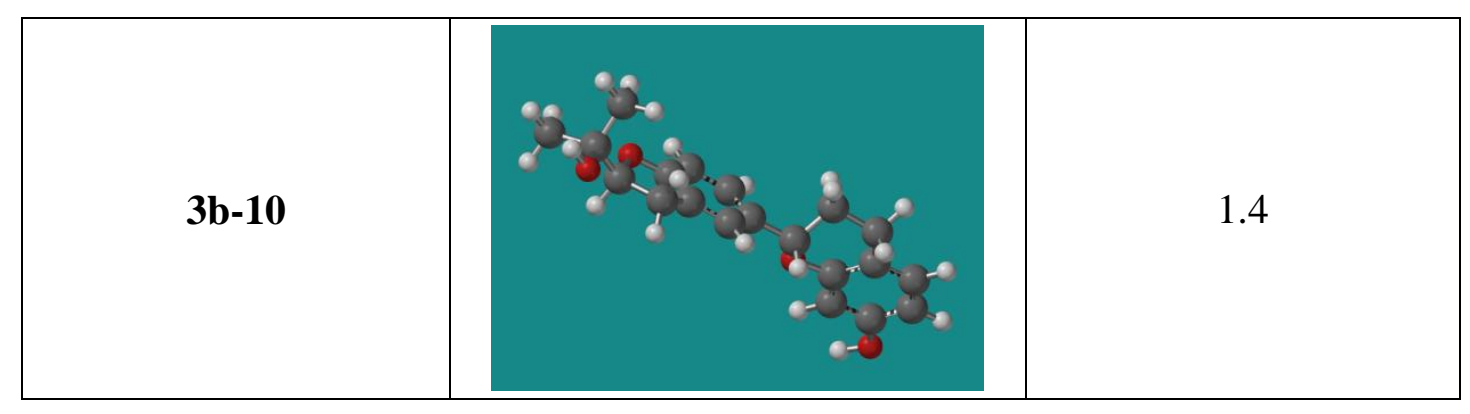

Table S4. The computational results for ECD of daphnegiralin $\mathrm{C}_{2}(\mathbf{3 b})\left(2 S, 2^{\prime \prime} S\right)$

Standard orientation:

\begin{tabular}{|c|c|c|c|c|c|}
\hline \multirow{2}{*}{$\begin{array}{l}\text { Center } \\
\text { Number }\end{array}$} & \multirow{2}{*}{$\begin{array}{l}\text { Atomic } \\
\text { Number }\end{array}$} & \multirow{2}{*}{$\begin{array}{l}\text { Atomic } \\
\text { Type }\end{array}$} & \multicolumn{3}{|c|}{ Coordinates (Angstroms) } \\
\hline & & & $\mathrm{X}$ & $\mathrm{Y}$ & $\mathrm{Z}$ \\
\hline 1 & 1 & 0 & 2.897478 & 2.270689 & -0.849138 \\
\hline 2 & 6 & 0 & 3.507270 & 1.457946 & -0.468446 \\
\hline 3 & 6 & 0 & 5.047650 & -0.637456 & 0.505901 \\
\hline 4 & 6 & 0 & 2.920941 & 0.218214 & -0.192720 \\
\hline 5 & 6 & 0 & 4.873385 & 1.640472 & -0.255046 \\
\hline 6 & 6 & 0 & 5.656662 & 0.586008 & 0.232554 \\
\hline 7 & 6 & 0 & 3.680367 & -0.855891 & 0.304587 \\
\hline 8 & 1 & 0 & 6.721558 & 0.724955 & 0.401958 \\
\hline 9 & 1 & 0 & 5.653648 & -1.452366 & 0.896248 \\
\hline 10 & 6 & 0 & 3.017425 & -2.180349 & 0.618099 \\
\hline 11 & 1 & 0 & 3.226742 & -2.908962 & -0.178595 \\
\hline 12 & 1 & 0 & 3.437321 & -2.604795 & 1.537886 \\
\hline 13 & 6 & 0 & 1.500997 & -2.005402 & 0.756477 \\
\hline 14 & 1 & 0 & 1.253237 & -1.492443 & 1.694404 \\
\hline 15 & 1 & 0 & 0.994990 & -2.976381 & 0.769980 \\
\hline 16 & 6 & 0 & 0.962230 & -1.175084 & -0.414056 \\
\hline 17 & 1 & 0 & 1.238656 & -1.673616 & -1.354342 \\
\hline 18 & 8 & 0 & 1.570574 & 0.138861 & -0.418779 \\
\hline 19 & 8 & 0 & 5.393487 & 2.874336 & -0.542647 \\
\hline 20 & 1 & 0 & 6.347026 & 2.865943 & -0.359452 \\
\hline 21 & 6 & 0 & -0.536675 & -0.978932 & -0.379520 \\
\hline 22 & 6 & 0 & -3.298711 & -0.717170 & -0.281593 \\
\hline 23 & 6 & 0 & -1.359252 & -1.717185 & -1.239460 \\
\hline 24 & 6 & 0 & -1.122420 & -0.091187 & 0.542016 \\
\hline 25 & 6 & 0 & -2.503230 & 0.037839 & 0.584281 \\
\hline 26 & 6 & 0 & -2.754242 & -1.602947 & -1.203687 \\
\hline 27 & 1 & 0 & -0.905387 & -2.396332 & -1.957108 \\
\hline 28 & 1 & 0 & -0.490976 & 0.495856 & 1.202891 \\
\hline 29 & 1 & 0 & -3.387325 & -2.173723 & -1.875291 \\
\hline
\end{tabular}




\begin{tabular}{|c|c|c|c|c|c|}
\hline 30 & 6 & 0 & -3.409042 & 0.881657 & 1.452263 \\
\hline 31 & 1 & 0 & -3.362781 & 0.581839 & 2.505198 \\
\hline 32 & 1 & 0 & -3.160561 & 1.949026 & 1.408757 \\
\hline 33 & 6 & 0 & -4.806884 & 0.602382 & 0.842699 \\
\hline 34 & 1 & 0 & -5.531290 & 0.246990 & 1.579994 \\
\hline 35 & 8 & 0 & -4.639005 & -0.495260 & -0.118986 \\
\hline 36 & 6 & 0 & -5.390080 & 1.783536 & 0.075548 \\
\hline 37 & 1 & 0 & -4.637528 & 2.158015 & -0.637226 \\
\hline 38 & 1 & 0 & -5.624735 & 2.593075 & 0.774560 \\
\hline 39 & 8 & 0 & -6.600110 & 1.437652 & -0.582308 \\
\hline 40 & 1 & 0 & -6.387976 & 0.668816 & -1.138359 \\
\hline
\end{tabular}

Figure S80. Chiral HPLC separation profiles of $\mathbf{1 a} / \mathbf{1} \mathbf{b}-\mathbf{2 a} / \mathbf{2 b}$

(1) Chiral HPLC separation profile of 1a/1b (n-hexane-isopropanol, 1:1; flow: 1.0mL/min)

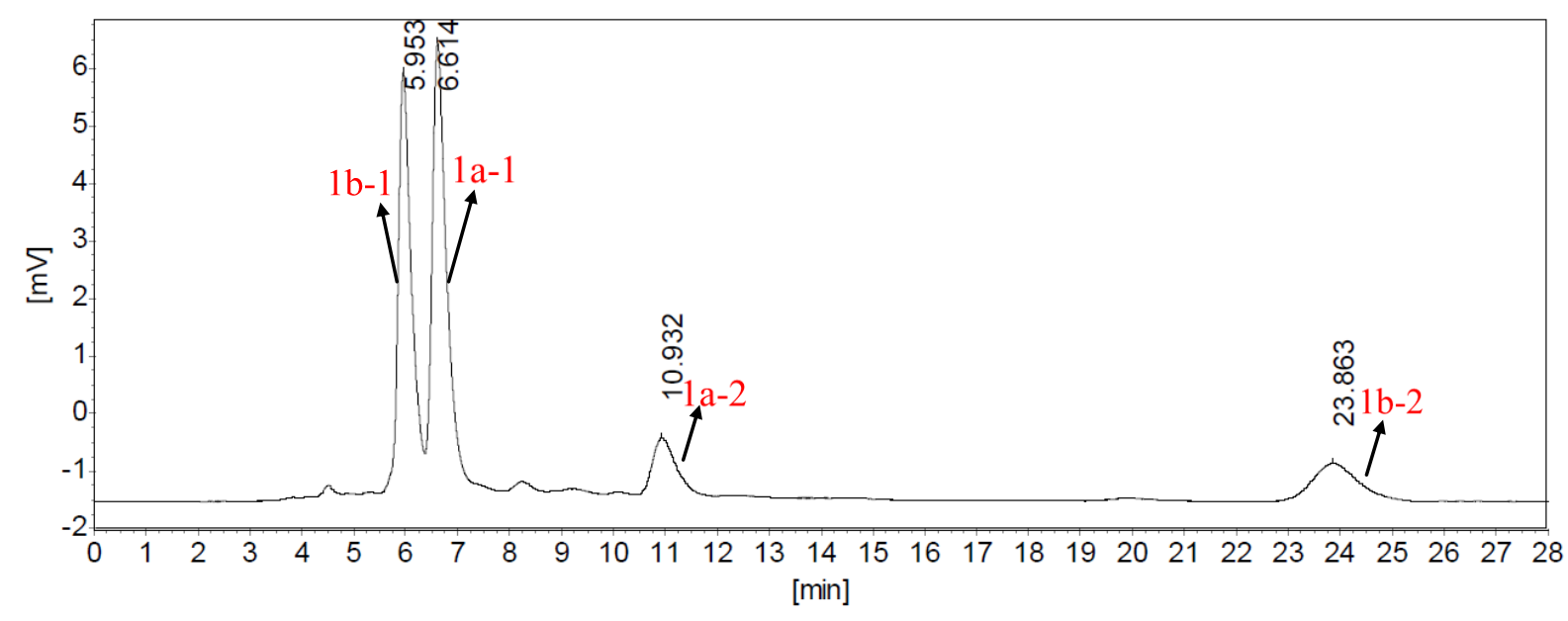

(2) Chiral HPLC separation profile of 1a (n-hexane-isopropanol, 1:1; flow: 1.0mL/min)

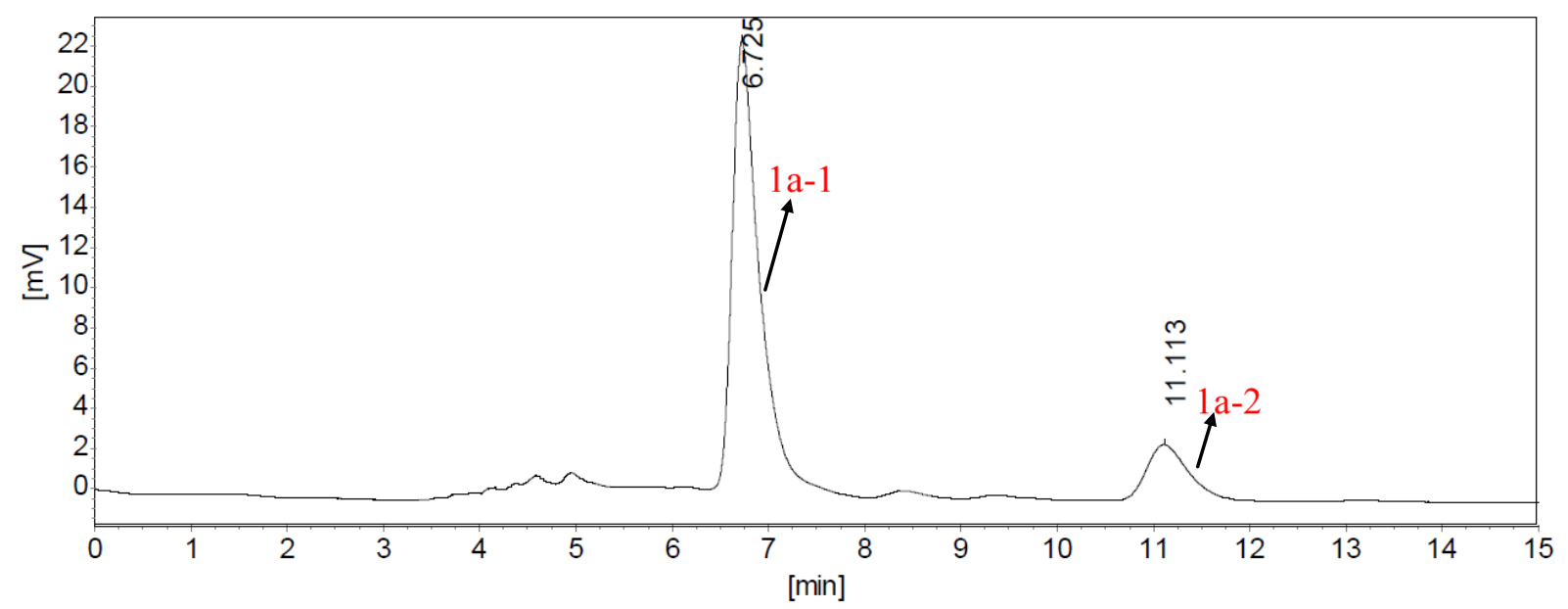


(3) Chiral HPLC separation profile of $\mathbf{1 b}$ (n-hexane-isopropanol, 1:1; flow: 1.0mL/min)

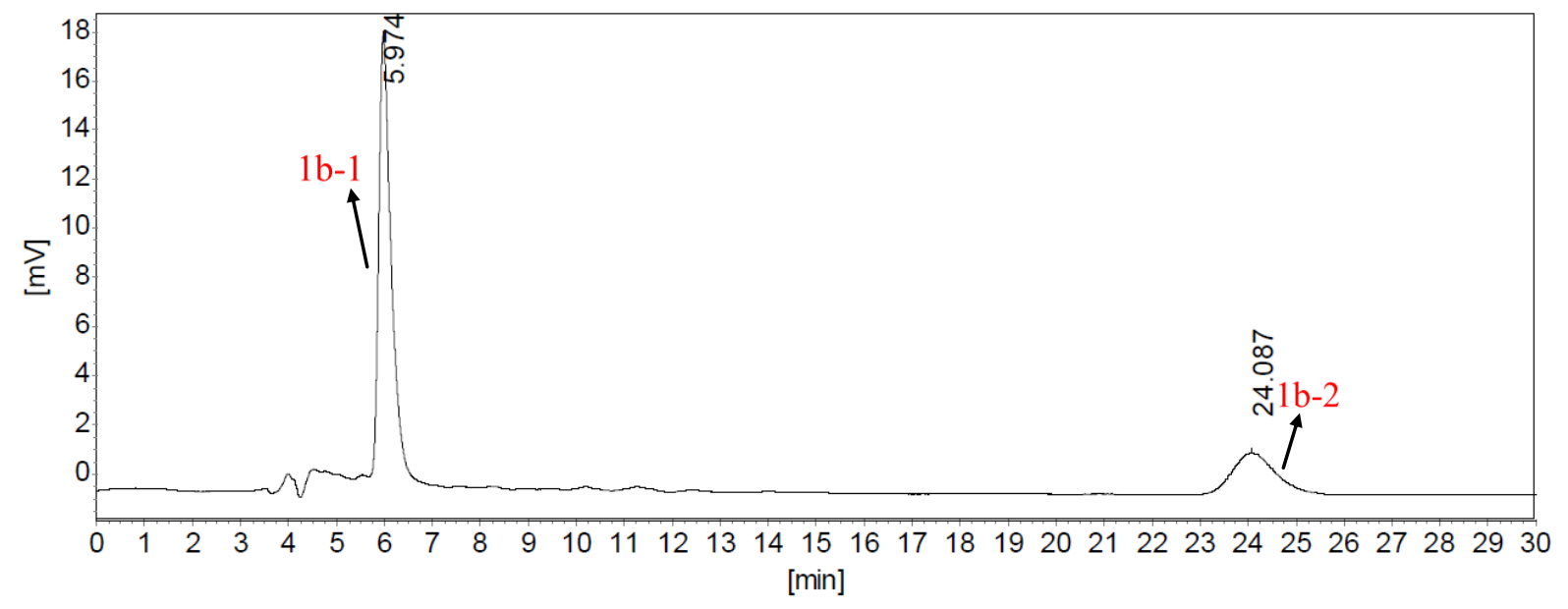

(4) Chiral HPLC separation profile of $\mathbf{2 a} / \mathbf{2 b}$ (n-hexane-isopropanol, 1:1; flow: 1.0mL/min)

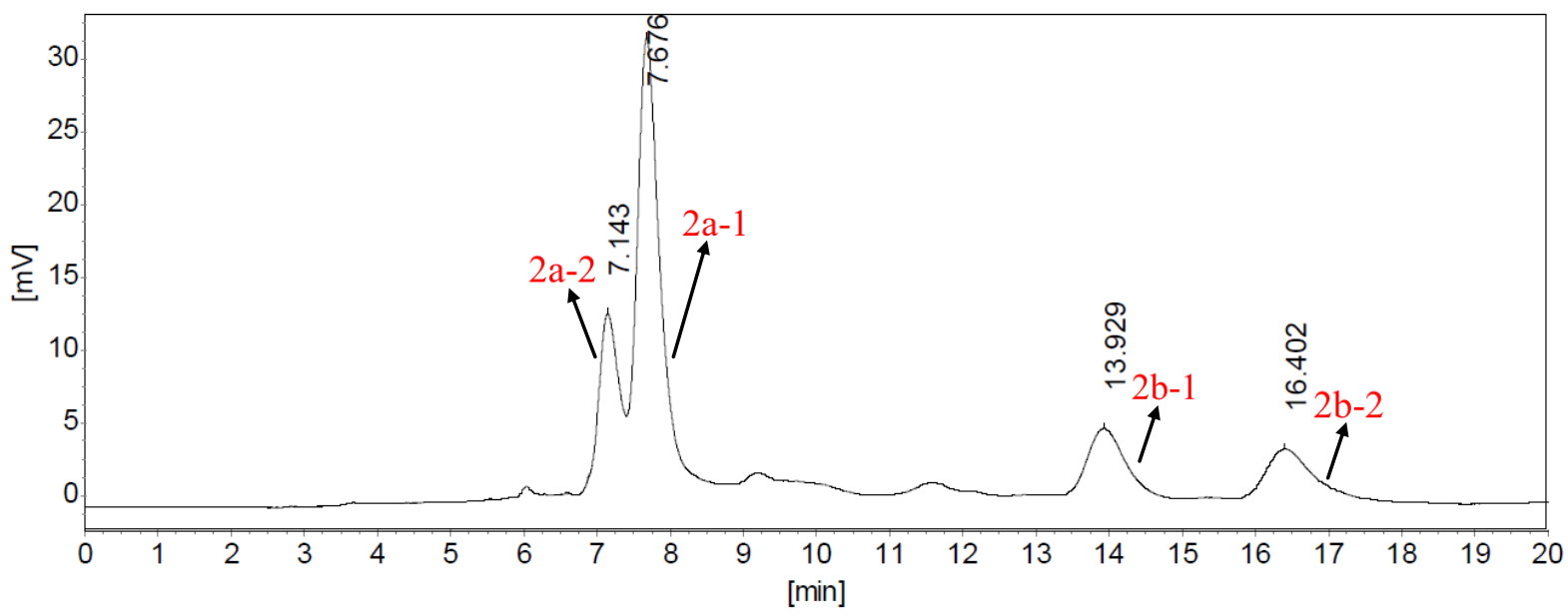

(5) Chiral HPLC separation profile of 2a (n-hexane-isopropanol, 5:1; flow: 1.0mL/min)

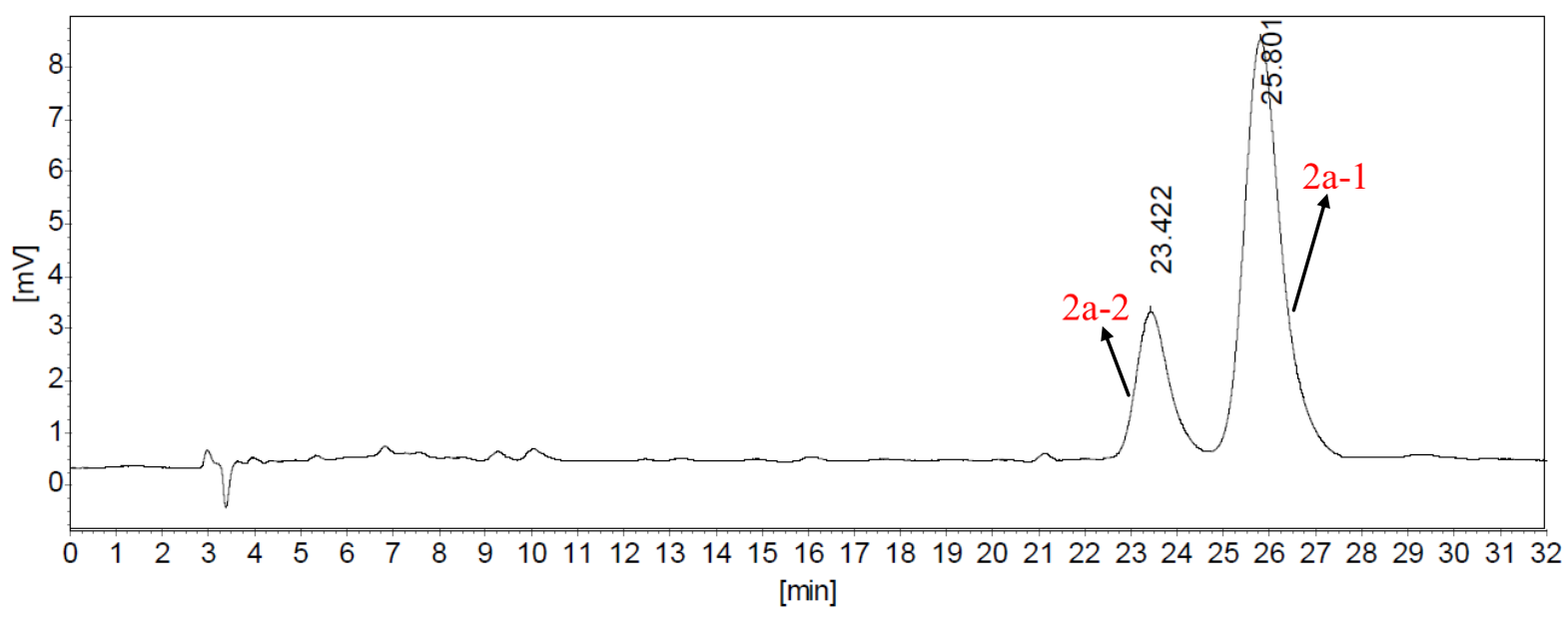


(6) Chiral HPLC separation profile of $\mathbf{2 b}$ (n-hexane-isopropanol, 1:1; flow: 1.0mL/min)

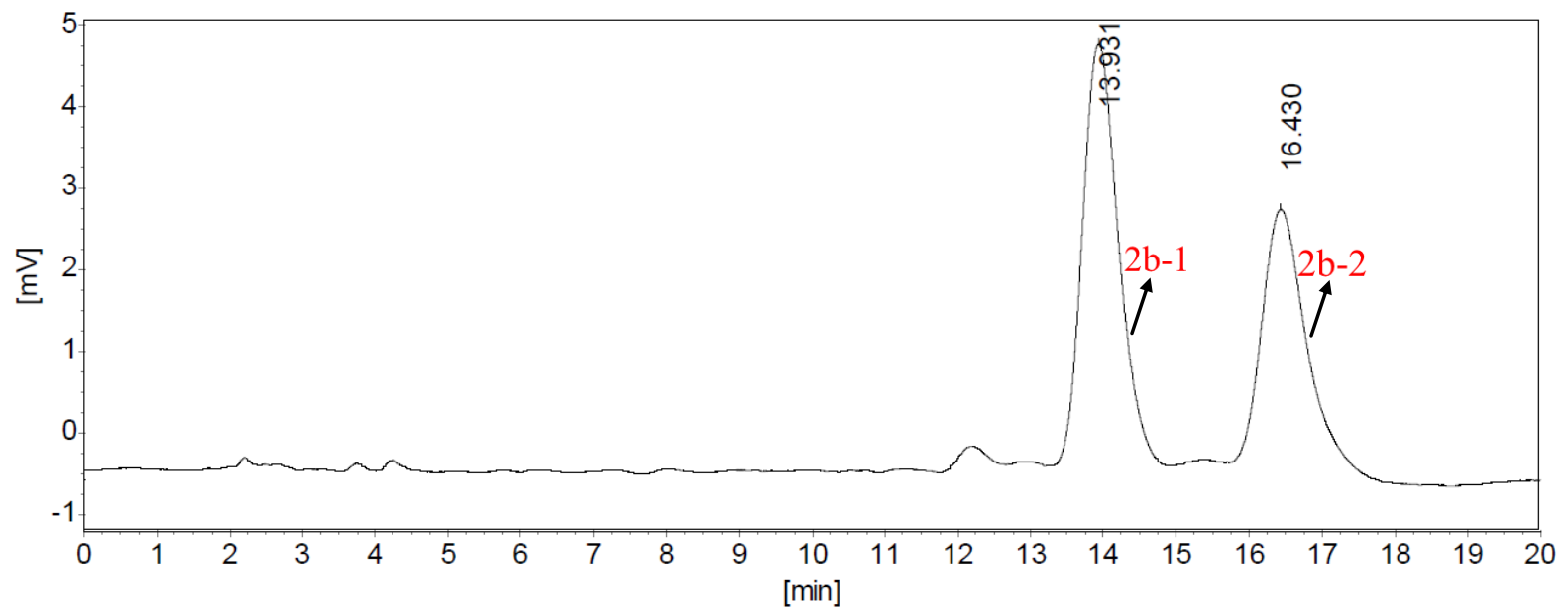

